\title{
Bioelectrical Impedance Analysis Methods for Prediction of Brook Trout Salvelinus fontinalis Percent Dry Weight
}

Andrew William Hafs

West Virginia University

Follow this and additional works at: https://researchrepository.wvu.edu/etd

\section{Recommended Citation}

Hafs, Andrew William, "Bioelectrical Impedance Analysis Methods for Prediction of Brook Trout Salvelinus fontinalis Percent Dry Weight" (2011). Graduate Theses, Dissertations, and Problem Reports. 3425.

https://researchrepository.wvu.edu/etd/3425

This Dissertation is protected by copyright and/or related rights. It has been brought to you by the The Research Repository @ WVU with permission from the rights-holder(s). You are free to use this Dissertation in any way that is permitted by the copyright and related rights legislation that applies to your use. For other uses you must obtain permission from the rights-holder(s) directly, unless additional rights are indicated by a Creative Commons license in the record and/ or on the work itself. This Dissertation has been accepted for inclusion in WVU Graduate Theses, Dissertations, and Problem Reports collection by an authorized administrator of The Research Repository @ WVU.

For more information, please contact researchrepository@mail.wvu.edu. 


\title{
Bioelectrical Impedance Analysis Methods for Prediction of Brook Trout Salvelinus fontinalis Percent Dry Weight
}

\author{
Andrew William Hafs \\ Dissertation submitted to the \\ Davis College of Agriculture, Natural Resources and Design \\ at West Virginia University \\ in partial fulfillment of the requirements \\ for the degree of
}
Doctor of Philosophy
in

Forest Resources Science
Kyle J. Hartman, Ph.D., Chair
F. Joseph Margraf, Ph.D.
Patricia M. Mazik, Ph.D.
J. Todd Petty, Ph.D.
John A. Sweka, Ph.D.
Division of Forestry

\author{
Morgantown, West Virginia \\ 2011
}

Keywords: Condition, Brook Trout, Bioelectrical Impedance Analysis, Temperature 


\section{ABSTRACT \\ Bioelectrical Impedance Analysis Methods for Prediction of Brook Trout Salvelinus fontinalis Percent Dry Weight}

\section{Andrew William Hafs}

Reliable fish condition estimates are valued by fisheries ecologists and managers. Fish condition is used as an indicator of ecosystem health or to assess the population status for a species of interest. In aquaculture, proximate composition estimates are often wanted because of their relationship to fillet quality. Past researchers have used bioelectrical impedance analysis (BIA) to provide nonlethal mass based estimates of proximate composition for fish. Percent dry weight (PDW) of a fish is highly correlated to proximate composition values and energy density, therefore reliable predictions of PDW would eliminate the need for costly and laboratory analyses lethal to the fish. Past researchers have had limited success predicting percent based estimates of proximate composition using BIA, indicating that improvements in the method are needed. Therefore, objectives were to determine if electrode location influences BIA models, develop methods for small fish, develop temperature corrections for BIA measures, and field validate laboratory derived BIA models. To determine electrode location influence and develop small fish methods, 270 brook trout (50-300 mm TL) had BIA measurements taken at seven different electrode locations. Temperature corrections were developed by sampling 270 fish at three different temperatures $\left(5,12.5\right.$, and $\left.20^{\circ} \mathrm{C}\right)$. Field validation of BIA models was accomplished by sampling brook trout monthly at nine Appalachian Mountain headwater stream sites for an entire year. For adult brook trout, one set of measurements should be taken by placing the electrodes along the dorsal midline of the fish and a second set should be taken at the dorsal to ventral pre dorsal fin location (DTV). For age-0 fish the DTV location should be used in combination with a second set taken at the dorsal total length location. Temperature correction equations were successfully developed and improved model performance. Field validation demonstrated that BIA can provide reliable estimates of mean percent dry weight or energy density but estimates for individual fish were unreliable. The BIA model predictions were able to demonstrate that large changes in adult Appalachian brook trout body condition occurred. These changes were likely related to energy depletion from reproduction and changes in terrestrial invertebrate consumption. 


\section{Dedication}

I dedicate this work to my father William Charles Hafs who provided me with a strong background in natural resource science by taking me hunting and fishing on a regular basis as I grew up. He also provided me with support and encouragement throughout my educational career. I also dedicate this work to my Ph.D. advisor Dr. Kyle J. Hartman and my M.S. advisor Dr. Charles J. Gagen. They both provided me with important guidance during my graduate tenure that helped me learn all aspects of the scientific process from study design to manuscript preparation. Finally, I dedicate this work to my wife Lindsey who understood the amount time and energy required of me as a graduate student and supported me every step of the way. 


\section{Acknowledgements}

I would like to thank John Sweka, Patricia Mazik, Joseph Margraf, and Todd Petty for technical guidance, John Howell, Geoff Weichert, Lee Yost, Matthew Belcher, Jared Varner, Chris Grady, William Haus, Lisa Hudson, Amy Fitzwater, Lindsey Richie, Mike Porto, Ed McGinley, Jon Niles, Daniel Hanks, Melinda Evick, Jonathan Hulse, and Greg Klinger for help with data collection and entry. I also thank Phil Turk and George Merovich for statistical comments as well as Frank Williams from Bowden State Fish Hatchery for providing the brook trout and fish food used in this study. Lastly, I thank WVDNR and the USFS for funding this project. 


\section{Table of Contents}

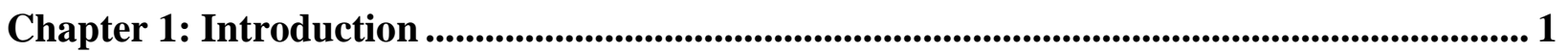

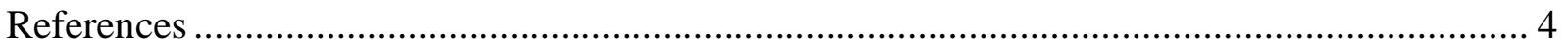

Chapter 2: Evaluation of Electrode Type and Measurement Location upon BIA Models of Water Content in Brook Trout ...................................................................................................... 9

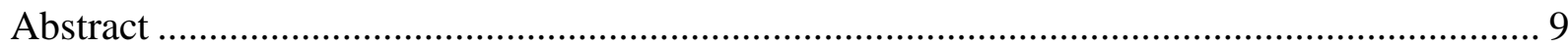

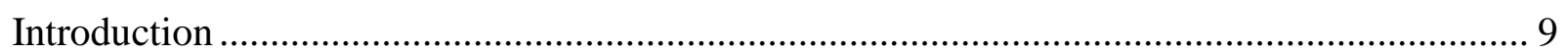

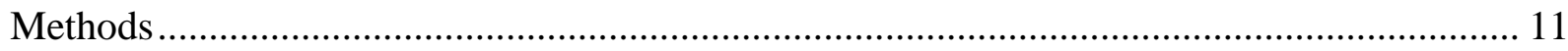

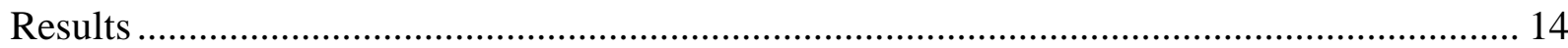

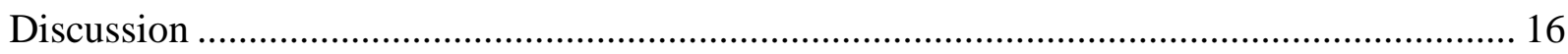

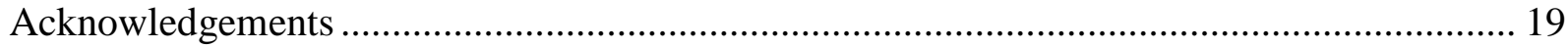

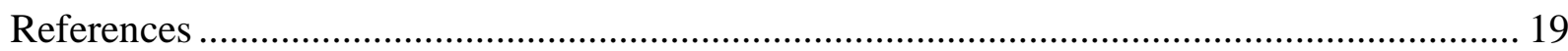

Chapter 3: Developing Bioelectrical Impedance Analysis Methods for Small Fish ............. 28

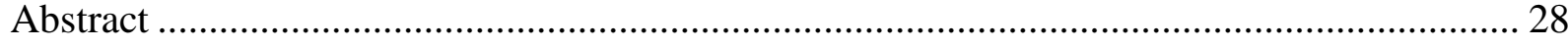

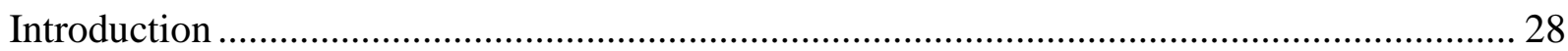

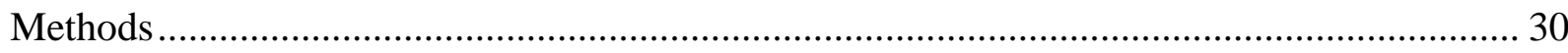

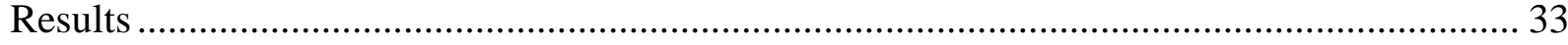

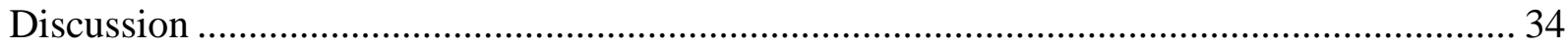

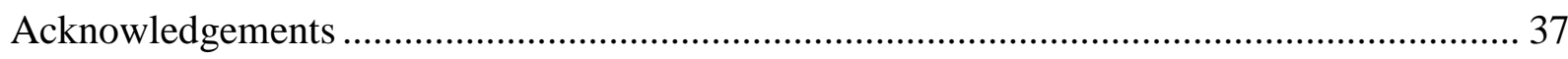

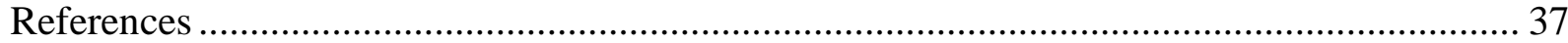

Chapter 4: Temperature Corrections for Bioelectrical Impedance Analysis Models

Developed for Age-0 and Adult Brook Trout............................................................................ 50

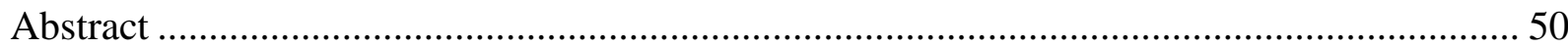

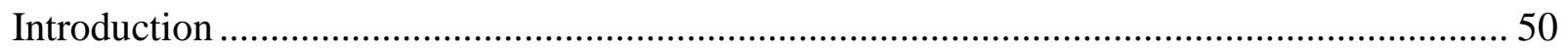

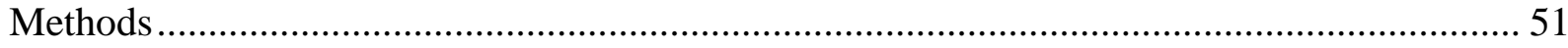

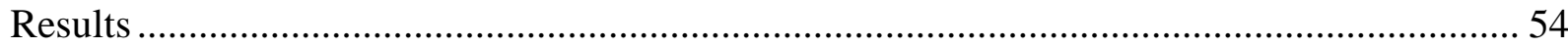

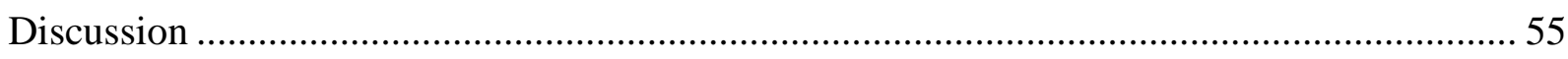

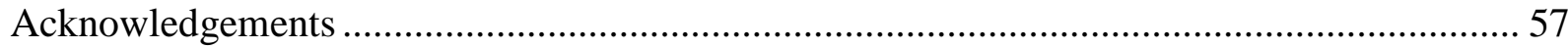

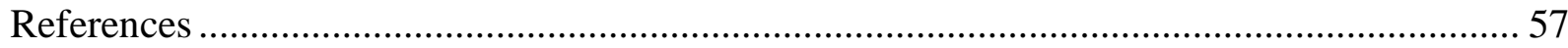

Chapter 5: Application of BIA to Fish Ecology: Validation and Application of Brook Trout BIA Models to Detect Seasonal Changes in Percent Dry Weight and Energy Density .. 70 


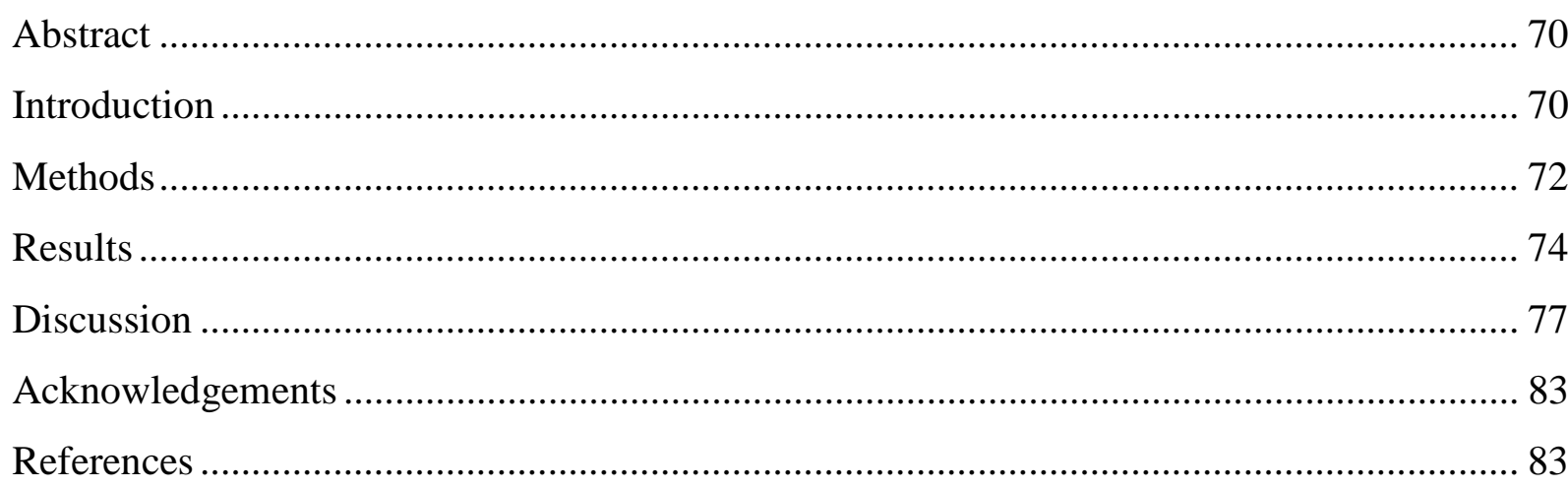

Appendix A: Sample Size Effects on the Ability to Predict the Mean Percent Dry Weight of a Population ....................................................................................................................... 100

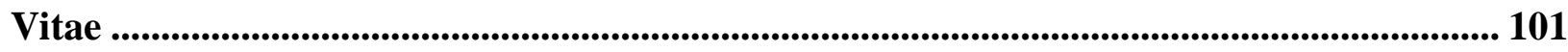




\section{Chapter 1: Introduction}

Bioelectrical impedance analysis (BIA) was first introduced to the biological sciences when Lukaski et al. (1985) used it to assess fat-free mass of humans. Since that time BIA has been used on humans to estimate total body water (Kushner and Schoeller 1986), lean body mass (Segal et al. 1988), body cell mass (Kotler et al. 1996) and even survival of patients with HIV (Ott et al. 1995). Shortly after BIA was used for the prediction of body composition in humans, researchers from animal sciences became interested and BIA was used for similar purposes with lambs (Berg et al. 1996), raccoons (Pitt et al. 2006), buffalo (Sarubbi et al. 2008), and even skunks (Hwang et al. 2005). It was not until recently, however, that BIA was used on poikilotherms such as fish.

The basic methods for conducting BIA on fish are relatively simple. A small electrical current $(425 \mu \mathrm{A}, 50 \mathrm{kHz})$ is passed through fish tissue and the resistance and reactance values are measured, typically using a Quantum II bioelectrical body composition analyzer (RJL Systems, Clinton Township, MI). The concept is that resistance and reactance values, or other electrical parameters calculated from resistance and reactance, will be correlated to measures of proximate composition. This occurs because resistance is a measure of how well electricity can pass through a substance and since fat is an insulator (Lukaski 1987) resistance should be increased in fish with more fat. Reactance measures the ability of a substance to hold a charge and because the lipid bilayer of cells serves as a capacitor (Lukaski 1987) reactance should be increased in healthy fatter fish. The fish is sacrificed after BIA measurements have been taken and actual proximate composition values are measured. Regression procedures are then used to develop models that predict proximate composition values from the suite of electrical parameters. Recent studies have shown there are strong relationships between proximate composition values (Hartman and Margarf 2008) and percent dry weight as well as energy density (Hartman and Brandt 1995) and percent dry weight. Because of this it is possible to develop BIA models that predict percent dry weight and then use established relationships to estimate the proximate composition value of interest. This eliminates expensive laboratory procedures such as bomb calorimetry and proximate composition analysis. Once BIA models have been developed fish no longer have to be sacrificed and proximate composition or energy density can be estimated in a non-lethal manner. 
Fisheries researchers and biologist are often interested in estimating fish condition. Accurate estimates of fish condition allow for better predictions of fish population status and future trends. The ultimate estimate of fish condition is body fat, often expressed as a mass percentage of total weight, because lipids are the fish's energy reserves that are used to survive stressful periods and live long enough to reproduce (Thompson et al. 1991; Miranda and Hubbard 1994; Sogard and Olla 2000; Biro et al. 2004; Finstad et al. 2004). Therefore, any good estimate of fish condition should be correlated to the amount of fat the fish has in reserve. Relative weight (Wr) has long been one of the condition estimates of choice (Anderson and Gutreuter 1983); however, Wr has some alarming flaws. For example, like most other condition estimators (e.g. Fulton's K; Heincke 1908), the method uses only length and weight to estimate fish condition. The problem is that often times when a fish loses fat it is replaced with water (Love 1970) resulting in the fish's weight and the Wr value to remain unchanged. This can result in a poor relationship between Wr and the amount of fat reserve a fish actually has (Figure 1). BIA has the potential to provide more accurate estimates of fish condition by taking body composition estimates into consideration. The percent dry weight of a fish is strongly correlated to the amount of fat a fish has (Hartman and Margraf 2008) and it can be easily and accurately measured with very minimal expense. Therefore, in the following chapters, percent dry weight will be used as a substitute for condition and is the goal for prediction in all of our BIA models.

When taking BIA measures past researchers have all used subdermal needle electrodes that were fabricated by the individual researchers. For example, Cox and Hartman (2005) used 28 gauge needles that penetrated $2 \mathrm{~mm}$ into brook trout Salvelinus fontinalis. Duncan et al. (2007) used 28 gauge $12 \mathrm{~mm}$ needles that penetrated just below the skin of juvenile cobia (Rachycentron canadum). Pothoven et al. (2008) used 23 gauge needles that penetrated $3 \mathrm{~mm}$ into yellow perch Perca flavescens, walleye Sander vitreus, and whitefish Coregonus clupeaformis. Willis and Hobday (2008) used 20 and 28 gauge needles that penetrated approximately $10 \mathrm{~mm}$ into juvenile southern bluefin tuna Thunnus maccoyii. Although, all of these different types of electrodes have been used by past researchers no one has ever attempted to determine the effect that electrode type has on BIA model development.

Similar to the background information regarding electrode type, very little research has been done to determine where on the fish BIA measurements should be taken. Past researchers have placed the electrodes along the side of the fish, typically with one electrode just posterior to 
the head and the other electrode anterior to the tail. Often one set of measurements is taken above the lateral line and second set is taken below the lateral line (Cox and Hartman 2005). Although these locations have provided reliable mass based estimates of proximate composition it may be possible that there are superior electrode locations or orientations that could potentially improve BIA predictive power and allow prediction of percent based estimates.

Previous BIA research has focused on adults of larger fish species. Bosworth and Wolters (2001) used BIA on catfish ranging 450-900 g. Cox and Hartman (2005) developed BIA models for brook trout ranging 110-285 mm and Pothoven et al. (2008) used BIA on fish ranging 138$639 \mathrm{~mm}$. Duncan et al. (2005) used BIA on juvenile cobia but the mean wet weight at the start of the study was $28.3 \mathrm{~g}$, larger than the weight of many age-0 fish. Although there has been some success developing BIA models that predict mass based estimates of proximate composition for fish, the previous research has indicated that more work with BIA is needed when attempting to predict percent based estimates of small fish. For many fishes cohort strength is often determined by age-0 survival through winter (Hubbs and Trautman 1935; Garvey et al. 2004). Increased fat reserves improve the probability of winter survival for small fish (Thompson et al. 1991; Miranda and Hubbard 1994; Sogard and Olla 2000; Biro et al. 2004; Finstad et al. 2004). If BIA can be used on small fish to provide accurate estimates of percent dry weight (a surrogate of condition), cohort success could possibly be predicted with greater reliability.

Temperature has been shown to have large influences on BIA measurements (Gudivaka et al. 1996; Marchello et al. 1999; Buono et al. 2004; Cox et al. 2011; Hartman et al. 2011) but few of the models developed for fish have accounted for temperature. Previous models for fish that have provided solid predictions of proximate composition have either held fish at a constant temperature $\left(26^{\circ} \mathrm{C}\right.$, Bosworth and Wolters 2001; $27^{\circ} \mathrm{C}$, Duncan et al. 2007; $20{ }^{\circ} \mathrm{C}$ Hafs and Hartman 2011; 15 and $27{ }^{\circ} \mathrm{C}$, Hartman et al. 2011) or fish have been sampled from a relatively narrow range of temperatures (Cox and Hartman 2005). Because temperature has a large influence on BIA measures it is likely that for BIA models to produce reliable estimates of condition or energy density under circumstances where temperature cannot be controlled, temperature will have to be included in BIA models.

The field applications of BIA range from providing reliable estimates of fish condition to estimating seasonal changes in energy density without having to sacrifice fish. However, a BIA field study that validates previously developed BIA models by collecting data that is completely 
independent from model development, and is also from a large temporal and temperature range is needed. This dissertation is made up of a series of laboratory studies (Chapters 2-4) designed to answer critical questions about the BIA methods that previous researches have been using. This is followed by an in depth field validation study (Chapter 5) designed to determine if BIA models developed in Chapters 2-4 are ready for use over a wide range of field conditions. Hopefully by answering these questions BIA methods are improved and models provide more reliable predictions of percent dry weight.

\section{References}

Anderson, R. O., and S. J. Gutreuter. 1983. Length, weight, and associated structural indices. Pages 283-300 in L. A. Nielsen and D. L. Johnson, editors. Fisheries techniques. American Fisheries Society, Bethesda, Maryland.

Berg, E. P., M. K. Neary, J. C. Forrest, D. L. Thomas, and R. G. Kaufmann. 1996. Assessment of lamb carcass composition from live animal measurement of bioelectrical impedance or ultrasonic tissue depths. Journal of Animal Science 74:2672-2678.

Biro, P. A., A. E. Morton, J. R. Post, and E. A. Parkinson. 2004. Over-winter lipid depletion and mortality of age-0 rainbow trout (Oncorhynchus mykiss). Canadian Journal of Fisheries and Aquatic Sciences 61:1513-1519.

Bosworth, B. G., and W. R. Wolters. 2001. Evaluation of bioelectric impedance to predict carcass yield, carcass composition, and fillet composition in farm-raised catfish. Journal of the World Aquaculture Society 32:72-78.

Buono, M. J., S. Burke, S. Endemann, H. Graham, C. Gressard, L. Griswold, and B. Michalewicz. 2004. The effect of ambient air temperature on whole-body bioelectrical impedance. Physiological Measurement 25:119-123.

Cox, M. K., and K. J. Hartman. 2005. Non-lethal estimation of proximate composition in fish. Canadian Journal on Fisheries and Aquatic Sciences 62:269-275.

Cox, M. K., R. Heintz, and K. Hartman. 2011. Measurements of resistance and reactance in fish with the use of bioelectrical impedance analysis: sources of error. Fisheries Bulletin 109:3447.

Duncan, M., S. R. Craig, A. N. Lunger, D. D. Kuhn, G. Salze, and E. McLean. 2007. Bioimpedance assessment of body composition in cobia Rachycentron canadum (L. 1766). Aquaculture 271:432-438. 
Finstad, A. G., O. Ugedal, T. Forseth, and T. F. Naesje. 2004. Energy-related juvenile winter mortality in a northern population of Atlantic salmon (Salmo salar). Canadian Journal of Fisheries and Aquatic Sciences 61:2358-2368.

Garvey, J. E., K. G. Ostrand, and D. H. Wahl. 2004. Energetics, predation, and ration affect sizedependent growth and mortality of fish during winter. Ecology 85:2860-2871.

Gudivaka, R., D. Schoeller, and R. F. Kushner. 1996. Effect of skin temperature on multifrequency bioelectrical impedance analysis. Journal of Applied Physiology 81:838-845.

Hafs, A. W., and K. J. Hartman. 2011. Influence of electrode type and location upon bioelectrical impedance analysis measurements of brook trout. Transactions of the American Fisheries Society 140:1290-1297.

Hartman, K. J., and F. J. Margraf. 2008. Common relationships among proximate composition components in fishes. Journal of Fish Biology 73:2352-2360.

Hartman, K. J., and S. B. Brandt. 1995. Estimating energy density of fish. Transactions of the American Fisheries Society 124:347-355.

Hartman, K. J., B. A. Phelan, and J. E. Rosendale. 2011. Temperature effects on bioelectrical impedance analysis (BIA) used to estimate dry weight as a condition proxy in coastal bluefish. Marine and Coastal Fisheries: Dynamics, Management, and Ecosystem Science 3:307-316.

Heincke, F. 1908. Bericht über die Untersuchungen der Biologischen Anstalt auf Helgoland zur Naturgeschichte der Nutzfische. Die Beteiligung Deutschlands an der Internationalen Meeresforschung 1908:4/5:67-155.

Hubbs, C. L., and M. B. Trautman. 1935. The need for investigating fish conditions in winter. Transactions of the American Fisheries Society 65:51-56.

Hwang, Y. T., S. Larivière, and F. Messier. 2005. Evaluating body condition of striped skunks using non-invasive morphometric indices and bioelectrical impedance analysis. The Wildlife Society Bulletin 33:195-203.

Kotler, D. P., S. Burastero, J. Wang, and R. N. Pierson Jr. 1996. Prediction of body cell mass, fat-free mass, and total body water with bioelectrical impedance analysis: effects of race, sex, and disease. The American Journal of Clinical Nutrition 64(suppl):489S-497S.

Kushner, R. F., and D. A. Schoeller 1986. Estimation of total body water by bioelectrical impedance analysis. The American Journal of Clinical Nutrition 44:417-424. 
Love, R. M. 1970. The chemical biology of fishes, Academic Press, New York, New York, USA.

Lukaski, H. C. 1987. Methods for the assessment of human body composition: traditional and new. The American Journal of Clinical Nutrition 46:537-556.

Lukaski, H. C., P. E. Johnson, W. W. Bolonchuk, and G. I. Lykken. 1985. Assessment of fat-free mass using bioelectrical impedance measurements of the human body. The American Journal of Clinical Nutrition 41:810-817.

Marchello, M. J., W. D. Slanger, and J. K. Carlson. 1999. Bioelectrical impedance: fat content of beef and pork from different size grinds. Journal of Animal Science 77:2464-2468.

Miranda, L. E., and W. D. Hubbard. 1994. Length-dependent winter survival and lipid composition of age-0 largemouth bass in Bay Springs Reservoir, Mississippi. Transactions of the American Fisheries Society 123:80-87.

Ott, M., H. Fischer, H. Polat, E. Brigitte Helm, M. Frenz, W. F. Caspary, and B. Lembcke. 1995. Bioelectrical impedance analysis as a predictor of survival in patients with human immunodeficiency virus infection. Journal of Acquired Immune Deficiency Syndromes and Human Retrovirology 9:20-25.

Pitt, J. A., S. Lariviere, and F. Messier. 2006. Condition indices and bioelectrical impedance analysis to predict body condition of small carnivores. Journal of Mammalogy 87:717-722.

Pothoven, S. A., S. A. Ludsin, T. O. Hook, D. L. Fanslow, D. M. Mason, P. D. Collingsworth, and J. J. Van Tassell. 2008. Reliability of bioelectrical impedance analysis for estimating whole-fish energy density and percent lipids. Transactions of the American Fisheries Society 137:1519-1529.

Sarubbi, F., R. Baculo, and D. Balzarano. 2008. Bioelectrical impedance analysis for the prediction of fat-free mass in buffalo calf. Animal 2:1340-1345.

Segal, K. R., M. V. Loan, P. I. Fitzgerald, J. A. Hodgdon, and T. B. Van Itallie. 1988. Lean body mass estimation by bioelectrical impedance analysis: a four-site cross-validation study. The American Journal of Clinical Nutrition 47:7-14.

Sogard, S. M., and B. L. Olla. 2000. Endurance of simulated winter conditions by age-0 walleye pollock: effects of body size, water temperature and energy stores. Journal of Fish Biology $56: 1-21$. 
Thompson, J. M., E. P. Bergersen, C. A. Carlson, and L. R. Kaeding. 1991. Role of size, condition, and lipid content in the overwinter survival of age-0 Colorado Squawfish. Transactions of the American Fisheries Society 120:346-353.

Willis, J., and A. J. Hobday. 2008. Application of bioelectrical impedance analysis as a method for estimating composition and metabolic condition of southern bluefin tuna (Thunnus maccoyii) during conventional tagging. Fisheries Research 93:64-71. 

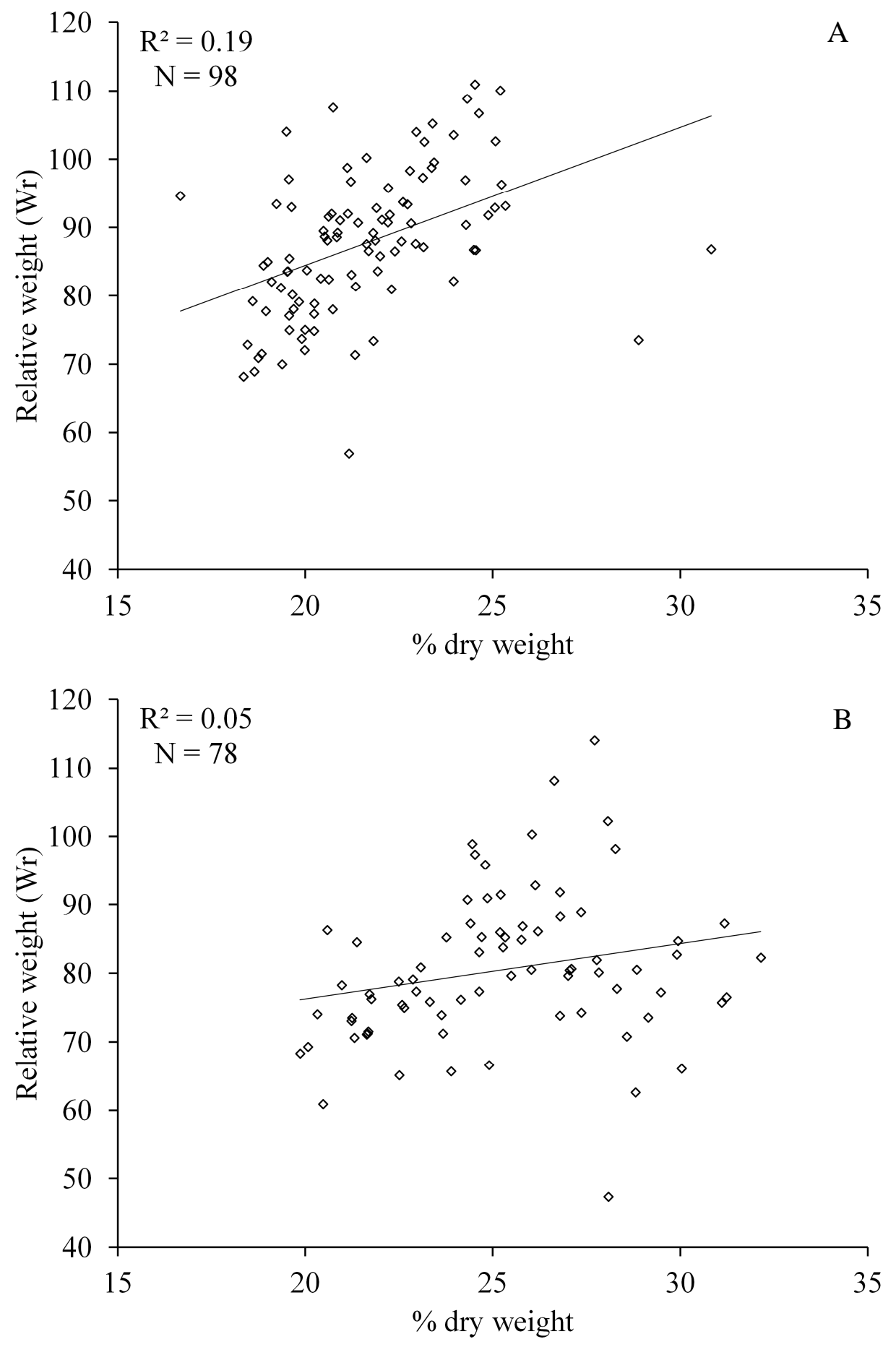

Figure 1.-Relationship between relative weight ( $\mathrm{Wr}$ ) and percent dry weight for the validation brook trout (A) from Hafs (2011, Chapter 5) and for (B) 78 bluegill Lepomis macrochirus that were used as pilot data to help develop this dissertation (Hafs, A.W., unpublished data). 


\title{
Chapter 2: Evaluation of Electrode Type and Measurement Location upon BIA Models of Water Content in Brook Trout
}

\begin{abstract}
Bioelectrical impedance analysis (BIA) in recent years has started to develop into a low cost tool that can provide accurate estimates of fish condition. Past researchers have had success predicting mass based proximate condition components, but attempts to predict percent based components have not been as successful suggesting that methodological improvements are needed. The percent dry weight (\%DW) of a fish is a desirable estimate because from it energy density and body composition estimates can be obtained using previously developed or easily developable relationships. The objective of this study was to determine the location that electrodes should be placed to provide the best estimates of $\% \mathrm{DW}$ on brook trout Salvelinus fontinalis ranging 140-330 $\mathrm{mm}$ (total length). A second objective was to determine the effect that electrode type had on the ability to predict \%DW. Models developed using two electrode locations performed better than when only one location was used. When taking BIA measurements on brook trout, one set of measurements should be taken by placing the electrodes along the dorsal midline (DML) of the fish. A second set should be taken by placing one electrode on the dorsal midline directly in front of the dorsal fin while placing the other electrode on the ventral midline directly below the other electrode (DTVpre). Models developed using these locations explained on average $13.2 \%$ more variation in $\% \mathrm{DW}$ than locations used by previous researchers. Validation of BIA models demonstrated that both subdermal needle $\left(\mathrm{RMSE}=1.34\right.$, and $\left.\mathrm{R}^{2}=0.82\right)$ and less invasive external rod electrodes $\left(\mathrm{RMSE}=1.37\right.$, and $\mathrm{R}^{2}=$ 0.79) provided accurate estimates of \%DW when using the DML and DTVpre locations. More research is needed to determine if these patterns hold true for smaller fish or other species with distinctly different morphologies, bone structure, or scale type.
\end{abstract}

\section{Introduction}

Bioelectrical impedance analysis (BIA) can be used as a low cost nonlethal method for estimating the proximate composition of fish (Cox and Hartman 2005). BIA is done by passing an electrical current through the subject of interest and the resistance and reactance is measured. Resistance measures the ability of a substance to conduct electricity (Cox and Hartman 2005). Because fat is a poor conductor of electricity there should be a relationship between the amount 
of fat in the subject and the resistance measured by BIA. Reactance measures the ability of a substance to hold a charge. Because the lipid bilayer of a cell serves as a capacitor (Lukaski 1987), reactance is subsequently a measure of total cell volume and should be related to the size and condition of the subject. Simple regression models have been developed that can predict mass based proximate composition estimates from BIA measurements (Bosworth and Wolters 2001; Cox and Hartman 2005; Duncan et al. 2007; Pothoven et al. 2008). Although previous models predict mass based proximate composition estimates it would be useful if models predicting percent based estimates of proximate composition were developed. By obtaining reliable predictions of percent dry weight we could use equations developed by previous research to estimate both energy density for use in bioenergetics studies (Hartman and Brandt 1995) and body composition values (Hartman and Margraf 2008). Previous models attempting to predict percent based estimates using BIA have been unreliable (Pothoven et al. 2008) suggesting improvements in the method are needed.

Past BIA models for fish have been developed by measuring the resistance and reactance of a small electrical current $(425 \mu \mathrm{A}, 50 \mathrm{kHz})$ that is passed between two electrodes placed on the side of the fish. The resistance and reactance measures are then regressed against measures of proximate composition. Recent researchers have used subdermal needle electrodes. Cox and Hartman (2005) used 28 gauge needles that penetrated $2 \mathrm{~mm}$ into brook trout Salvelinus fontinalis ranging from 110-285 mm in total length (TL). Pothoven et al. (2008) used 23 gauge needles that penetrated $3 \mathrm{~mm}$ into yellow perch Perca flavescens $(138-358 \mathrm{~mm})$, walleye Sander vitreus (328-639 mm), and whitefish Coregonus clupeaformis (246-564 mm). Willis and Hobday (2008) used 20 and 28 gauge needles that penetrated approximately $10 \mathrm{~mm}$ into juvenile southern bluefin tuna Thunnus maccoyii ranging 410-1090 mm fork length (FL). Although past researchers have used different electrodes little research has been done to see how the type of electrode influences BIA measurements.

In addition to the type of electrodes used, the location that the electrodes are placed may also affect BIA measures. Past researchers have placed the electrodes along the side of the fish typically with one electrode just posterior to the head and the other electrode anterior to the tail. Often one set of measurements is taken above the lateral line and second set is taken below the lateral line (Cox and Hartman 2005). Although these locations have provided reliable mass based 
estimates of proximate composition alternative locations need to be tested to see if improvements in the method are available that will provide reliable percent based estimates.

The objective of this study was to determine the electrode location on fish that provides the best estimate of percent dry weight on brook trout, a streamlined fish with small cycloid scales. A second objective was to determine how well BIA models developed using three different electrode types could predict percent dry weight of brook trout and to test whether results from one electrode can be applied to a model developed with another electrode type.

\section{Methods}

Brook trout $(\approx 150 \mathrm{~mm}$ TL) were donated from Bowden State fish hatchery, Bowden, West Virginia and transported to the West Virginia University Ecophysiology Laboratory where fish were maintained in recirculating tanks $(0.58 \mathrm{~m} \times 0.58 \mathrm{~m} \times 2.13 \mathrm{~m})$ at $12.5 \pm 0.5^{\circ} \mathrm{C}$. Cox and Hartman (2005) had previously developed models for fish ranging 110-285 mm so for this study we sampled fish from three size classes similar to that range $(150,225$, and $300 \mathrm{~mm})$. At the time the fish were received from the hatchery 45 fish were randomly selected to represent the $150 \mathrm{~mm}$ size class and were isolated from the rest of the fish in a separate recirculating tank. The remaining fish were fed ad libitum daily until their selected size class (225 and $300 \mathrm{~mm}$ TL) was reached. All fish were acclimated to the recirculating system at West Virginia University Ecophysiology Laboratory for at least two weeks before any BIA was done.

In developing BIA models it is desirable to include fish at the range of possible body conditions. Because the fish were fed ad libitum daily until they reached their appropriate size class it was assumed that those fish were in the best possible condition at that time. In order to have fish at a wide range of body conditions while controlling for interactive effects of size and condition, fish from each size class were fasted (no food was provided) for varying lengths of time before being selected for BIA. To accomplish this fish were sampled at approximately seven evenly spaced intervals over each of the individual fasting periods. Within the $150 \mathrm{~mm}$ size class the leanest fish were fasted for approximately four months. The leanest fish in the 225 $\mathrm{mm}$ size class were fasted approximately five months and lastly, the $300 \mathrm{~mm}$ fish were randomly sampled over the course of a six month fasting period.

\section{Bioelectrical impedance analysis}

Resistance and reactance were measured using a Quantum II bioelectrical body composition analyzer (RJL Systems, Clinton Township, MI). The Quantum II passes a small 
current $(425 \mu \mathrm{A}, 50 \mathrm{kHz})$ through the fish and measures resistance and reactance in ohms. For this study two sets of electrodes (subdermal needle and external electrodes) were created by the experimenters and one set (subdermal needle electrodes) was manufactured by a medical supply company (Model FE24, The Electrode Store, Enumclaw, WA) following the experimenters' designs (Figure 1). Subdermal needles used were 29 gauge mounted $10 \mathrm{~mm}$ apart set to penetrate to a depth of $3 \mathrm{~mm}$. External electrodes consisted of stainless steel rods $3.2 \mathrm{~mm}$ in diameter with the center of the rods mounted $10 \mathrm{~mm}$ apart (Figure 1). For the remainder of the manuscript the subdermal needles created by the experimenters will be called Epoxy because the needles were set in epoxy. The Electrode Store subdermal needles will be called FE24 and the external rod electrodes will be called Rods.

We also assessed which location on the fish electrodes should be placed to produce the best estimates of percent dry weight. To do this resistance and reactance was measured at seven different locations: dorsal midline (DML), dorsal total length (DTL), lateral line (LL), ventral total length (VTL), ventral midline (VML), dorsal to ventral pre dorsal fin (DTVpre), and dorsal to ventral post dorsal fin (DTVpost). These seven electrode locations are shown in detail in Figure 2. It is important to note that each electrode has two needles or rods with one serving as the signal and the other serving as the detector electrode (Cox and Hartman 2005). Although it appears from our own unpublished observations that the orientation of the signal and detector needles or rods has no influence on the readings, for this study signal electrodes were always kept towards the head of the fish.

Because ambient air temperature can influence BIA measurements (Gudivaka et al. 1996), fish were acclimated in water with temperature equal to the room temperature (range 18.0-21.0) for at least $12 \mathrm{~h}$ prior to all BIA measurements. This was done to minimize the influence of air temperature on BIA measurements. After the 12 hour acclimation period the fish was anesthetized using MS-222, the fish was blotted dry, and the wet weight (WW; g), fork length and total length ( $\mathrm{mm})$ was measured. The fish was then placed on a nonconductive board with the head facing left. Resistance and reactance was measured at all seven locations with all three electrode types on each fish. The distance between the inner needles or rods of the two electrodes was recorded for every measurement. So that detector length was equal to the distance between the signal needles or rods $10 \mathrm{~mm}$ was added to all lateral measurements. The person holding the electrodes wore rubber gloves to insulate the bioimpedance of the researcher from 
that of the fish. To avoid bias due to temperature changes from handling or repeated BIA measures the order of both the electrode type and location that the measurements were taken was changed for every fish during the study. After all BIA measurements were completed for a fish it was euthanized in an overdose of MS-222 and the whole fish was oven-dried to a constant weight at $80{ }^{\circ} \mathrm{C}$. Percent dry weight was calculated by dividing dry weight by wet weight and multiplying by 100 .

\section{Data analysis}

From measured resistance and reactance for each location and electrode type a suite of electrical parameters were calculated following the methods outlined by Cox and Hartman (2005) and Cox et al. (2011). Table 1 outlines the calculations for parameters used in regression analysis: resistance $(r)$, reactance $(x)$, resistance in series $\left(R_{s}\right)$, reactance in series $\left(X_{c}\right)$, resistance in parallel $\left(\mathrm{R}_{\mathrm{p}}\right)$, reactance in parallel $\left(\mathrm{X}_{\mathrm{cp}}\right)$, capacitance $\left(\mathrm{C}_{\mathrm{pf}}\right)$, impedance in series $\left(\mathrm{Z}_{\mathrm{s}}\right)$, impedance in parallel $\left(\mathrm{Z}_{\mathrm{p}}\right)$, phase angle (PA), and standardized phase angle (DLPA). Because detector length is correlated to fish size all electrical parameters were standardized to electrical volume by dividing detector length (DL) squared with each parameter (e.g. $\mathrm{DL}^{2} / \mathrm{R}_{\mathrm{s}}$ ) following the methods of Cox and Hartman (2005). Standardized phase angle was calculated by multiplying PA and DL.

BIA models predicting percent dry weight were developed by running ordinary least squares regression using the function ols (Harrell 2009), part of the package rms in program $R$ ( $R$ Development Core Team 2009). Fish from all three size classes ( $n=45-47$ per each size class) were included for model development and models were also developed for each size class individually. A BIA model was developed for each electrode location/type combination individually. To determine if using two electrode locations improved predictive ability, BIA models were also developed for all two electrode location combinations for each electrode type individually. The function leaps (Lumley 2009), part of the package leaps in program $\mathrm{R}(\mathrm{R}$ Development Core Team 2009), was used to calculate Mallows' $C_{p}$ (Mallows 1973) for every possible model for each electrode location and type combination (Figure 3). From every electrode type and location combination the model with the lowest Mallows' $C_{p}$ value from each possible model size was selected for validation.

BIA models were validated using the function validate (Harrell 2009), part of the package rms in program $\mathrm{R}$ ( $\mathrm{R}$ Development Core Team 2009). The validate function uses bootstrapping 
methods developed by Efron (1983) to randomly select training data sets of size $\mathrm{n}$. The original whole data set is used as the test data set. The training data sets are used to develop the models and the test data is used to validate the model. R-square and root mean square error (RMSE) values are then calculated based on how well the test data fits the models. The validate function was set so 10,000 permutations were run to develop each model and estimate the R-square and RMSE values. Akaike's information theoretical criterion (Akaike 1973) corrected for sample size (AICc; McQuarrie and Tsai 1998) was used to determine the best model from those previously selected by Mallows' $\mathrm{C}_{\mathrm{p}}$ values.

After the validation was complete and the best models had been determined we randomly selected $80 \%$ of the fish to represent a training data set and the other $20 \%$ of the fish to represent a test data set. To compare needle electrode types we then entered the resistance and reactance values from the test data set for the Epoxy subdermal needles into the regression model that was developed using the FE24 training data set. Root mean square estimates were calculated to determine if a model would be applicable for sets of electrodes not used during model development. We also tested all other model-electrode combinations in a similar manner.

Finally because the distance between the electrodes could be related to the percent dry weight, especially for the DTVpre and DTVpost locations where the detector length is basically the body depth, we wanted to make sure that the BIA measurements and not the detector lengths was the driving force behind our models. To test this possible pitfall we selected the best model after all validation results were complete. For each fish that had previously been used to develop the model we changed the measured resistance and reactance values to one while leaving the measured detector lengths unchanged. The electrical parameters were calculated as normal using the new resistance and reactance values and the unchanged detector lengths. The calculated electrical parameter estimates were then entered into the model to predict percent dry weight for each fish. The resulting RMSE and R-square estimates were compared to the results obtained using actual resistance and reactance values. In addition to changing all resistance and reactance values to one we also developed a model that attempted to predict percent dry weight using only, TL, FL, WW, and Rod DL from all seven locations.

\section{Results}

The percent dry weight of brook trout sampled from 150, 225, and $300 \mathrm{~mm}$ size classes ranged 17.64-27.14, 17.80-28.38, and 17.93-32.55, respectively (Figure 4). Model validation 
demonstrated that all three electrode types were able to accurately predict percent dry weight. When the three fish size classes were analyzed individually, on average the best models were developed using the VML DTVpre locations or the DML DTVpre locations. On average, across models for all size classes and electrode types, the VML DTVpre location combination produced models with AICc $=23.00, \mathrm{RMSE}=1.11$, and $\mathrm{R}^{2}=0.84$. The DML DTVpre location combination provided similar results on average $\left(\mathrm{AICc}=23.61, \mathrm{RMSE}=1.08\right.$, and $\left.\mathrm{R}^{2}=0.85\right)$.

Models developed for individual size classes preformed only slightly better than models including all size classes. The best model developed while including all size fish resulted in RMSE (1.34) and $\mathrm{R}^{2}(0.82)$ estimates that were only slightly worse than the models developed for individual size classes $\left(\mathrm{RMSE}=1.11\right.$, and $\left.\mathrm{R}^{2}=0.84\right)$. Since models developed using all size classes of fish preformed similarly to models for individual size classes the rest of the results and discussion focuses on models that were developed using all size classes of fish.

Models developed using two locations performed better than when only one location was used. The best model developed using only one measurement location was the DTVpre location using the Epoxy electrodes $\left(\mathrm{AICc}=115.19, \mathrm{RMSE}=1.43\right.$, and $\left.\mathrm{R}^{2}=0.79\right)$ and it performed similarly to models developed with two locations. However, $\operatorname{Rod}(\mathrm{AICc}=144.01, \mathrm{RMSE}=1.59$, and $\left.\mathrm{R}^{2}=0.72\right)$ and FE24 $\left(\mathrm{AICc}=125.32, \mathrm{RMSE}=1.51\right.$, and $\left.\mathrm{R}^{2}=0.77\right)$ models developed using only the DTVpre location did not perform quite as well (Figure 5). There were 21 different models developed using two locations that outperformed the best single location model. The regression coefficients for the FE24 and Rod DTVpre models are located in Table 2.

The location that the electrodes were placed on the fish did have a large influence on the ability to accurately predict percent dry weight. The best 27 models all were developed using DTVpre or VML as at least one of the two locations. On average across electrode types the models developed using the DML and DTVpre locations preformed the best (Epoxy - AICc $=$ 95.90, $\mathrm{RMSE}=1.32$, and $\mathrm{R}^{2}=0.82 ;$ FE24 $-\mathrm{AICc}=100.28, \mathrm{RMSE}=1.34$, and $\mathrm{R}^{2}=0.82 ;$ Rods - $\mathrm{AICc}=111.19, \mathrm{RMSE}=1.37$, and $\mathrm{R}^{2}=0.79$; Figure 5). Models developed using locations from previous research (DTL and VTL) on average explained 13.2\% less variability in comparison to the DML and DTVpre locations. The regression coefficients for the FE24 and Rod models developed using the DML and DTVpre locations are can be found in Table 2.

Because the models developed using the DML and DTVpre locations provided the most reliable results across all three electrode types, that was the location combination used to 
determine if models developed for one electrode type could be used for data collected with other electrodes. Entering the Epoxy test data set into the training Epoxy model resulted in a RMSE estimate of 0.99. The test data from FE24 subdermal needles and the Epoxy training model produced a RMSE estimate of 1.36 and the Rod test data set RMSE estimate was 1.31. When the Rod training model was developed the resulting RMSE estimates were 4.00, 0.96, and 2.74, for the Epoxy, Rod, and FE24 test data sets, respectively. Finally, when the FE24 training model was created the resulting RMSE estimates were 1.17, 1.17, and 0.96, for Epoxy, Rod, and FE24 training data sets, respectively. In summary, the models developed for subdermal needle electrodes (FE24 and Epoxy) preformed well when data from either subdermal needles or external rod electrodes was entered. However, the model developed for the Rod electrodes did not perform as well when data from the subdermal needle electrodes was entered.

BIA models developed using only detector length did a much poorer job at predicting percent dry weight than models that included measured resistance and reactance values. For example, the Epoxy model developed using the DML and DTVpre locations was able to predict percent dry weight with a RMSE of 1.32 and an $\mathrm{R}^{2}=0.82$. Conversely, when only detector length from the DML and DTVpre were used and all resistance and reactance values were changed to one the best model that could be developed was only able to predict percent dry weight with a RMSE of 2.53 and an $\mathrm{R}^{2}=0.36$. The model that attempted to predict percent dry weight using only, TL, FL, WW, and Rod DL from all seven locations resulted in RMSE of 2.77 and an $\mathrm{R}^{2}=0.13$.

\section{Discussion}

Previous researchers attempting to predict percent based composition estimates have had limited success (Pothoven et al. 2008) suggesting that improvements in the methods were needed. By determining which location the electrodes should be placed on the brook trout we were able to substantially improve the reliability of our BIA models allowing accurate prediction of percent dry weight. Future researchers can now use the methods and models provided in this paper to accurately predict percent dry weight. Hartman and Brandt (1995) have previously established relationships between percent dry weight and energy density. In addition to the relationship established by Hartman and Brandt (1995), relationships have also been established among proximate composition estimates and percent dry weight (Hartman and Margraf 2008). Therefore, once percent dry weight has been predicted researchers can relate percent dry weight 
to energy density and body composition values at a fraction of the cost needed for laboratory analysis of proximate composition or bomb calorimetry.

Past researchers have commonly used what we call in this paper the DTL and VTL locations to take their BIA measurements (Cox and Hartman 2005; Pothoven et al. 2008; Hartman et al. 2011). In this study when we used the locations from previous research (DTL and VTL) and the Epoxy subdermal needle electrodes, resulting models could only predict percent dry weight with an $\mathrm{R}^{2}=0.61$ and an RMSE of 1.96 . By testing seven different locations we were able to determine that the DML and DTVpre locations produced models that preformed much better $\left(\mathrm{R}^{2}=0.82, \mathrm{RMSE}=1.32\right)$. The Epoxy model developed using the DML and DTVpre locations was able to explain an extra $21 \%$ of the variability in comparison to the methods provided by previous researchers. The other two electrode types used in this study also provided similar results. The DTVpre location resulted in models that did a much better job at predicting percent dry weight than models developed using other electrode locations. Because the detector length for the DTVpre location is essentially the body depth in front of the dorsal fin it can be measured very accurately, minimizing a source of error present in the models developed not using this location. Additionally, it is likely that by taking measurements from the DTVpre location and one lateral location (DML) the electrical current is forced to pass through a greater proportion of the fish than when two similar lateral locations are used, ultimately resulting in better prediction from the models. For future BIA research on brook trout or other fish species with similar body morphology we suggest that taking BIA measurements at the DML and DTVpre locations will improve results and should allow for accurate prediction of percent based estimates. If time or money permits that only one measurement is taken per fish the DTVpre location should be used but researchers should expect some loss in the accuracy of their predictions compared to when two measurement locations are used.

This is the first study that we are aware of where external electrodes were used to take BIA measurements on fish. The external rod electrodes used in this study produced estimates of percent dry weight that were comparable to those estimates provided from subdermal needle electrode models. This is important because external rod electrodes are far less invasive than subdermal needles. The less invasive external rod technique may be required when working with small, fragile fish, or endangered species. Even though the external rod electrodes worked well on brook trout, a Salmonidae with very small cycloid scales, researchers should use caution. It is 
likely that external rod electrodes will have limited success on other fish species with larger or thicker scales. More research is needed to determine if these patterns hold true for brook trout smaller than $140 \mathrm{~mm}$ or fish species with different morphologies, bone or scale structure.

A total of 21 measurements (seven locations with three electrodes types) were taken on each fish. Although air temperature and water temperatures were controlled we assume that over the course of taking 21 measurements although gloved, the contact with the experiment's hands would cause a slight rise in the fish's body temperature. Both the order of the locations and electrode type was changed for each fish so the results should not be biased in any way but the changing body temperatures would affect the BIA measurements (Gudivaka et al. 1996; Cox et al. 2011) incorporating an amount of variation into our models that could not be explained. This suggests that our results are conservative and that if only two measurements (DML and DTVpre for example) were taken on each fish and a model was then developed the RMSE would likely be lower than 1.34 .

Another important result from this research was that models developed for subdermal needle electrodes provided accurate predictions of percent dry weight even when resistance and reactance values measured from a different electrode type were entered. This means that as long as future researchers follow our methods and electrode specifications they should be able to build their own electrodes or purchase some from The Electrode Store (www.electrodestore.com) and the models provided in this paper should provide reliable predictions $\left(\mathrm{R}^{2}>0.80\right)$ of percent dry weight. That being stated, future research is needed to determine if other researchers can replicate our accuracy levels using the models and methods provided in this paper. Furthermore, we strongly encourage researchers that plan on using our methods and models to independently validate them on a subset of the fish sampled. Lastly, both types of subdermal needle electrodes used in this study were the same gauge (29) and penetrated the same distance (3 $\mathrm{mm})$ and it is unclear if our models would provide reliable results when using electrodes with different specifications. Research is warranted that attempts to determine the effect that gauge and penetration depth has on BIA measurements.

The models presented in this paper were developed under strict laboratory conditions where both air and water temperatures were held constant. Because temperature can have a large influence on BIA measurements (Gudivaka et al. 1996; Cox et al. 2011) future researchers should use care when attempting to use our models outside of the range of temperatures that 
were present during our laboratory experiments $\left(18.0-21.0^{\circ} \mathrm{C}\right)$. There is a need to develop temperature corrections for BIA measurements so the models provided in this paper can be used in the field where large fluctuations in both air and water temperature are common. It is our opinion that if BIA is used in the field where variable water temperatures are present, without temperatures corrections for resistance and reactance too much unexplained variation will be incorporated into the models to allow for any reliable predictions. Until temperature corrections are developed BIA models will be limited to the conditions that they were developed under in the laboratory.

\section{Acknowledgements}

We would like to thank John Sweka, Patricia Mazik, Joseph Margraf, and Todd Petty for technical guidance, John Howell, Geoff Weichert, Amy Fitzwater, Lindsey Richie, for help with data collection and entry. We also thank Phil Turk and George Merovich for statistical comments as well as Frank Williams from Bowden State Fish Hatchery for providing the brook trout and fish food used in this study. Lastly, we thank WVDNR and the USFS for funding this project. All methods in this study were conducted in compliance with Animal Care and Use Committee protocol number 08-0602.

\section{References}

Akaike, H. 1973. Information theory and an extension of the maximum likelihood principle. Pages 267-281. in Petrov, B. N. and F. Csaki. Second international symposium on information theory. Akademiai Kiado. Budapest, Hungary.

Bosworth, B. G., and W. R. Wolters. 2001. Evaluation of bioelectric impedance to predict carcass yield, carcass composition, and fillet composition in farm-raised catfish. Journal of the World Aquaculture Society 32:72-78.

Cox, M. K., and K. J. Hartman. 2005. Non-lethal estimation of proximate composition in fish. Canadian Journal on Fisheries and Aquatic Sciences 62:269-275.

Cox, M. K., R. Heintz, and K. Hartman. 2011. Measurements of resistance and reactance in fish with the use of bioelectrical impedance analysis: sources of error. Fisheries Bulletin 109:3447.

Duncan, M., S. R. Craig, A. N. Lunger, D. D. Kuhn, G. Salze, and E. McLean. 2007. Bioimpedance assessment of body composition in cobia Rachycentron canadum (L. 1766). Aquaculture 271:432-438. 
Efron, B. 1983. Estimating the error rate of a prediction rule: Improvement on cross-validation. Journal of the American Statistical Association 78:316-331.

Gudivaka, R., D. Schoeller, and R. F. Kushner. 1996. Effect of skin temperature on multifrequency bioelectrical impedance analysis. Journal of Applied Physiology 81:838-845.

Harrell, F. E., Jr. 2009. rms: Regression Modeling Strategies. R package version 2.1-0. http://CRAN.R-project.org/package=rms.

Hartman, K. J., and F. J. Margraf. 2008. Common relationships among proximate composition components in fishes. Journal of Fish Biology 73:2352-2360.

Hartman, K. J., and S. B. Brandt. 1995. Estimating energy density of fish. Transactions of the American Fisheries Society 124:347-355.

Hartman, K. J., B. A. Phelan, and J. E. Rosendale. 2011. Temperature effects on bioelectrical impedance analysis (BIA) used to estimate dry weight as a condition proxy in coastal bluefish. Marine and Coastal Fisheries: Dynamics, Management, and Ecosystem Science 3:307-316.

Lukaski, H. C. 1987. Methods for the assessment of human body composition: traditional and new. The American Journal of Clinical Nutrition 46:537-556.

Lumley, T. using Fortran code by A. Miller. 2009. leaps: regression subset selection. R package version 2.9. http://CRAN.R-project.org/package=leaps.

Mallows, C. L. 1973. Some comments on $C_{p}$. Technometrics 15:661-675.

McQuarrie, A. D., and C. L. Tsai. 1998. Regression and time series model selection. World Scientific Publishing. Singapore.

Pothoven, S. A., S. A. Ludsin, T. O. Hook, D. L. Fanslow, D. M. Mason, P. D. Collingsworth, and J. J. Van Tassell. 2008. Reliability of bioelectrical impedance analysis for estimating whole-fish energy density and percent lipids. Transactions of the American Fisheries Society 137:1519-1529.

R Development Core Team 2009. R: A language and environment for statistical computing. R Foundation for Statistical Computing, Vienna, Austria. ISBN 3-900051-07-0, URL http://www.R-project.org.

Willis, J., and A. J. Hobday. 2008. Application of bioelectrical impedance analysis as a method for estimating composition and metabolic condition of southern bluefin tuna (Thunnus maccoyii) during conventional tagging. Fisheries Research 93:64-71. 
Table 1.-Electrical parameters (converted to electrical volume when $\mathrm{DL}^{2}$ is included in equation) used during BIA model development.

\begin{tabular}{lcll}
\hline Parameter & Symbol & Units & Calculation \\
\hline Resistance & $\mathrm{r}$ & ohms & measured by Quantum II \\
Reactance & $\mathrm{x}$ & ohms & measured by Quantum II \\
Resistance in series & $\mathrm{R}_{\mathrm{s}}$ & ohms & $\mathrm{DL}^{2} / \mathrm{r}$ \\
Reactance in series & $\mathrm{X}_{\mathrm{c}}$ & ohms & $\mathrm{DL}^{2} / \mathrm{x}$ \\
Resistance in parallel & $\mathrm{R}_{\mathrm{p}}$ & ohms & $\mathrm{DL}^{2} /\left(\mathrm{r}+\left(\mathrm{x}^{2} / \mathrm{r}\right)\right)$ \\
Reactance in parallel & $\mathrm{X}_{\mathrm{cp}}$ & ohms & $\mathrm{DL}^{2} /\left(\mathrm{x}+\left(\mathrm{r}^{2} / \mathrm{x}\right)\right)$ \\
Capacitance & $\mathrm{C}_{\mathrm{pf}}$ & picoFarads & $\mathrm{DL}^{2} /\left((1 /(2 \cdot \pi \cdot 50000 \cdot \mathrm{r})) \cdot\left(1 \cdot 10^{12}\right)\right)$ \\
Impedance in series & $\mathrm{Z}_{\mathrm{s}}$ & ohms & $\mathrm{DL}^{2} /\left(\mathrm{r}^{2}+\mathrm{x}^{2}\right)^{0.5}$ \\
Impedance in parallel & $\mathrm{Z}_{\mathrm{p}}$ & ohms & $\mathrm{DL}^{2} /\left(\mathrm{r} \cdot \mathrm{x} /\left(\mathrm{r}^{2}+\mathrm{x}^{2}\right)^{0.5}\right)$ \\
Phase angle & $\mathrm{PA}$ & degrees & $\mathrm{atan}(\mathrm{x} / \mathrm{r})^{*} 180 / \pi$ \\
Standardized phase angle & $\mathrm{DLPA}$ & degrees & $\mathrm{DL}^{2}\left(\mathrm{atan}(\mathrm{x} / \mathrm{r})^{*} 180 / \pi\right)$ \\
\hline DL = detector length & & &
\end{tabular}


Table 2.-Regression coefficients for the prediction of percent dry weight for brook trout ranging approximately 140-330 mm TL. Four models are presented, two for FE24 subdermal needle electrodes and two for external rod electrodes. The models presented allow BIA measurements to be taken from two locations (use the DML DTVpre column) or only one (use DTVpre column). The parameter column tells which location's resistance and reactance measurements should be used when calculating the electrical parameter in parenthesis. Calculations for the electrical parameters are listed in Table 1. See Figure 2 for definitions of measurement location notations.

\begin{tabular}{|c|c|c|c|c|}
\hline \multirow[b]{3}{*}{ Parameter } & \multicolumn{4}{|c|}{ Model } \\
\hline & \multicolumn{2}{|c|}{ FE24 location(s) } & \multicolumn{2}{|c|}{ Rod location(s) } \\
\hline & DML DTVpre & DTVpre & DML DTVpre & DTVpre \\
\hline Intercept & 14.2881 & 7.6944 & 42.1160 & 26.01171 \\
\hline FL & & & -0.0765 & -0.04109 \\
\hline WW & 0.0504 & 0.0211 & 0.0878 & 0.02553 \\
\hline DML(r) & -0.0159 & & -0.0233 & \\
\hline $\operatorname{DML}\left(\mathrm{R}_{\mathrm{s}}\right)$ & & & 3.1429 & \\
\hline $\operatorname{DML}\left(\mathrm{X}_{\mathrm{c}}\right)$ & & & -0.4166 & \\
\hline $\operatorname{DML}\left(\mathrm{X}_{\mathrm{cp}}\right)$ & -0.4690 & & -7.5129 & \\
\hline $\operatorname{DML}\left(\mathrm{C}_{\mathrm{pf}}\right)$ & 30.0180 & & 21.4788 & \\
\hline DML(PA) & 0.9160 & & & \\
\hline DML(DLPA) & -0.0123 & & & \\
\hline DTVpre(r) & 0.0390 & 0.0518 & & \\
\hline DTVpre(x) & & & 0.0720 & 0.06974 \\
\hline DTVpre $\left(X_{c}\right)$ & & & -0.0430 & \\
\hline $\operatorname{DTV} \operatorname{pre}\left(\mathrm{X}_{\mathrm{cp}}\right)$ & & -0.9262 & & -1.83278 \\
\hline $\operatorname{DTV} \operatorname{pre}\left(\mathrm{Z}_{\mathrm{p}}\right)$ & -0.0262 & & & \\
\hline DTVpre(PA) & & & -0.3170 & -0.63769 \\
\hline DTVpre(DLPA) & & 0.0060 & & 0.01875 \\
\hline
\end{tabular}



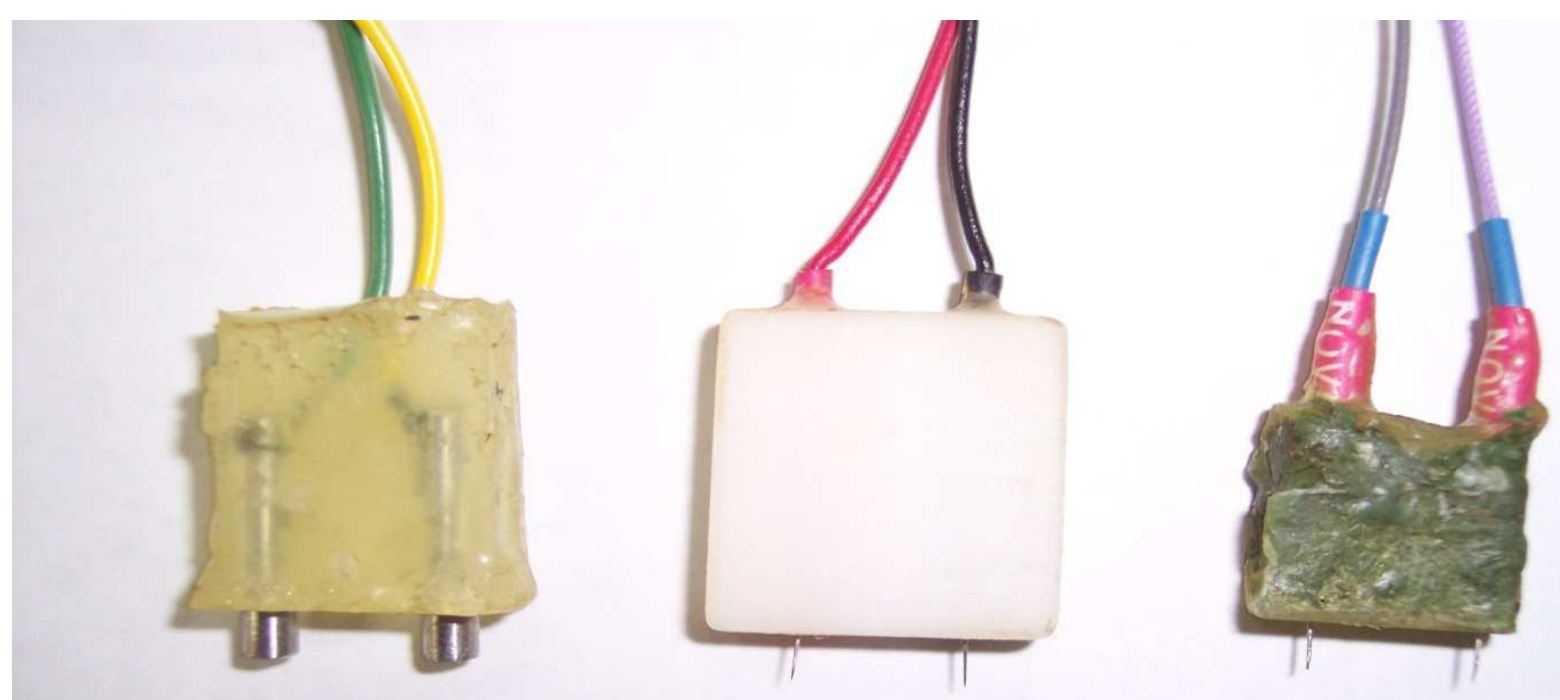

Figure 1.-Pictures of the electrodes types used in this study. Subdermal needle (Epoxy; right) and external (Rod; left) electrodes created by experimenter and Model FE24 subdermal needle electrode manufactured by The Electrode Store (FE24; center). 


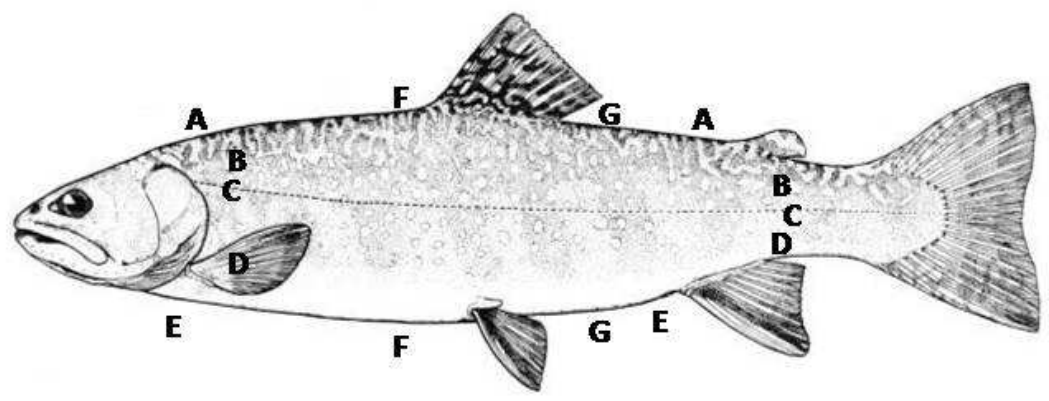

Figure 2.-Electrode locations: (A) dorsal midline (DML), (B) dorsal total length (DTL), (C) lateral line (LL), (D) ventral total length(VTL), (E) ventral midline (VML), (F) dorsal to ventral pre dorsal fin (DTVpre), and (G) dorsal to ventral post dorsal fin (DTVpost). 


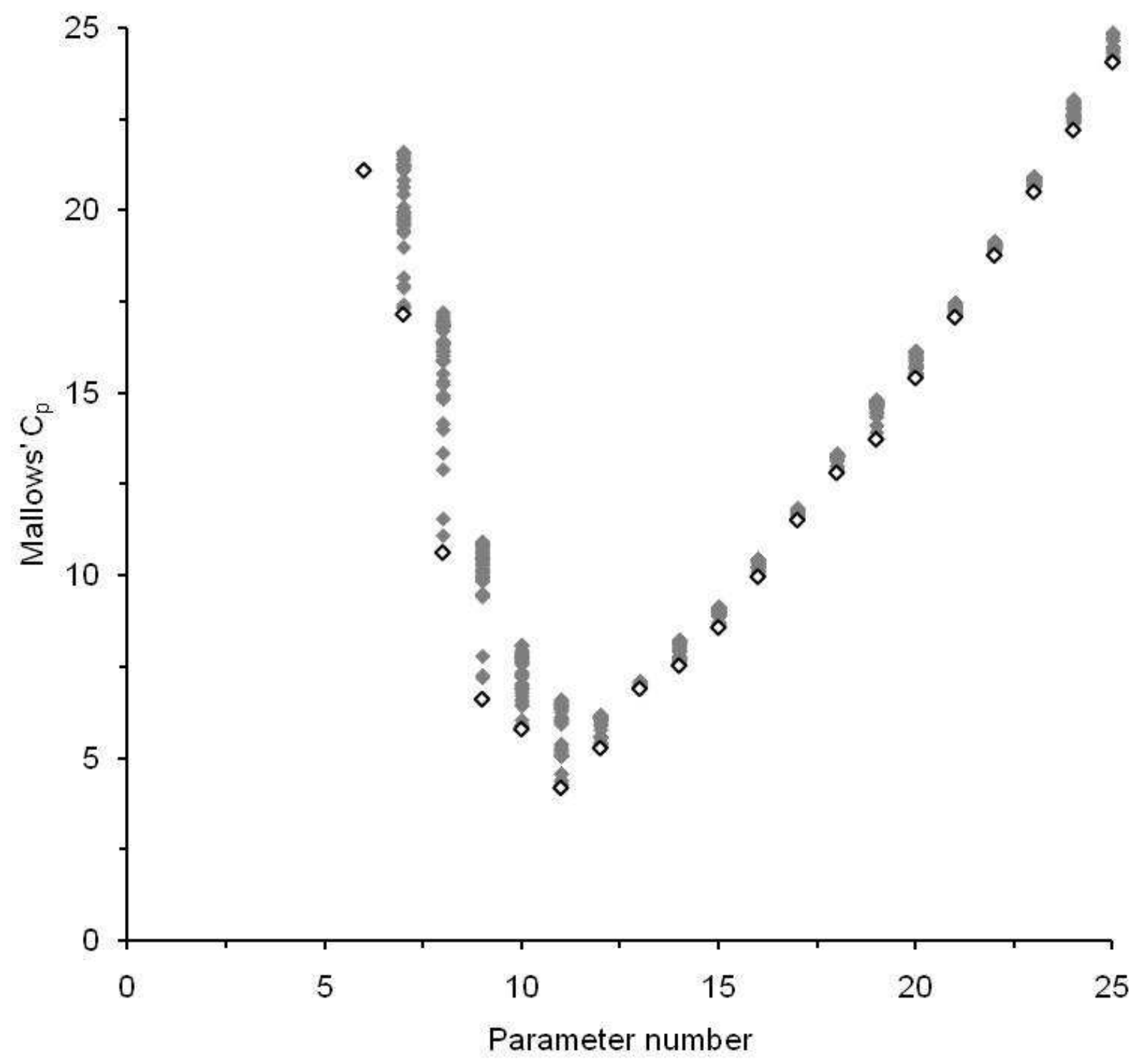

Figure 3.-Mallows' $C_{p}$ values for The Electrode Store subdermal needle electrodes using DML and DTVpre electrode locations. Mallows' $\mathrm{C}_{\mathrm{p}}$ values (grey diamonds) for all possible models are plotted for each model size (parameter number). The model with the lowest Mallows' $\mathrm{C}_{\mathrm{p}}$ value from each size model was selected for validation (black outlined diamonds). This is an example for one electrode location combination of The Electrode Store subdermal needle electrodes. This was also done for all other location and electrode combinations. 


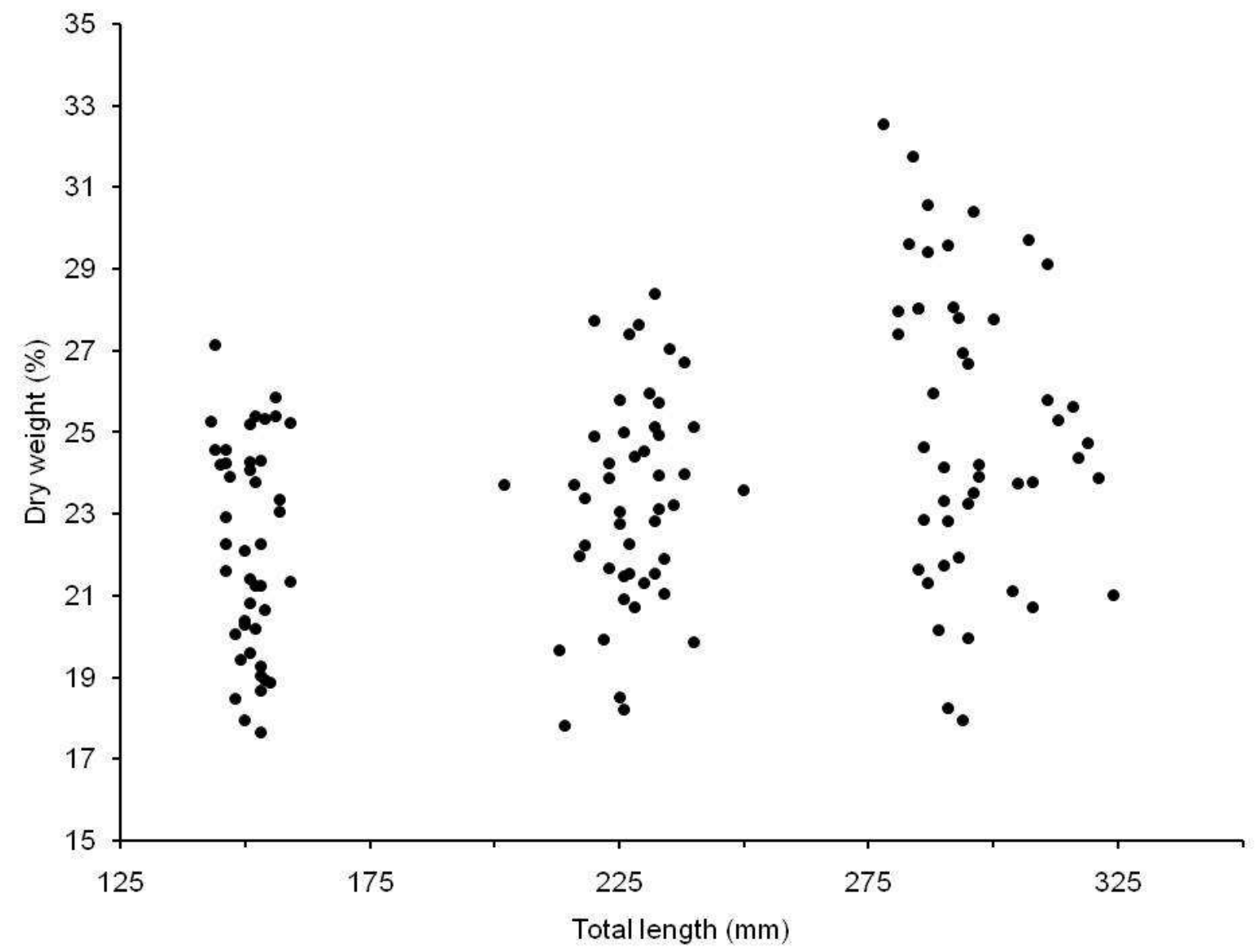

Figure 4.-Range of percent dry weights and total lengths of the brook trout $(n=139)$ used to develop the BIA models in this study. 

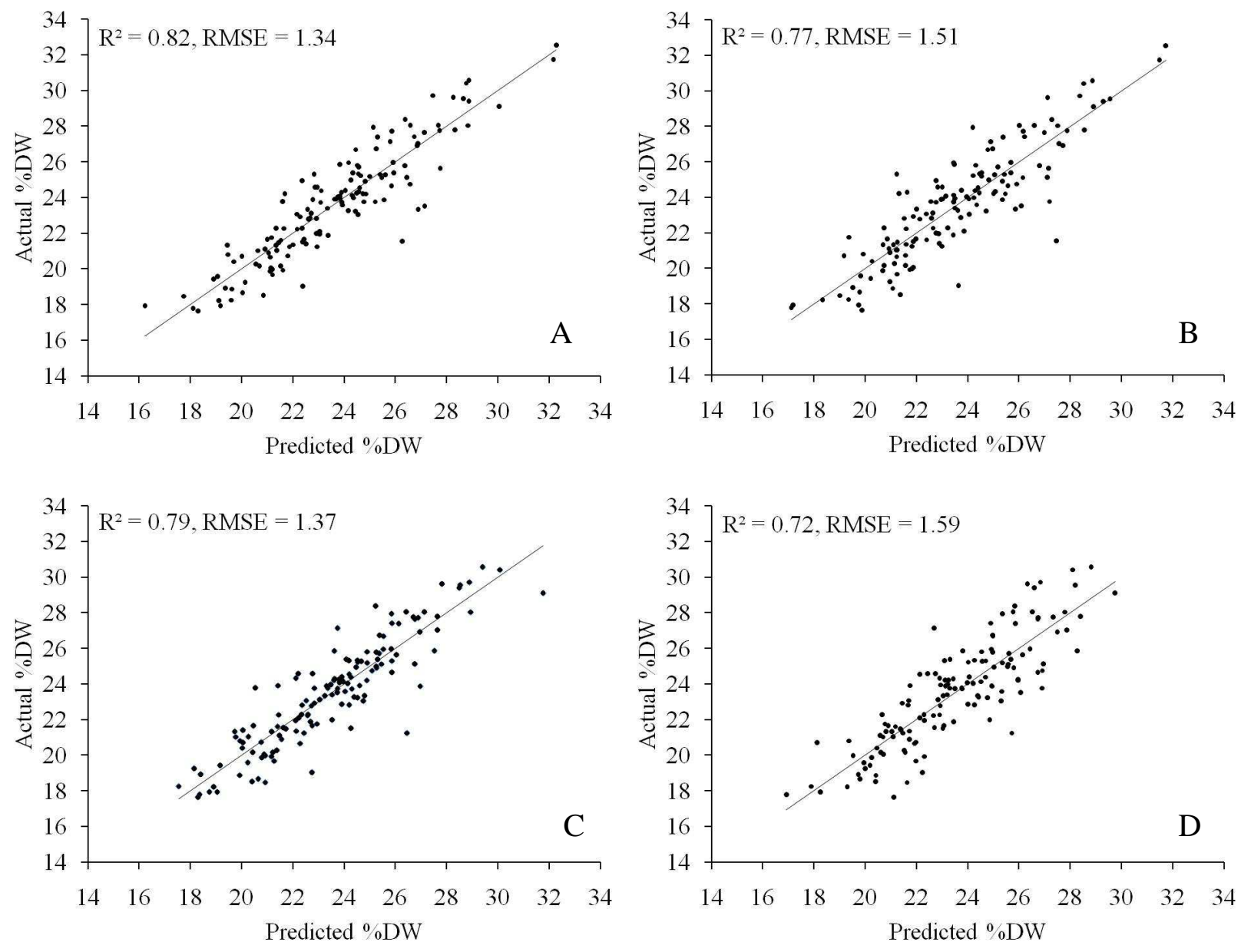

Figure 5.-Predicted compared to actual percent dry weight (\%DW) for both Model FE24 subdermal needle electrode manufactured by The Electrode Store (FE24; A = model developed using DML and DTVpre locations, B = model developed using only DTVpre location) and external $(\operatorname{Rod} ; \mathrm{C}=$ model developed using DML and DTVpre locations, $\mathrm{D}=$ model developed using only DTVpre location) electrodes created by experimenter. 


\title{
Chapter 3: Developing Bioelectrical Impedance Analysis Methods for Small Fish
}

\begin{abstract}
Bioelectrical impedance analysis (BIA) is a tool that can produce nonlethal proximate composition estimates for fish. For many fishes year class strength is largely determined by survival through the first winter. Increased fat reserves of small fish result in improved winter survival and overall cohort success. BIA methods are established for estimating proximate composition of brook trout Salvelinus fontinalis ranging 110-285 mm but none have been developed for early life stages or adults of small-bodied forms. BIA on small fish would provide detailed information about age- 0 condition allowing for better prediction of cohort success. The objective of this study was to develop BIA methods that provide reliable percent based estimates of body composition for small fish. To achieve this objective brook trout ranging 48-115 mm total length, from a wide range of body conditions, had BIA measurements taken at seven locations using both subdermal needle and external rod electrodes. BIA models predicted percent dry weight of test data sets well (best model, $\mathrm{RMSE}=1.03, \mathrm{R}^{2}=0.86$ ). Subdermal needles produced the best model but it was only slightly better than the best model developed using the external rod electrodes $\left(\mathrm{RMSE}=1.09, \mathrm{R}^{2}=0.85\right)$. Models developed using two electrode locations performed better than models developed with only one location. For small brook trout the dorsal to ventral pre dorsal fin electrode location should be used in conjunction with the dorsal total length or dorsal midline locations when taking BIA measurements to produce the best results. More work is needed to determine if these patterns hold true for fishes with different body shapes and bone structures.
\end{abstract}

\section{Introduction}

Bioelectrical impedance analysis (BIA) is a low cost nonlethal method of estimating proximate composition (Lukaski et al. 1985; Cox and Hartman 2005; Sarubbi et al. 2008). BIA has been used extensively for estimating proximate composition of both humans (Kushner and Schoeller 1986; Lukaski et al. 1985; Houtkooper et al. 1996; Sun et al. 2003) and animals (Berg et al. 1996; Hwang et al. 2005; Pitt et al. 2006; Sarubbi et al. 2008). In recent years there have also been several attempts to use BIA on fish (Bosworth and Wolters 2001; Cox and Hartman 2005; Duncan et al. 2007; Pothoven et al. 2008; Willis and Hobday 2008; Fitzhugh et al. 2010; Cox et al. 2011). Bosworth and Wolters (2001) used BIA to predict the carcass yield, fat and 
moisture content of catfish ranging 450-900 g. Cox and Hartman (2005) developed BIA models that were able to predict mass based estimates of proximate composition for brook trout Salvelinus fontinalis ranging 110-285 mm. Pothoven et al. (2008) attempted to predict energy density and percent lipids of yellow perch Perca flavescens (138-358 mm), walleye Sander vitreus (328-639 mm), and lake whitefish Coregonus clupeaformis (246-564 mm) but concluded that the models would need improvement before reliable predictions could be made. Duncan et al. (2007) was able to develop models capable of predicting mass based proximate composition estimates of cobia Rachycentron canadum. Although there has been some success developing BIA models for fish that predict mass based estimates of proximate composition, the previous research has indicated that more work with BIA is needed when attempting to predict percent based estimates of small fish.

Previous BIA with fishes has focused on fish larger than $110 \mathrm{~mm}$ indicating a need for development of BIA methods that can be used for early life stages of fish or adults of smallbodied forms. For many fishes cohort strength is often determined by age- 0 survival through winter (Hubbs and Trautman 1935; Garvey et al. 2004). Increased fat reserves improve the probability of winter survival for small fish (Thompson et al. 1991; Miranda and Hubbard 1994; Sogard and Olla 2000; Biro et al. 2004; Finstad et al. 2004). If BIA can be used on small fish to provide accurate estimates of condition, cohort success could possibly be predicted with greater reliability. Cox and Hartman (2005) developed BIA models that could predict mass based proximate composition of adult brook trout. In their study Cox and Hartman (2005) used two electrodes, each consisting of two needles spaced $10 \mathrm{~mm}$ apart that penetrated to a depth of 2 mm. Hafs and Hartman (2011) expanded upon these methods by determining that one set of measurements should be taken by placing the electrodes on the dorsal and ventral midline directly in front of the dorsal fin insertion and a second set of measurements should be taken laterally on the fish as Cox and Hartman (2005) did. This method was successful at predicting percent dry weight of adult brook trout (Hafs and Hartman 2011). Previous researchers have provided a good foundation for small fish BIA methods but new electrode designs are needed that will work with fish that are thinner and shorter than the adult brook trout used in previous studies. Furthermore, electrode locations need to be tested to determine if the findings of Hafs and Hartman (2011) are similar for smaller fish. 
Predictive models have been developed that describe relationships between proximate composition values and percent dry weight (Hartman and Margraf 2008). There are also models available for use in bioenergetics studies that can predict energy density from percent dry weight (Hartman and Brandt 1995). If BIA can be used to provide reliable estimates of percent dry weight, proximate composition and energy density estimates can in turn be calculated. Previous attempts to predict percent based estimates of proximate composition (Pothoven et al. 2008) using BIA have had limited success. Past studies have all used similar electrode locations while taking BIA measurements, although it is relatively unknown if these locations provide the best BIA measurements. Other electrode locations may allow the electrical current to flow more evenly through the body of the fish resulting in models that are able to do a better job predicting percent dry weight. The objective of this study was to develop a BIA method for age-0 brook trout producing a model that provides reliable predictions of percent dry weight.

\section{Methods}

Age-0 brook trout $(\approx 50 \mathrm{~mm}$ total length) were donated from Bowden State Fish Hatchery, Bowden, West Virginia and transported to the West Virginia University Ecophysiology Laboratory where fish were maintained in recirculating tanks $(0.5 \mathrm{~m} \times 1.5 \mathrm{~m})$ at $14 \pm 1{ }^{\circ} \mathrm{C}$. An approximate cut off for age- 1 and older brook trout is $100 \mathrm{~mm}$ (Hakala 2000; Sweka 2003) and Cox and Hartman (2005) had previously developed models for fish ranging 110-285 mm. For this study we chose to sample fish from three sizes classes $(50,75,100 \mathrm{~mm})$ that cover the normal range of sizes for age- 0 brook trout. At the time fish were received from the hatchery 45 fish were randomly selected to represent the $50 \mathrm{~mm}$ size class and were isolated from the rest of the fish in a separate recirculating tank $(0.5 \mathrm{~m} \times 1.5 \mathrm{~m})$. The remaining fish were fed ad libitum until their selected size class $(75$ and $100 \mathrm{~mm}$ ) was reached. All fish were acclimated to the recirculating system at West Virginia University Ecophysiology Laboratory for at least two weeks before any BIA was done.

In developing BIA models it is desirable to include fish at the range of possible body conditions. Because the fish were fed ad libitum until they reached their appropriate size class it was assumed that those fish were in the best possible condition at that time. In order to have fish at a wide range of body conditions while controlling for interactive effects of size and condition, fish from each size class were fasted for varying lengths of time before being selected for BIA. For the $50 \mathrm{~mm}$ size class fasting began on 19 March 2009, 10 fish were randomly sampled on 20 
March 2009, 10 more fish were sampled on 27 March 2009, and the remaining 25 fish were sampled on 3-5 April 2009. These same procedures were done for the 75- and 100-mm size classes but because it takes larger fish a longer time to use up fat reserves fasting periods were extended. For the 75-mm fish fasting began on 13 April 2009 and the last fish were sampled on 15 May 2009. Lastly, for the 100-mm fish, food was withheld starting on 27 May 2009 and the last fish were sampled on 17 September 2009.

\section{Bioelectrical impedance analysis}

Resistance and reactance were measured using a Quantum II bioelectrical body composition analyzer (RJL Systems, Clinton Township, MI). The Quantum II passes a small current $(425 \mu \mathrm{A}, 50 \mathrm{kHz})$ through the fish and measures resistance and reactance in ohms. To assess if subdermal needles or external electrodes worked best, two sets of electrodes were built and used on each fish. Subdermal needle electrodes were built using 27 gauge $(0.4 \mathrm{~mm}$ diameter $)$ needles set into epoxy $5 \mathrm{~mm}$ apart. The needles were set into the epoxy so that they could penetrate into the fish a maximum of $1.5 \mathrm{~mm}$. A second set of external rod electrodes was built by setting two stainless steel rods (1.6 mm diameter) $5 \mathrm{~mm}$ apart in epoxy (Figure 1). It is important to note that each electrode has two needles or rods with one serving as the signal and the other serving as the detector electrode (Cox and Hartman 2005). For this study signal needles/rods were always kept in an anterior position relative to the detector needles/rods.

We also assessed which location on the fish electrodes should be placed to produce the best estimates of percent dry weight. To do this we modeled our methods after a previous study done by Hafs and Hartman (2011). Seven different locations were tested (Figure 2): dorsal midline (DML), dorsal total length (DTL), lateral line (LL), ventral total length (VTL), ventral midline (VML), dorsal to ventral pre dorsal fin (DTVpre), and dorsal to ventral post dorsal fin (DTVpost).

Because ambient air temperature can influence BIA measurements (Gudivaka et al. 1996), fish were acclimated to water temperature equal to ambient room temperature (range $18.0-21.0^{\circ} \mathrm{C}$ ) for at least $12 \mathrm{~h}$ prior to all BIA measurements to minimize the influence of air temperature on measurements. After the $12 \mathrm{~h}$ acclimation period the fish was euthanized in an overdose of MS-222, the fish was blotted dry, and the wet weight (WW; g), fork length (FL; $\mathrm{mm}$ ) and total length (TL; $\mathrm{mm}$ ) was measured. The fish was then placed on a nonconductive board with the head facing to the left. Resistance and reactance was measured at all seven 
locations with both electrode types. To avoid bias due to temperature changes from handling or repeated BIA measures, the order of both the electrode type and location that the measurements were taken was chosen randomly for every fish during the study. The distance between the needles or rods of the two electrodes (detector length) was recorded for every measurement. So that detector length was equal to the distance between the signal needles or rods, $5 \mathrm{~mm}$ was added to all lateral measurements. The person holding the electrodes wore rubber gloves to insulate them from the BIA measurements. After all BIA measurements were complete for a fish it was oven-dried to a constant weight at $80^{\circ} \mathrm{C}$. Percent dry weight was calculated by dividing dry weight by wet weight and multiplying by 100 .

\section{Data analysis}

From measured resistance and reactance for each location and electrode, a suite of electrical parameters were calculated following the methods outlined by Cox and Hartman (2005) and again in Hafs and Hartman (2011). Table 1 outlines the calculations for parameters used in regression analysis: resistance $(r)$, reactance $(x)$, resistance in series $\left(R_{s}\right)$, reactance in series $\left(X_{c}\right)$, resistance in parallel $\left(R_{p}\right)$, reactance in parallel $\left(X_{c p}\right)$, capacitance $\left(C_{p f}\right)$, impedance in series $\left(Z_{\mathrm{s}}\right)$, impedance in parallel $\left(\mathrm{Z}_{\mathrm{p}}\right)$, phase angle $(\mathrm{PA})$, and standardized phase angle (DLPA). Because detector length is correlated to fish size all electrical parameters were standardized to electrical volume by dividing detector length (DL) squared with each parameter (e.g. $\mathrm{DL}^{2} / \mathrm{R}_{\mathrm{s}}$ ) following the methods of Cox and Hartman (2005). Standardized phase angle was calculated by multiplying PA and DL. TL, FL, WW, and a parameter termed Resid were also included for model building process. The Resid parameter was the residual for each fish from a length-weight equation $\left(\mathrm{WW}=0.0000072 \cdot \mathrm{TL}^{3.0056}\right.$ ).

A BIA model predicting percent dry weight was developed for each electrode location for both external and subdermal electrodes individually. BIA models were also developed for all two electrode location combinations for both external and subdermal electrodes individually. Models were developed by ordinary least squares regression using the function ols (Harrell 2009), part of the package rms in program $R$ ( $R$ Development Core Team 2009). Fish from all three size classes ( $\mathrm{n}=45$ for each size class) were included for model development. Mallows' $\mathrm{C}_{\mathrm{p}}$ (Mallows 1973) was calculated for every possible model using the function leaps (Lumley 2009) which is part of the package leaps in program $R$ ( $R$ Development Core Team 2009). Mallows' $C_{p}$ values were then used to select subsets of models for validation from every electrode location 
combination and possible model size. BIA models were validated using the function validate (Harrell 2009) part of the package rms in program R (R Development Core Team 2009). The validate function uses bootstrapping methods developed by Efron (1983) to randomly separate the original data into training data sets and test data sets. The training data sets are used to develop the models and the test data sets are used to validate the model. R-square and root mean square error (RMSE) values are then calculated based on how well the test data sets fit the models. The validate function was set so 10,000 permutations were run to develop each model and estimate the R-square and RMSE values. Akaike's information theoretical criterion (Akaike 1973) corrected for sample size (AICc; McQuarrie and Tsai 1998) was used to determine the best model.

After model development and validation were complete, a sensitivity analysis was done to determine which of the measured variables were most likely to cause errors in the BIA models. A sensitivity analysis was done on the best BIA model from each electrode type. Thirty fish were randomly selected from each electrode type and values for each measured variable present in the model were altered individually by $\pm 10 \%$ similar to the methods of Hartman et al. (2011). Subsequent changes in predicted percent dry weight were then compared to original predictions from unaltered BIA models and percent change resulting from the $\pm 10 \%$ alteration was calculated. Variables that resulted in a percent change greater than $10 \%$ were considered to be sensitive (Bartell et al. 1986).

\section{Results}

The brook trout from this study used to develop BIA models ranged 48-115 mm TL and 0.63-10.61 $\mathrm{g} \mathrm{WW}$. The leanest fish had a percent dry weight of 15.09 while the percent dry weight of the fattest fish was 26.08 (Figure 3). Models including BIA parameters were better at predicting percent dry weight than the best model developed using only TL, FL, WW, and Resid $\left(\mathrm{AICc}=99.18, \mathrm{RMSE}=1.41, \mathrm{R}^{2}=0.74\right.$; Figure 4$)$. The best six models all were developed using two electrode locations and the DTVpre location was one of the two locations in each model (Table 2). When BIA models were developed using subdermal needles and measurements from two locations the DTL and DTVpre locations produced the best model (AICc $=33.67$, RMSE $=1.03, \mathrm{R}^{2}=0.86$; Figure 5). The DML and DTVpre locations in combination also produced a reliable model $\left(\mathrm{AICc}=40.20, \mathrm{RMSE}=1.06, \mathrm{R}^{2}=0.85\right)$. The two best models developed using two electrode locations and the external rods were developed using the DTL and 
DTVpre electrode locations $\left(\mathrm{AICc}=39.63, \mathrm{RMSE}=1.09, \mathrm{R}^{2}=0.85\right)$, and the DML and DTVpre electrode locations $\left(\mathrm{AICc}=44.40, \mathrm{RMSE}=1.07, \mathrm{R}^{2}=0.85\right)$. When only one location was used with subdermal needles the DTVpre location produced the best model (AICc $=57.42$, $\mathrm{RMSE}=1.17, \mathrm{R}^{2}=0.82$ ). With the external rods the DTVpost location resulted in the best model $\left(\mathrm{AICc}=61.73, \mathrm{RMSE}=1.19, \mathrm{R}^{2}=0.82\right)$. The best model developed using subdermal needle electrodes preformed only slightly better than the best model developed using external rod electrodes (Table 2). Coefficients for the parameters of models with the lowest AICc estimates are located in Table 3.

Sensitivity analysis results indicated that none of the measured BIA variables should be considered sensitive (Figure 6). TL was the most sensitive variable and DTLr came in a close second in both of the models that were tested. However, when altered by $\pm 10 \%$ neither of these variables resulted in changes of $\pm 10 \%$ from original predicted percent dry weight estimates.

\section{Discussion}

The models provided in this study demonstrate that it is possible to predict percent dry weight of the early life stages of fish with precision and accuracy using BIA. Previous attempts to predict percent based estimates (Pothoven et al. 2008; Hafs and Hartman 2011; Hartman et al. 2011) have had varying success. Pothoven et al. (2008) used BIA models to predict percent lipids of lake whitefish that were captured using gill nets. Their best BIA model had a $\mathrm{R}^{2}=0.53$. Hafs and Hartman (2011) were successful at predicting percent dry weight of brook trout in a laboratory setting $\left(\mathrm{R}^{2}=0.82\right)$ and Hartman et al. (2011) demonstrated that BIA could produce reliable estimates $\left(\mathrm{R}^{2}=0.86\right)$ of percent dry weight of bluefish Pomatomus saltatrix ranging 193-875 mm TL. Gudivaka et al. (1996) reported that impedance measurements at all frequencies were significantly influenced by changes in skin temperature. Furthermore, Cox et al. (2011) provided evidence that suggests temperature is a significant source of error in BIA models. Based on previous research with BIA and temperature effects it is likely that the success of this study and that of Hafs and Hartman (2011) is probably attributed to the fact the temperature was held constant, minimizing an important source of error (Gudivaka et al. 1996; Cox et al. 2011).

Two other factors that likely contributed to the strong predictive power of BIA models developed in this study is that fish were fasted, achieving a wide range of body conditions for model development and that several locations on fish were tested to determine which provided 
the best estimates. Hafs and Hartman (2011) used the same strategy and determined that when DML and DTV were used in place of locations used by previous researchers (DLT VTL) models explained $13 \%$ more of the variation in percent dry weight. By determining where on the fish the electrodes should be placed we also were able to produce models that explained a larger portion of the variation in percent dry weight than if we had used the locations previous researchers had used. The results from this study suggest that the DTVpre location should be used in conjunction with the DTL or DML locations when taking BIA measurement on small brook trout. The two best location combinations were the DTL DTVpre and the DML DTVpre when the models were developed using two electrode locations and the subdermal needle electrodes. These were the same two location combinations that developed the two best models when using external rod electrodes increasing our confidence that these locations are superior. RMSE was reduced by an average of $11.6 \%$ when the DTL DTV locations were used instead of those used by previous researchers (DTL VTL). Based on the results of this study and those of Hafs and Hartman (2011) it is clear that BIA models can be substantially improved by determining which locations should be used for model development. Future researchers using BIA on fishes other than brook trout should consider using similar methods to determine which locations produce the best results.

Similar to the results of Hafs and Hartman (2011) we demonstrated that is possible to use external rod electrodes while taking BIA measurements on fish. Even though the subdermal needles only penetrated the age-0 fish $1.5 \mathrm{~mm}$, external rod electrodes are intuitively less invasive. Using subdermal needle electrodes and taking measurements at two locations as we suggest results in eight small puncture wounds on the fish. Furthermore, in order to make the subdermal needles penetrate the skin, more pressure was applied in comparison to when external rods were just placed on the surface of the fish. Age-0 fish would have to allocate a portion of their energy intake to heal the eight small puncture wounds and any injuries that would have occurred due to the added pressure applied when using subdermal needle electrodes. Because larger age-0 fish with higher energy reserves are more like to survive winter (Miranda and Hubbard 1994) age-0 fish that are forced to use energy to heal from BIA wounds could be more susceptible during stressful periods. Cox and Hartman (2005) determined that BIA had minimal influence on both external appearance and growth of brook trout greater than $110 \mathrm{~mm}$. In this study we did not assess the influence that BIA had on small fish and it is possible decreased growth or some mortality could occur on the smaller more fragile age- 0 fish. Fortunately, both 
subdermal needles and external rods produced models that performed similarly. Therefore, we suggest that, until more research is done that assesses the effects of BIA on small fish health, external rod electrodes are used.

In this study we only used age-0 brook trout to develop and validate our models. In our opinion the major species related factors that would affect BIA models are scale thickness, fat storage location, body morphology, and bone structure. From our experience, as scale thickness increases external rod electrodes have a difficult time connecting to the fish. Because age- 0 salmonids such as brown trout Salmo trutta and rainbow trout Oncorhynchus mykiss have small cycloid scales this should have minimal influence on BIA readings. Additionally, in general salmonids store fat reserves in the muscle (Ackman 1989) and differences in bone structure and body shape are minimal. Therefore, assuming future researchers used our methods, it is likely our models would produce similar results when used on other age- 0 salmonids such as brown trout, rainbow trout, and Pacific salmon (genus Oncorhynchus). More research is needed to determine if the models presented in this manuscript can be applied to similar species.

Results from the sensitivity analysis provides evidence to suggest that measurement errors of $\pm 10 \%$ in BIA variables such as detector length, resistance, and reactance have limited influence on model predictions of percent dry weight for small age-0 brook trout. These results are similar to those of the sensitivity analysis done by Hartman et al. (2011) on their BIA models that predict the percent dry weight of bluefish. The most sensitive variable in our models was TL. This is encouraging because TL can be measured easily and it is unlikely errors would exceed $\pm 10 \%$. The model we developed that includes only length and weight based measurements (traditional condition analysis) accounts for $74 \%$ of the variability in percent dry weight. The addition of BIA variables into our models helped to explain an additional $12 \%$ of the variation in percent dry weight. One possible explanation for the low sensitivity levels reported for BIA variables is that length and weight based measurements are explaining the majority of the variation in percent dry weight while BIA variables are essentially fine tuning the models achieving predictive power that was not previously possible.

By demonstrating that it is possible to the predict percent dry weight of small fish using BIA future researchers can use the methods outlined in this study as a framework for the development of BIA models for small fish. These methods should allow future researchers to better assess seasonal changes in condition for small fish as well as provide energy density 
estimates of prey species for use in bioenergetics models. Although the methods used in this study provide a good starting point for BIA on small fish the effects of temperature still need to be considered. The models provided by this study were developed in a laboratory setting where temperature was controlled $\left(18-21^{\circ} \mathrm{C}\right)$. Because temperature has large influence on BIA (Gudivaka et al. 1996; Cox et al. 2011; Hartman et al. 2011) care should be taken when using these methods in conditions where the fish's body temperature is outside the range of $18-21^{\circ} \mathrm{C}$. More work is needed providing temperature corrections to the models provided in this study.

\section{Acknowledgements}

We would like to thank John Sweka, Patricia Mazik, Joseph Margraf, and Todd Petty for technical guidance, John Howell, Geoff Weichert, Amy Fitzwater, Lindsey Richie, Ed McGinley, and Jon Niles for help with data collection and entry. We also thank Phil Turk and George Merovich for statistical comments as well as Frank Williams from Bowden State Fish Hatchery for providing the brook trout and fish food used in this study. Lastly, we thank WVDNR and the USFS for funding this project. All methods in this study were conducted in compliance with Animal Care and Use Committee protocol number 08-0602.

\section{References}

Ackman, R. G. 1989. Nutritional composition of fats in seafoods. Progress in Food and Nutrition Science 13:161-241.

Akaike, H. 1973. Information theory and an extension of the maximum likelihood principle. Pages 267-281. in Petrov, B. N. and F. Csaki. Second international symposium on information theory. Akademiai Kiado. Budapest, Hungary.

Bartell, S. M., J. E. Breck, R. H. Gardner, and A. L. Brenkert. 1986. Individual parameter perturbation and error analysis of fish bioenergetics models. Canadian Journal of Fisheries and Aquatic Sciences 43:160-168.

Berg, E. P., M. K. Neary, J. C. Forrest, D. L. Thomas, and R. G. Kaufmann. 1996. Assessment of lamb carcass composition from live animal measurement of bioelectrical impedance or ultrasonic tissue depths. Journal of Animal Science 74:2672-2678.

Biro, P. A., A. E. Morton, J. R. Post, and E. A. Parkinson. 2004. Over-winter lipid depletion and mortality of age-0 rainbow trout (Oncorhynchus mykiss). Canadian Journal of Fisheries and Aquatic Sciences 61:1513-1519. 
Bosworth, B. G., and W. R. Wolters. 2001. Evaluation of bioelectric impedance to predict carcass yield, carcass composition, and fillet composition in farm-raised catfish. Journal of the World Aquaculture Society 32:72-78.

Cox, M. K., and K. J. Hartman. 2005. Non-lethal estimation of proximate composition in fish. Canadian Journal on Fisheries and Aquatic Sciences 62:269-275.

Cox, M. K., R. Heintz, and K. Hartman. 2011. Measurements of resistance and reactance in fish with the use of bioelectrical impedance analysis: sources of error. Fisheries Bulletin 109:3447.

Duncan, M., S. R. Craig, A. N. Lunger, D. D. Kuhn, G. Salze, and E. McLean. 2007. Bioimpedance assessment of body composition in cobia Rachycentron canadum (L. 1766). Aquaculture 271:432-438.

Efron, B. 1983. Estimating the error rate of a prediction rule: Improvement on cross-validation. Journal of the American Statistical Association 78:316-331.

Finstad, A. G., O. Ugedal, T. Forseth, and T. F. Naesje. 2004. Energy-related juvenile winter mortality in a northern population of Atlantic salmon (Salmo salar). Canadian Journal of Fisheries and Aquatic Sciences 61:2358-2368.

Fitzhugh, G. R., M. J. Wuenschel, and R. S. McBride. 2010. Evaluation of bioelectrical impedance analysis (BIA) to measure condition and energy allocated to reproduction in marine fishes. Journal of Physics: Conference Series 224:1-4.

Garvey, J. E., K. G. Ostrand, and D. H. Wahl. 2004. Energetics, predation, and ration affect sizedependent growth and mortality of fish during winter. Ecology 85:2860-2871.

Gudivaka, R., D. Schoeller, and R. F. Kushner. 1996. Effect of skin temperature on multifrequency bioelectrical impedance analysis. Journal of Applied Physiology 81:838-845.

Hafs, A. W., and K. J. Hartman. 2011. Influence of electrode type and location upon bioelectrical impedance analysis measurements of brook trout. Transactions of the American Fisheries Society 140:1290-1297.

Hakala, J. P. 2000. Factors influencing brook trout (Salvelinus fontinalis) abundance in forested headwater streams with emphasis on fine sediment. Master's thesis. West Virginia University, Morgantown.

Harrell, F. E., Jr. 2009. rms: Regression Modeling Strategies. R package version 2.1-0. http://CRAN.R-project.org/package=rms. 
Hartman, K. J., B. A. Phelan, and J. E. Rosendale. 2011. Temperature effects on bioelectrical impedance analysis (BIA) used to estimate dry weight as a condition proxy in coastal bluefish. Marine and Coastal Fisheries: Dynamics, Management, and Ecosystem Science 3:307-316.

Hartman, K. J., and F. J. Margraf. 2008. Common relationships among proximate composition components in fishes. Journal of Fish Biology 73:2352-2360.

Hartman, K. J., and S. B. Brandt. 1995. Estimating energy density of fish. Transactions of the American Fisheries Society 124:347-355.

Houtkooper, L. B., T. G. Lohman, S. B. Going, and W. H. Howell. 1996. Why bioelectrical impedance analysis should be used for estimating adiposity. The American Journal of Clinical Nutrition 64:436S-438S.

Hubbs, C. L., and M. B. Trautman. 1935. The need for investigating fish conditions in winter. Transactions of the American Fisheries Society 65:51-56.

Hwang, Y. T., S. Larivière, and F. Messier. 2005. Evaluating body condition of striped skunks using non-invasive morphometric indices and bioelectrical impedance analysis. The Wildlife Society Bulletin 33:195-203.

Kushner, R. F., and D. A. Schoeller 1986. Estimation of total body water by bioelectrical impedance analysis. The American Journal of Clinical Nutrition 44:417-424.

Lukaski, H. C., P. E. Johnson, W. W. Bolonchuk, and G. I. Lykken. 1985. Assessment of fat-free mass using bioelectrical impedance measurements of the human body. The American Journal of Clinical Nutrition 41:810-817.

Lumley, T. using Fortran code by A. Miller. 2009. leaps: regression subset selection. R package version 2.9. http://CRAN.R-project.org/package=leaps.

Mallows, C. L. 1973. Some comments on $C_{p}$. Technometrics 15:661-675.

McQuarrie, A. D. and C. L. Tsai. 1998. Regression and time series model selection. World Scientific Publishing. Singapore.

Miranda, L. E., and W. D. Hubbard. 1994. Length-dependent winter survival and lipid composition of age-0 largemouth bass in Bay Springs Reservoir, Mississippi. Transactions of the American Fisheries Society 123:80-87.

Pitt, J. A., S. Lariviere, and F. Messier. 2006. Condition indices and bioelectrical impedance analysis to predict body condition of small carnivores. Journal of Mammalogy 87:717-722. 
Pothoven, S. A., S. A. Ludsin, T. O. Hook, D. L. Fanslow, D. M. Mason, P. D. Collingsworth, and J. J. Van Tassell. 2008. Reliability of bioelectrical impedance analysis for estimating whole-fish energy density and percent lipids. Transactions of the American Fisheries Society 137:1519-1529.

R Development Core Team 2009. R: A language and environment for statistical computing. R Foundation for Statistical Computing, Vienna, Austria. ISBN 3-900051-07-0, URL http://www.R-project.org.

Sarubbi, F., R. Baculo, and D. Balzarano. 2008. Bioelectrical impedance analysis for the prediction of fat-free mass in buffalo calf. Animal 2:1340-1345.

Sogard, S. M., and B. L. Olla. 2000. Endurance of simulated winter conditions by age-0 walleye pollock: effects of body size, water temperature and energy stores. Journal of Fish Biology $56: 1-21$.

Sun, S. S., W. C. Chumlea, S. B. Heymsfield, H. C. Lukaski, D. Schoeller, K. Friedl, R. J. Kuczmarski, K. M. Flegal, C. L. Johnson, and V. S. Hubbard. 2003. Development of bioelectrical impedance analysis prediction equations for body composition with the use of a multicomponent model for use in epidemiologic surveys. The American Journal of Clinical Nutrition 77:331-340.

Sweka, J. A. 2003. Aquatic-terrestrial linkages in Appalachian streams: influence of riparian inputs on stream habitat, brook trout populations, and trophic dynamics. Doctoral dissertation. West Virginia University, Morgantown.

Thompson, J. M., E. P. Bergersen, C. A. Carlson, and L. R. Kaeding. 1991. Role of size, condition, and lipid content in the overwinter survival of age-0 Colorado Squawfish. Transactions of the American Fisheries Society 120:346-353.

Willis, J., and A. J. Hobday. 2008. Application of bioelectrical impedance analysis as a method for estimating composition and metabolic condition of southern bluefin tuna (Thunnus maccoyii) during conventional tagging. Fisheries Research 93:64-71. 
Table 1.-Electrical parameters (converted to electrical volume when $\mathrm{DL}^{2}$ is included in equation) used to develop BIA models (from Hafs and Hartman 2011).

\begin{tabular}{lcll}
\hline Parameter & Symbol & Units & Calculation \\
\hline Resistance & $\mathrm{r}$ & ohms & measured by Quantum II \\
Reactance & $\mathrm{x}$ & ohms & measured by Quantum II \\
Resistance in series & $\mathrm{R}_{\mathrm{s}}$ & ohms & $\mathrm{DL}^{2} / \mathrm{r}$ \\
Reactance in series & $\mathrm{X}_{\mathrm{c}}$ & ohms & $\mathrm{DL}^{2} / \mathrm{x}$ \\
Resistance in parallel & $\mathrm{R}_{\mathrm{p}}$ & ohms & $\mathrm{DL}^{2} /\left(\mathrm{r}+\left(\mathrm{x}^{2} / \mathrm{r}\right)\right)$ \\
Reactance in parallel & $\mathrm{X}_{\mathrm{cp}}$ & ohms & $\mathrm{DL}^{2} /\left(\mathrm{x}+\left(\mathrm{r}^{2} / \mathrm{x}\right)\right)$ \\
Capacitance & $\mathrm{C}_{\mathrm{pf}}$ & picoFarads & $\mathrm{DL}^{2} /\left((1 /(2 \cdot \pi \cdot 50000 \cdot \mathrm{r})) \cdot\left(1 \cdot 10^{12}\right)\right)$ \\
Impedance in series & $\mathrm{Z}_{\mathrm{s}}$ & ohms & $\mathrm{DL}^{2} /\left(\mathrm{r}^{2}+\mathrm{x}^{2}\right)^{0.5}$ \\
Impedance in parallel & $\mathrm{Z}_{\mathrm{p}}$ & ohms & $\mathrm{DL}^{2} /\left(\mathrm{r} \cdot \mathrm{x} /\left(\mathrm{r}^{2}+\mathrm{x}^{2}\right)^{0.5}\right)$ \\
Phase angle & $\mathrm{PA}$ & degrees & atan $(\mathrm{x} / \mathrm{r})^{*} 180 / \pi$ \\
Standardized phase angle & $\mathrm{DLPA}$ & degrees & $\mathrm{DL} \cdot\left(\operatorname{atan}(\mathrm{x} / \mathrm{r})^{*} 180 / \pi\right)$ \\
\hline
\end{tabular}

$\mathrm{DL}=$ detector length 
Table 2.- $\mathrm{R}^{2}$, RMSE, and AICc estimates for the six best models developed using two locations and the four best models using only one location.

\begin{tabular}{llccc}
\hline Location(s) & Needles/Rods & $\mathrm{R}^{2}$ & RMSE & AICc \\
\hline DTL DTVpre & Needles & 0.86 & 1.03 & 33.67 \\
DTL DTVpre & Rods & 0.85 & 1.09 & 39.63 \\
DML DTVpre & Needles & 0.85 & 1.06 & 40.20 \\
DML DTVpre & Rods & 0.85 & 1.07 & 44.40 \\
LL DTVpre & Needles & 0.84 & 1.12 & 47.43 \\
VML DTVpre & Rods & 0.84 & 1.11 & 48.40 \\
DTVpre & Needles & 0.82 & 1.17 & 57.42 \\
DTVpost & Rods & 0.82 & 1.19 & 61.73 \\
DML & Rods & 0.82 & 1.17 & 61.75 \\
DTVpre & Rods & 0.81 & 1.20 & 63.15 \\
\hline
\end{tabular}


Table 3.-Regression models and coefficients for predicting percent dry weight of brook ranging 48-115 $\mathrm{mm}$ TL. The Resid parameter was the residual for each fish from a length-weight equation $\left(\mathrm{WW}=0.0000072 \cdot \mathrm{TL}^{3.0056}\right)$.

\begin{tabular}{|c|c|c|c|c|c|c|c|}
\hline \multirow[b]{3}{*}{ Parameter } & \multicolumn{7}{|c|}{ Model } \\
\hline & \multicolumn{3}{|c|}{ Subdermal needles } & \multicolumn{4}{|c|}{ External rods } \\
\hline & $\begin{array}{c}\text { DTL } \\
\text { DTVpre }\end{array}$ & $\begin{array}{c}\text { DML } \\
\text { DTVpre }\end{array}$ & DTVpre & $\begin{array}{c}\text { DTL } \\
\text { DTVpre }\end{array}$ & $\begin{array}{c}\text { DML } \\
\text { DTVpre }\end{array}$ & DTVpost & DML \\
\hline Intercept & 10.3260 & -3.6549 & 11.1439 & 26.1464 & -2.7827 & 14.4224 & 2.6748 \\
\hline $\mathrm{FL}$ & & & 0.0712 & & & & \\
\hline WW & & & & & & 0.3497 & \\
\hline DTLr & & & & -0.0059 & & & \\
\hline DTLx & -0.0219 & & & & & & \\
\hline DTLRs & -45.0939 & & & & & & \\
\hline DTLRp & 46.9168 & & & 72.3372 & & & \\
\hline DTLCpf & & & & 15.6299 & & & \\
\hline DTLZs & & & & -70.9148 & & & \\
\hline DTLPA & 0.8428 & & & & & & \\
\hline DTLDLPa & 0.0089 & & & & & & \\
\hline DMLr & & 0.0098 & & & 0.0095 & & 0.0077 \\
\hline DMLx & & -0.0473 & & & -0.0440 & & -0.0548 \\
\hline DMLXc & & & & & 69.7732 & & 72.4768 \\
\hline DMLCpf & & -30.7870 & & & & & 60.9849 \\
\hline DMLZs & & & & & 16.1118 & & 10.7562 \\
\hline DMLZp & & 0.6673 & & & -71.1006 & & -73.4177 \\
\hline DMLPA & & 1.5783 & & & 1.3723 & & 1.5352 \\
\hline DTVr & 0.0074 & 0.0080 & 0.0067 & & 0.0034 & & \\
\hline DTVx & -0.0505 & -0.0629 & -0.0555 & & -0.0235 & & \\
\hline DTVRs & -246.9491 & & & -9.8058 & & & \\
\hline DTVRp & 230.2351 & & & & & & \\
\hline DTVXcp & & -163.8167 & -139.2466 & & -70.5640 & & \\
\hline DTVCpf & & & & 300.4741 & & & \\
\hline DTVDLPa & 0.0825 & 0.1142 & 0.1019 & & 0.0567 & & \\
\hline DTVpox & & & & & & -0.0190 & \\
\hline DTVpoRs & & & & & & -52.7341 & \\
\hline DTVpoXc & & & & & & 9.1754 & \\
\hline DTVpoDLPa & & & & & & 0.0663 & \\
\hline Resid & 0.8160 & 0.6360 & 1.4155 & 1.1298 & 0.9981 & 1.3120 & 1.4773 \\
\hline
\end{tabular}




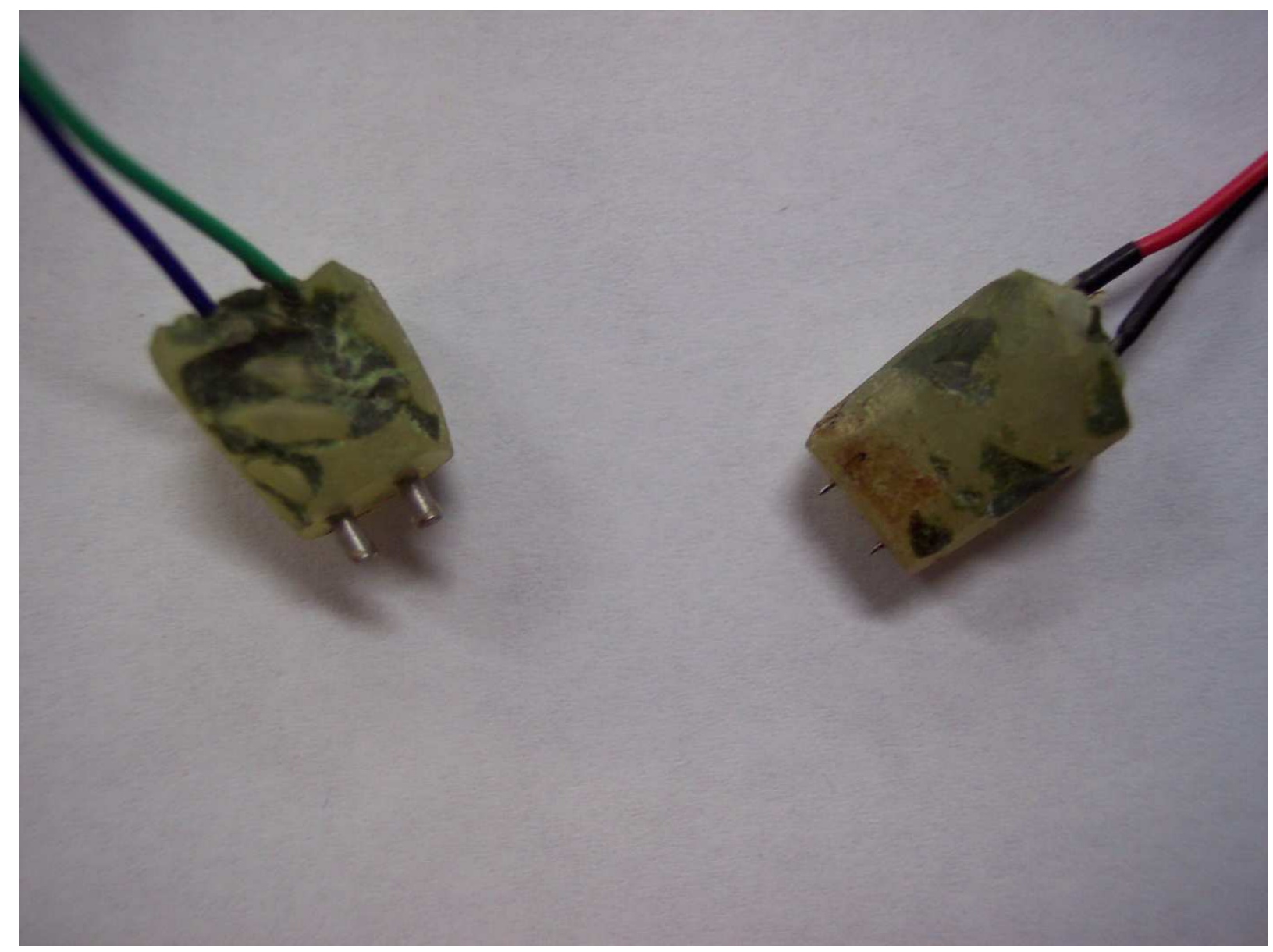

Figure 1.-Picture of external rods (left) and subdermal needle (right) electrodes used in this study. 


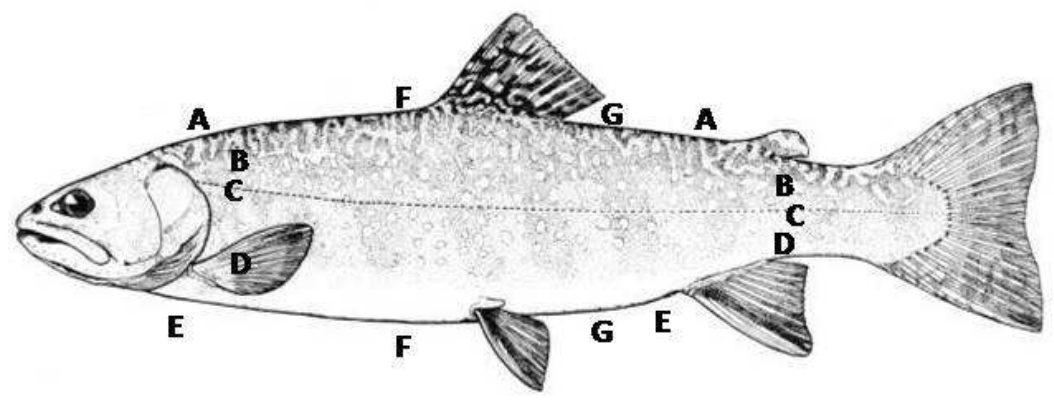

Figure 2.-Electrode locations: (A) dorsal midline (DML), (B) dorsal total length (DTL), (C) lateral line (LL), (D) ventral total length (VTL), (E) ventral midline (VML), (F) dorsal to ventral pre dorsal fin (DTVpre), and (G) dorsal to ventral post dorsal fin (DTVpost). 


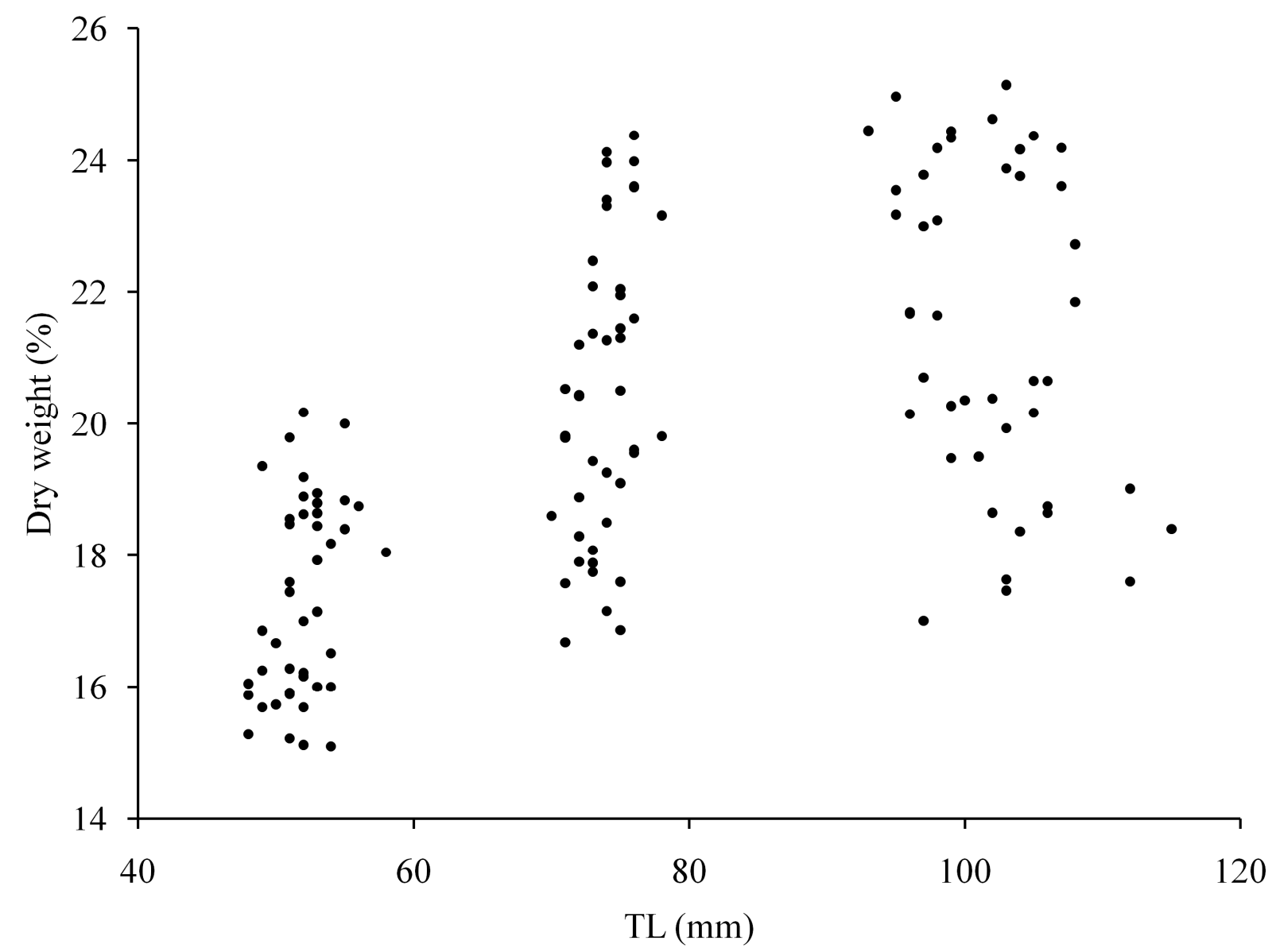

Figure 3.-Range of percent dry weights and total lengths of the brook trout $(n=135)$ used to develop the BIA models in this study. 


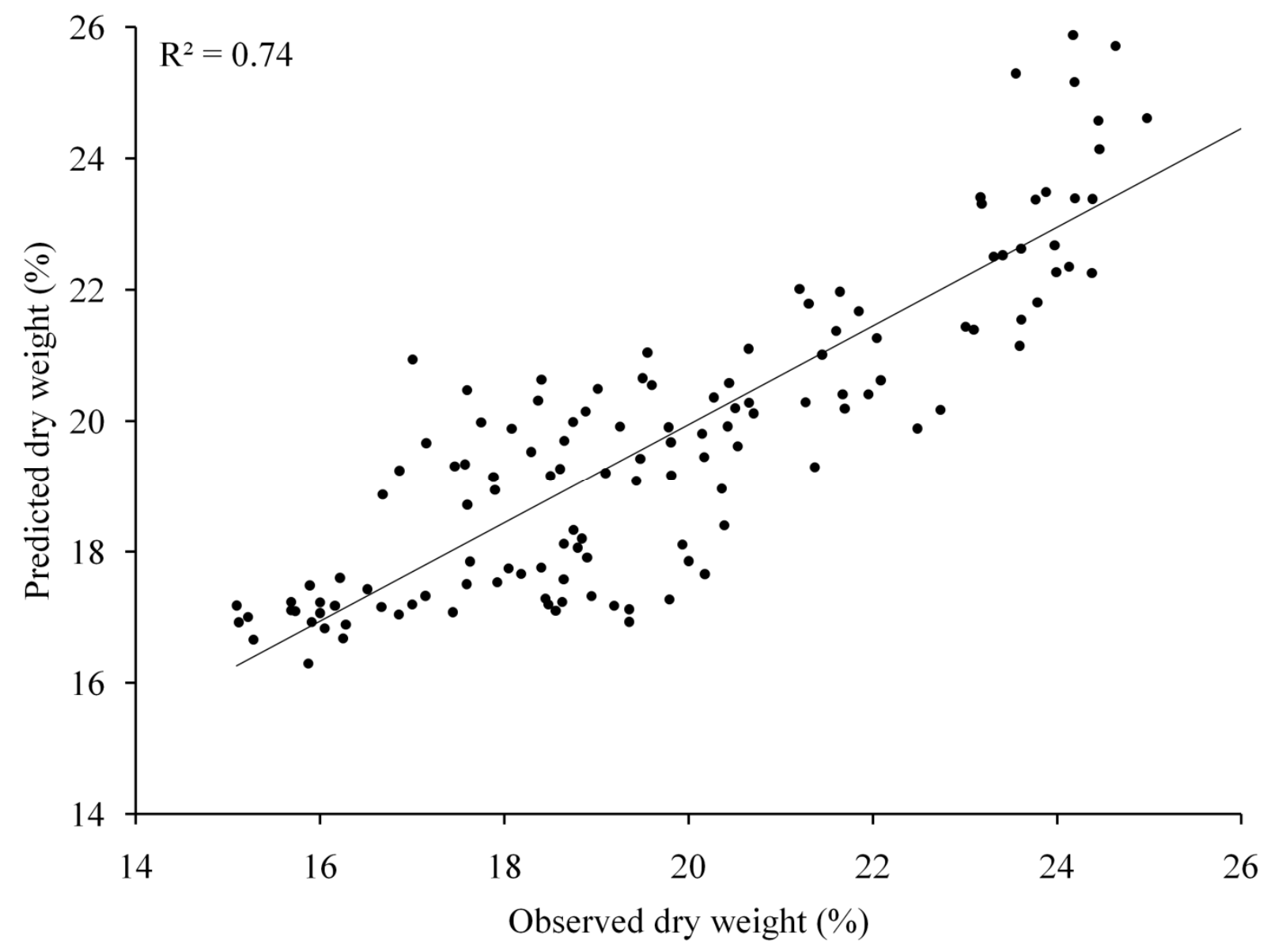

Figure 4.-Predicted percent dry weights resulting from the model, percent dry weight $=$ $8.4378+0.1902$ (FL) $-0.6570(\mathrm{WW})+2.6017$ (Resid), plotted against the observed percent dry weights. The model resulted in an $\mathrm{R}^{2}=0.74$ and a $\mathrm{RMSE}=1.40$. 


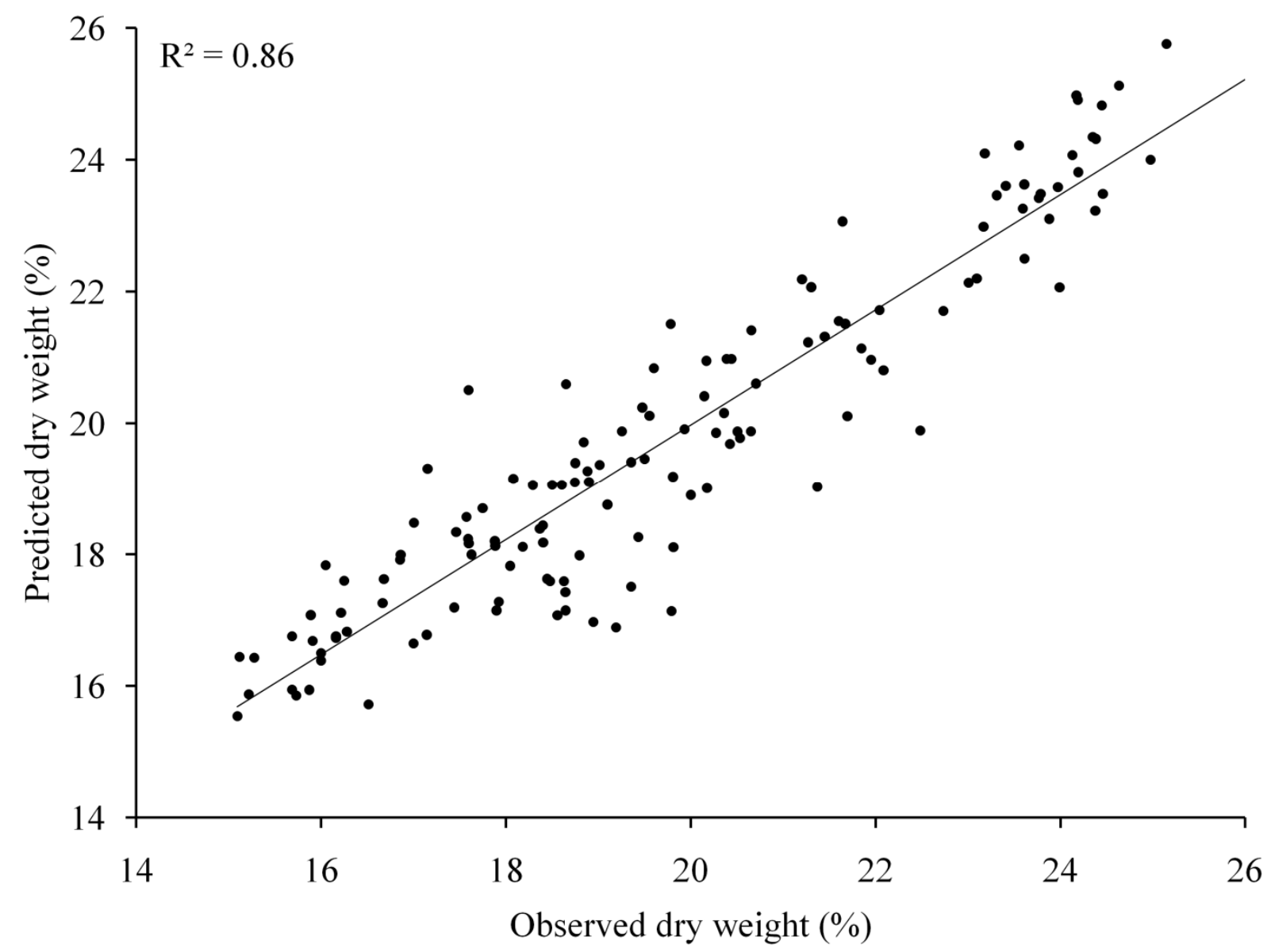

Figure 5.-Predicted percent dry weights resulting from the model, percent dry weight $=$ 10.3260 - 0.0219(DTLx) -45.0939 (DTLRs $)+46.9168($ DTLRp $)+0.8428($ DTLPA $)+$ 0.0089(DTLDLPa) - 0.0505(DTVx) - 246.9491(DTVRs) + 0.0074(DTVr) + 230.2351(DTVRp) $+0.0825(\mathrm{DTVDLPa})+0.8160$ (Resid), plotted against the observed percent dry weights. This model was developed using subdermal needle electrodes and resulted in an $\mathrm{R}^{2}=0.86$ and a RMSE $=1.03$. 

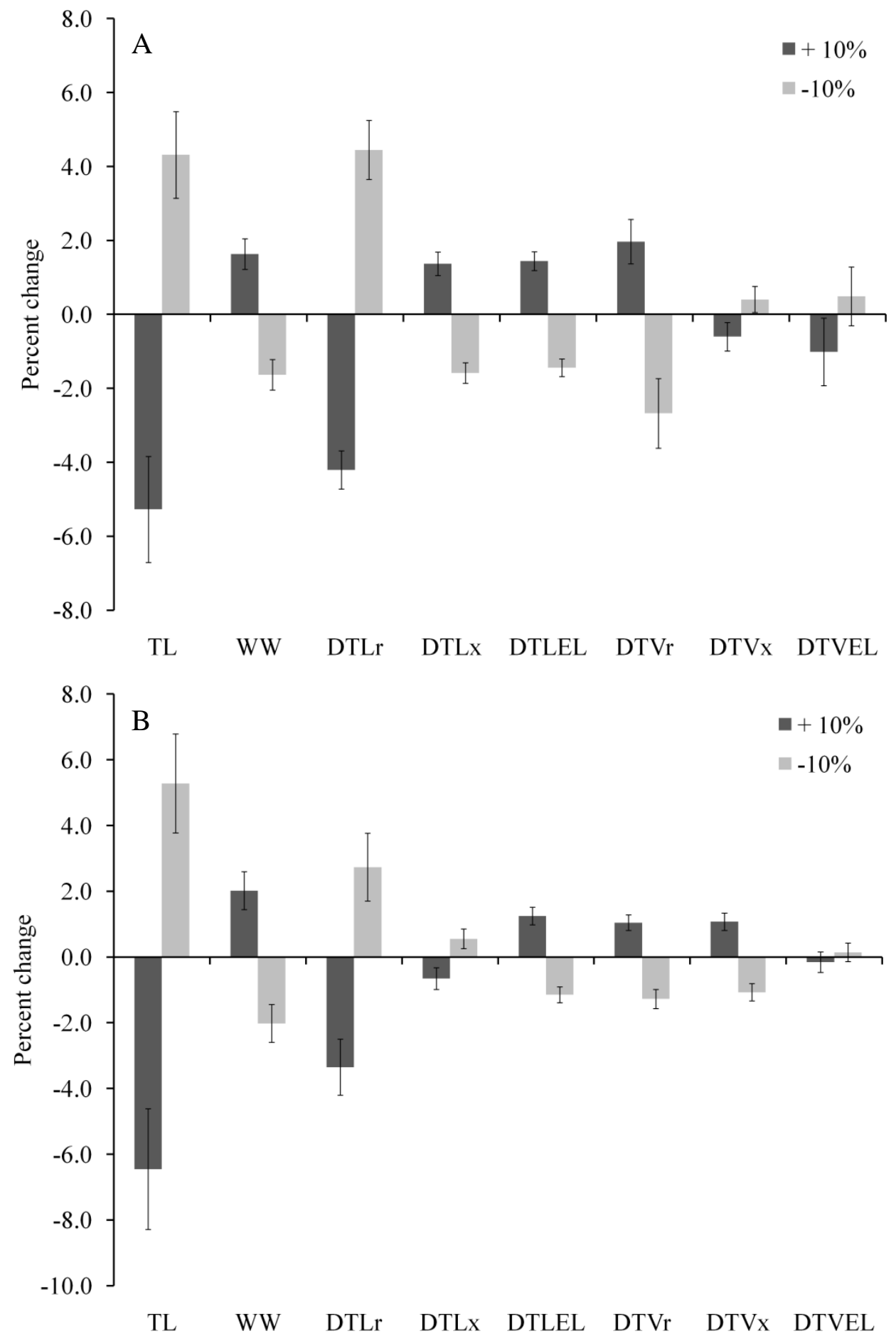

Figure 6.-Results from the sensitivity analysis done on the DTL DTVpre model for both needles (A) and rods (B). TL and WW refer to total length and wet weight, respectively. DTLEL is the electrode length from the DTL location and DTVEL is the measured distance between the electrodes from the DTVpre location. All other abbreviations are identified in Table1. 


\title{
Chapter 4: Temperature Corrections for Bioelectrical Impedance Analysis Models Developed for Age-0 and Adult Brook Trout
}

\begin{abstract}
Bioelectrical impedance analysis (BIA) models for brook trout that predict percent dry weight, a surrogate for condition, have previously been developed in the laboratory where temperature was held constant $\left(18-21^{\circ} \mathrm{C}\right)$. Previous research has determined that temperature has a significant influence on fish BIA measures. For BIA to be useful in the field where temperature deviates outside the range models were developed at, temperature corrections to BIA measures are needed. The objective of this study was to establish the relationships between BIA measures (resistance and reactance) and temperature and to determine if corrections improve BIA models when used over a wide range of temperatures. BIA measures were taken at three different temperatures $\left(5,12.5\right.$ and $\left.20^{\circ} \mathrm{C}\right)$ on 270 brook trout ranging $50-320 \mathrm{~mm}$ total length. Both resistance and reactance significantly decreased as temperature increased. Application of temperature corrections to BIA models reduced root mean squared error by an average of 36.7 and $27.3 \%$ for 5 and $12.5^{\circ} \mathrm{C}$, respectively. BIA temperature relationships for brook trout Salvelinus fontinalis were not similar to those reported in previous literature for coastal bluefish Pomatomus saltatrix indicating that temperature corrections are species or family specific. Field validation of the temperature corrections and BIA models developed by this study is needed.
\end{abstract}

\section{Introduction}

The recent success of multiple independent researchers using bioelectrical impedance analysis (BIA) to assess body condition and proximate composition of fishes has highlighted the potential of the method for use in fisheries research and management (Bosworth and Wolters 2001; Cox and Hartman 2005; Duncan et al. 2007; Pothoven et al. 2008; Willis and Hobday 2008; Fitzhugh et al. 2010; Cox et al. 2011; Hafs and Hartman 2011; Hartman et al. 2011). The major benefits of BIA are that it is cost efficient and once models are developed the procedure is nonlethal (Cox and Hartman 2005). Other major benefits are that the equipment required is compact, light weight, and easy to use making it ideal for remote field locations.

The basic principle of BIA is that when a small electrical current $(425 \mu \mathrm{A}, 50 \mathrm{kHz})$ is passed through fish tissue the resistance and reactance values measured will be correlated to measures of proximate composition. Resistance is a measure of how well electricity can pass 
through a substance and since fat is an insulator; resistance should be increased in fish with more fat (Lukaski 1987). Reactance measures the ability of a substance to hold a charge and because the lipid bilayer of cells serves as a capacitor reactance should be increased in healthy fatter fish (Lukaski 1987).

Temperature has been shown to have large influences on BIA measurements (Gudivaka et al. 1996; Marchello et al. 1999; Buono et al. 2004; Cox et al. 2011; Hartman et al. 2011), but few of the models developed for fish have accounted for temperature. Previous models for fish that have provided solid predictions of proximate composition have either held fish at a constant temperature $\left(26^{\circ} \mathrm{C}\right.$, Bosworth and Wolters 2001; $27^{\circ} \mathrm{C}$, Duncan et al. 2007; $20^{\circ} \mathrm{C}$ Hafs and Hartman 2011) or fish have been sampled from a relatively narrow range of temperatures (Cox and Hartman 2005). Slanger and Marchello (1994) measured resistance and reactance on several cuts of meat from beef cows over a wide range of temperatures $\left(\approx 0-16^{\circ} \mathrm{C}\right)$. They concluded that impedance measures were negatively related to temperature and that it was an important parameter in many of their models. Cox et al. (2011) concluded that temperature was a significant source of error in BIA models. Hartman et al. (2011) took BIA measurements on coastal bluefish Pomatomus saltatrix at 15 and $27^{\circ} \mathrm{C}$ and determined that temperature had a significant effect on both resistance and reactance. Furthermore, they concluded that as temperature increased from 15 to $27^{\circ} \mathrm{C}$, average resistance declined by 35.8 and $20.4 \%$ at what they called the dorsal and ventral locations, respectively. In their study, reactance measures also declined as temperature increased at rates of 12.7 and $12.9 \%$ for the dorsal and ventral locations, respectively.

Past research suggests that if BIA is used to estimate the condition or energy density of fish under circumstances where temperature cannot be controlled we will have to include temperature in our models. The objective of this study was to establish the relationships between BIA measures (resistance and reactance) and temperature taken on age- 0 and adult brook trout Salvelinus fontinalis and to determine if corrections improve BIA models when used over a wide range of temperatures. Developing temperature corrections for BIA models should provide more accurate estimates of body condition when used in the field over the range of temperatures normally present in Appalachian brook trout streams.

\section{Methods}


A total of 270 brook trout were collected from Bowden State Fish Hatchery, Bowden, WV and were transported back to the West Virginia University Ecophysiology Laboratory, Morgantown, WV. There fish were maintained in recirculating tanks $(0.5 \mathrm{~m} \mathrm{x} 1.5 \mathrm{~m})$ at $14 \pm 1{ }^{\circ} \mathrm{C}$ and grown to one of six size classes $(50,75,100,150,225,300 \mathrm{~mm}$ TL; 45 fish per size class). Once fish reached the selected size classes they were randomly selected for BIA during a fasting period of either two $(50 \mathrm{~mm})$ or seven $(75$ and $100 \mathrm{~mm})$ weeks for age-0 fish, and four $(150 \mathrm{~mm})$, five $(225 \mathrm{~mm})$, or six months $(300 \mathrm{~mm})$ for adults to ensure that fish were sampled from a wide range of both length and condition. All fish were acclimated to the recirculating system for at least two weeks before any BIA measurement was done.

\section{Bioelectrical impedance analysis}

Each fish had resistance and reactance measured at three different temperatures $(5,12.5$, and $20{ }^{\circ} \mathrm{C}$ ) covering the range of water temperatures that would normally be present for field measurements of BIA with brook trout. When a fish was selected for BIA it was acclimated to $20{ }^{\circ} \mathrm{C}$ for at least 12 hours prior to testing. Fish were anesthetized using MS-222, blotted dry with paper toweling, then placed on a nonconductive surface with the head facing left and both resistance and reactance (Quantum II bioelectrical body composition analyzer, RJL Systems, Clinton Township, MI) as well as the distance between the inner two needles or rods were measured $(\mathrm{mm})$. Each electrode is composed of one signal and one detector needle/rod and for this study signal needles/rods were always keep toward the head of the fish. Because we measured the distance between the inner needles or rods, $5 \mathrm{~mm}$ was added to measured detector length for age- 0 fish and $10 \mathrm{~mm}$ for adults for only measurements taken laterally on the fish. This was done so that the detector length (DL) was equal to the distance between detector needles/rods and not the inner needles/rods. Weight (g), total (TL) and fork (FL) lengths (mm) were measured after BIA was done at $20^{\circ} \mathrm{C}$. Adult fish had their core temperatures measured before (Pre core temp.) and after (Post core temp.) BIA measurements were taken by inserting an electronic meat thermometer down the esophagus into the stomach.

For both age-0 and adult fish BIA measurements were taken at two locations with both subdermal needle and external rod electrodes. For age-0 fish BIA measurements were taken at the dorsal total length (DTL) location as well as the dorsal to ventral pre dorsal fin location (DTV) following the recommendations of Hafs (2011, Chapter 3). To take BIA measurements at the DTL location one electrode was positioned with the needles or rods oriented parallel to the 
lateral line midway between the lateral line and the dorsal midline directly above where the lateral line intersects the operculum. The other electrode was positioned with the needles or rods oriented parallel to the lateral line midway between the lateral line and the dorsal midline directly below the adipose fin. For the DTV location one electrode was positioned along the dorsal midline directly anterior to the dorsal fin and the other electrode was positioned along the ventral midline directly under the other electrode. For adult fish BIA measurements were taken at the dorsal midline (DML) location and at the DTV location as recommended by Hafs and Hartman (2011). For the DML location both electrodes were positioned along the dorsal midline of the fish with one electrode directly posterior to the head and the other directly anterior to the adipose fin. For age-0 fish both subdermal needle and external rod electrodes were built following the specifications of Hafs (2011, Chapter 3). For adult fish we used Model FE24 subdermal needle electrodes (The Electrode Store, Enumclaw, WA) and rod electrodes were built following the specifications of Hafs and Hartman (2011).

Once the measures were taken at both locations with both electrode types the fish were placed into $12{ }^{\circ} \mathrm{C}$ water to recuperate. The adult fish acclimated 12 hours and age- 0 fish 6 hours to allow the core temperature to reach equilibrium with the water and then the BIA measurements were repeated. This same process was then done for $5{ }^{\circ} \mathrm{C}$ water. Once resistance and reactance had been measured at all three temperatures the fish were euthanized in an overdose of MS-222, oven dried to a constant weight, and percent dry weight was calculated by dividing dry weight with wet weight and multiplying by 100 .

\section{Data analysis}

Ordinary least squares regression was used to establish relationships between BIA measurements (resistance and reactance) and temperature for all electrode types and locations. The slopes from the regression equations were then used to correct all BIA measurements to 12.5 ${ }^{\circ} \mathrm{C}$, the temperature treatment closest to the average water temperature present in Appalachian mountain brook trout streams $\left(11.5^{\circ} \mathrm{C} ; \mathrm{A}\right.$. W. Hafs, unpublished data). Using the regression procedures from Hafs and Hartman (2011) and Hafs (2011, Chapter 3), BIA models were developed for age- 0 and adult fish separately, using only $12.5^{\circ} \mathrm{C}$ data. Percent dry weight was estimated using both temperature corrected and uncorrected BIA measurements at all three temperatures. Predicted percent dry weight was then compared to actual percent dry weight 
values and root mean square error (RMSE) and $\mathrm{R}^{2}$ was used to assess the ability of temperature corrections to improve BIA models.

In addition to developing temperature correction equations for BIA measurements, taking measurements of adult fish body temperatures allowed the inclusion of temperature as a parameter in the regression models as an another alternative. Therefore, forty-five adult fish were randomly selected from each temperature treatment and used to develop regression models following the methods of Hafs and Hartman (2011) and Hafs (2011, Chapter 3).

\section{Results}

A total of 135 age-0 fish ranging 50-110 mm TL and 15.24-21.88 percent dry weight, and 135 adult trout ranging 145-320 mm TL and 15.03-30.95 percent dry weight were sampled (Figure 1) to develop the temperature corrections. Because each fish had BIA measurements taken at all three temperatures 405 BIA measurements were used to develop each temperature correction. Regression analysis results indicate that BIA measures (resistance and reactance) decreased as temperature increased (Figures 2 and 3). This pattern held true independent of electrode type, location of measurements, or whether adult (Figure 2) or age-0 (Figure 3) brook trout were sampled. However, the $95 \%$ confidence intervals of the regression line slopes did not overlap in several instances suggesting that different correction equations would be needed for age-0/adults or rods/needles (Table 1).

Prior to applying temperature corrections, BIA model predictions of percent dry weight were worse at 5 and $20^{\circ} \mathrm{C}$ (Table 2). Residuals were clearly influenced by temperature and were not centered on zero for 5 and $20{ }^{\circ} \mathrm{C}$ for uncorrected BIA models (Figure 4). Application of temperature corrections clearly improved the ability of all BIA models to predict percent dry weight (Table 2) and centered residuals on zero (Figure 4). On average across all four models, temperature corrections reduced RMSE by $37 \%$ and $27 \%$ for 5 and $20{ }^{\circ} \mathrm{C}$ data, respectively. Because of the configuration of the temperature equation, no changes occurred to estimates of percent dry weight at $12.5^{\circ} \mathrm{C}$.

Changes in $\mathrm{R}^{2}$ estimates due to application of temperature corrections were not as clear as RMSE results. On average, RMSE estimates for temperature corrected models were lower for age-0 (0.78) than adult (0.92) fish, however, $\mathrm{R}^{2}$ values were lower for age-0 $(0.48)$ than adult models (0.91). Applying temperature corrections resulted in improved $\mathrm{R}^{2}$ values in most 
circumstances (Table 2). However, for age- 0 models at $5{ }^{\circ} \mathrm{C} \mathrm{R}^{2}$ values decreased by an average of 0.125 .

The $12.5^{\circ} \mathrm{C}$ BIA models developed from this research, when used in combination with temperature correction equations, predicted percent dry weight at similar accuracy levels when compared to BIA models that included temperature as a parameter. Coefficients for the $12.5^{\circ} \mathrm{C}$ BIA models are found in Table 3 and coefficients for temperature inclusive models are located in Table 4. RMSE and $\mathrm{R}^{2}$ values were similar between the two strategies but $12.5^{\circ} \mathrm{C}$ models had fewer parameters resulting in lower AICc scores and less complicated models (Table 5).

\section{Discussion}

The correction equations provided in this paper improved the ability of all four BIA models to predict percent dry weight. These results and those of previous literature (Gudivaka et al. 1996; Marchello et al. 1999; Buono et al. 2004; Cox et al. 2011; Hartman et al. 2011) clearly demonstrate that temperature has an influence on BIA measures and that temperature corrections are needed. Because Hartman et al. (2011) took BIA measures at the same location (DTL) as we did in this study, some valuable conclusions about the temperature relationships can be made. Hartman et al. (2011) determined that resistance measured on coastal bluefish decreased by 35.8 $\%$ as temperature increased from 15 to $27^{\circ} \mathrm{C}$. In our study, resistance decreased by an average of $22.1 \%$ for age- 0 brook trout over a $15^{\circ} \mathrm{C}$ temperature increase, even though our measurements were taken at the same location as in Hartman et al. (2011). For reactance, Hartman et al. (2011) reported a $12.7 \%$ decrease as temperature increased by $12^{\circ} \mathrm{C}$, while in our study reactance decreased by $36.9 \%$ with a $15^{\circ} \mathrm{C}$ increase in temperature. This suggests that BIA temperature relationships are more complicated than anticipated and could be species or possibly family specific.

The temperature corrections provided by this research were able to reduce the effect of temperature decreasing RMSE by as much as $56.9 \%$ and by an average of $36.7 \%$ and $27.3 \%$ when 5 and $20{ }^{\circ} \mathrm{C}$ data, respectively, were corrected to $12.5^{\circ} \mathrm{C}$. The $\mathrm{R}^{2}$ estimates for adult fish $12.5^{\circ} \mathrm{C}$ models developed during this study were all greater than 0.87 , slightly better than the $\mathrm{R}^{2}$ (0.82) estimate of the best models developed by Hafs and Hartman (2011). For age-0 fish the $\mathrm{R}^{2}$ estimates for both uncorrected and corrected models were lower than those reported in Hafs (2011, Chapter 3). Hafs (2011, Chapter 3) reported $\mathrm{R}^{2}$ estimates of 0.86 and 0.85 for subdermal needle electrodes and external rod electrodes, respectively. In this study, the best $\mathrm{R}^{2}$ achieved for 
age-0 fish was 0.66 . The reason our $\mathrm{R}^{2}$ estimates for age-0 fish were lower than those reported by Hafs (2011, Chapter 3) is that the range of percent dry weight for our fish was much narrower (15.24-21.88, this study; 15.09-26.08, Hafs 2011, Chapter 3). Evidence for this conclusion is provided by the RMSE estimates from this study which are lower than those provided by Hafs (2011, Chapter 3). In this study, when temperature corrections were applied, the average RMSE across all temperatures and electrode types for age-0 fish was 0.78 . This is lower than the RMSE (1.03) for the best model from Hafs (2011, Chapter 3). The substantial decreases in RMSE that occurred when we corrected for temperature is encouraging and we suggest that when future researchers use BIA models at temperatures outside the range they were developed, temperature correction equations should be used.

Because we measured body core temperatures for adult fish we were able to compare the results of the two different strategies to account for temperature affects, temperature correction equations and temperature inclusive regression models. Resulting RMSE and $\mathrm{R}^{2}$ estimates were similar for the two strategies, however, the models developed at $12.5^{\circ} \mathrm{C}$ contained fewer parameters on average and therefore AICc score were lower. The simplicity of the new $12.5^{\circ} \mathrm{C}$ models will be an attractive feature for researchers looking to minimize the use of the technical electrical parameters often used in BIA models.

The sampling design used in this study did potentially introduce some possible sources of error into the models. For example, because each fish was sampled at three different temperatures there could be a possible influence of repeated BIA measures. The effect of repeated BIA measures is a factor that has not been researched previously, however, we can speculate on the potential influence of this factor. The most likely influence is that stress over time from BIA sampling would cause plasma chloride levels to increase. Extra chloride in the extra cellular fluid should cause resistance values to decrease. Because we sampled higher temperatures first and resistance decreases as temperature increases it is possible that the temperature correction slopes are slightly closer to zero due to the influence of increased plasma chloride levels. An alternative sampling technique that tests different fish, of similar percent dry weight, at multiple temperatures may be warranted.

One other possible source of error is the effect of changing wet weight over time. Adult and age- 0 fish had BIA measures taken over the course of 24 and 12 hours, respectively. During these time periods it is likely that some changes in the weight wet of fish occurred by either 
uptake or release of water. This could have influenced RMSE estimates, especially for age-0 fish with higher metabolism. For this study we tried to pick an acclimation length that would be long enough to allow body temperatures to stabilize and chloride levels to drop while being short enough to prevent changes in fish wet weight. Because our age-0 RMSE estimates were similar to or better than those reported in Hafs (2011, Chapter 3) we feel that the effect of time was effectively minimized.

This is the first study that has attempted to develop temperature correction equations for use with BIA models on fish. Previous research has demonstrated that BIA measures are influenced by temperature (Gudivaka et al. 1996; Marchello et al. 1999; Buono et al. 2004; Cox et al. 2011; Hartman et al. 2011), but the development of correction equations, like the one from this research, will help BIA produce more reliable estimates, and will allow use over a much wider range of field conditions. In summary, the BIA temperature correction equations decreased RMSE estimates substantially and were very easy to administer. The next logical step in BIA brook trout research is an in depth field validation study that uses the temperature corrections and BIA models provided in this study and the BIA methods from previous literature (Hafs and Hartman 2011; Hafs 2011, Chapter 3) to determine if laboratory results hold up in more variable field conditions.

\section{Acknowledgements}

We would like to thank John Sweka, Patricia Mazik, Joseph Margraf, and Todd Petty for technical guidance and Geoff Weichert, Lindsey Richie, Chris Grady, John Howell, Ed McGinley, Mike Porto, Matthew Belcher, Jared Varner, Daniel Hanks, Melinda Evick, Jonathan Hulse, and Greg Klinger for help with data collection and entry. We also thank Frank Williams from Bowden State Fish Hatchery for providing the brook trout and fish food used in this study. Lastly, we thank WVDNR and the USFS for funding this project. All methods in this study were conducted in compliance with Animal Care and Use Committee protocol number 08-0602.

\section{References}

Bosworth, B. G., and W. R. Wolters. 2001. Evaluation of bioelectric impedance to predict carcass yield, carcass composition, and fillet composition in farm-raised catfish. Journal of the World Aquaculture Society 32:72-78. 
Buono, M. J., S. Burke, S. Endemann, H. Graham, C. Gressard, L. Griswold, and B. Michalewicz. 2004. The effect of ambient air temperature on whole-body bioelectrical impedance. Physiological Measurement 25:119-123.

Cox, M. K., and K. J. Hartman. 2005. Non-lethal estimation of proximate composition in fish. Canadian Journal on Fisheries and Aquatic Sciences 62:269-275.

Cox, M. K., R. Heintz, and K. Hartman. 2011. Measurements of resistance and reactance in fish with the use of bioelectrical impedance analysis: sources of error. Fisheries Bulletin 109:3447.

Duncan, M., S. R. Craig, A. N. Lunger, D. D. Kuhn, G. Salze, and E. McLean. 2007. Bioimpedance assessment of body composition in cobia Rachycentron canadum (L. 1766). Aquaculture 271:432-438.

Fitzhugh, G. R., M. J. Wuenschel, and R. S. McBride. 2010. Evaluation of bioelectrical impedance analysis (BIA) to measure condition and energy allocated to reproduction in marine fishes. Journal of Physics: Conference Series 224:1-4.

Gudivaka, R., D. Schoeller, and R. F. Kushner. 1996. Effect of skin temperature on multifrequency bioelectrical impedance analysis. Journal of Applied Physiology 81:838-845.

Hafs, A. W., and K. J. Hartman. 2011. Influence of electrode type and location upon bioelectrical impedance analysis measurements of brook trout. Transactions of the American Fisheries Society 140:1290-1297.

Hafs, A. W. 2011. Chapter 3: Developing bioelectrical impedance analysis methods for small fish. Doctoral dissertation. West Virginia University, Morgantown.

Hafs, A. W. 2011. Chapter 5: Application of BIA to fish ecology: validation and application of brook trout BIA models to detect seasonal changes in percent dry weight and energy density. Doctoral dissertation. West Virginia University, Morgantown.

Hartman, K. J., B. A. Phelan, and J. E. Rosendale. 2011. Temperature effects on bioelectrical impedance analysis (BIA) used to estimate dry weight as a condition proxy in coastal bluefish. Marine and Coastal Fisheries: Dynamics, Management, and Ecosystem Science 3:307-316.

Lukaski, H. C. 1987. Methods for the assessment of human body composition: traditional and new. The American Journal of Clinical Nutrition 46:537-556. 
Marchello, M. J., W. D. Slanger, and J. K. Carlson. 1999. Bioelectrical impedance: fat content of beef and pork from different size grinds. Journal of Animal Science 77:2464-2468.

Pothoven, S. A., S. A. Ludsin, T. O. Hook, D. L. Fanslow, D. M. Mason, P. D. Collingsworth, and J. J. Van Tassell. 2008. Reliability of bioelectrical impedance analysis for estimating whole-fish energy density and percent lipids. Transactions of the American Fisheries Society 137:1519-1529.

Slanger, W. D., and M. J. Marchello. 1994. Bioelectrical impedance can predict skeletal muscle and fat-free skeletal muscle of beef cow primal cuts. Journal of Animal Science 72:31243130.

Willis, J., and A. J. Hobday. 2008. Application of bioelectrical impedance analysis as a method for estimating composition and metabolic condition of southern bluefin tuna (Thunnus maccoyii) during conventional tagging. Fisheries Research 93:64-71. 
Table 1.-Slopes from regression equations along with upper (UCL) and lower (LCL) $95 \%$ confidence limits. Relationships are provided for both resistance (r) and reactance (x) at both dorsal total length (DTL) and dorsal to ventral (DTV) locations for age-0 brook trout and for the dorsal midline (DML) and DTV locations for adult fish. Relationships are also provided for both subdermal needle and external rod electrodes. In the temperature correction equation provided $\mathrm{T}=$ the temperature that BIA measures were taken at and $\mathrm{T}_{\mathrm{c}}=$ the temperature being corrected to $\left(12.5^{\circ} \mathrm{C}\right.$ in this study).

\begin{tabular}{|c|c|c|c|c|c|c|c|c|c|}
\hline \multirow[b]{2}{*}{ Model } & \multirow[b]{2}{*}{ Measurement } & \multicolumn{4}{|c|}{ Needles } & \multicolumn{4}{|c|}{ Rods } \\
\hline & & Slope & LCL & UCL & Equation & Slope & LCL & UCL & Equation \\
\hline \multirow[t]{4}{*}{ Age-0 } & DTLr & -23.6 & -26.1 & -21.1 & $\left(\left(\mathrm{~T}_{\mathrm{c}}-\mathrm{T}\right)^{*}-23.5881+\mathrm{DTLr}\right)$ & -24.9 & -27.8 & -21.9 & $\left(\left(\mathrm{~T}_{\mathrm{c}}-\mathrm{T}\right) *-24.8632+\mathrm{DTLr}\right)$ \\
\hline & DTLx & -8.8 & -9.9 & -7.8 & $\left(\left(\mathrm{~T}_{\mathrm{c}}-\mathrm{T}\right)^{*}-8.8444+\mathrm{DTLx}\right)$ & -8.7 & -9.7 & -7.8 & $\left(\left(\mathrm{~T}_{\mathrm{c}}-\mathrm{T}\right) *-8.7328+\mathrm{DTLx}\right)$ \\
\hline & DTVr & -8.8 & -10.4 & -7.2 & $\left(\left(\mathrm{~T}_{\mathrm{c}}-\mathrm{T}\right)^{*}-8.8232+\mathrm{DTVr}\right)$ & -12.3 & -13.6 & -11.0 & $\left(\left(\mathrm{~T}_{\mathrm{c}}-\mathrm{T}\right)^{*}-12.3012+\mathrm{DTVr}\right)$ \\
\hline & DTVx & -10.0 & -11.1 & -9.0 & $\left(\left(\mathrm{~T}_{\mathrm{c}}-\mathrm{T}\right)^{*}-10.0183+\mathrm{DTVx}\right)$ & -10.4 & -11.4 & -9.4 & $\left(\left(\mathrm{~T}_{\mathrm{c}}-\mathrm{T}\right) *-10.3659+\mathrm{DTV} \mathrm{x}\right)$ \\
\hline \multirow[t]{4}{*}{ Adult } & DMLr & -9.4 & -10.9 & -7.9 & $\left(\left(\mathrm{~T}_{\mathrm{c}}-\mathrm{T}\right)^{*}-9.4040+\mathrm{DMLr}\right)$ & -9.4 & -11.0 & -7.9 & $\left(\left(\mathrm{~T}_{\mathrm{c}}-\mathrm{T}\right)^{*}-9.4296+\mathrm{DMLr}\right)$ \\
\hline & DMLx & -2.0 & -2.4 & -1.7 & $\left(\left(\mathrm{~T}_{\mathrm{c}}-\mathrm{T}\right)^{*}-2.0361+\mathrm{DMLx}\right)$ & -2.2 & -2.6 & -1.9 & $\left(\left(\mathrm{~T}_{\mathrm{c}}-\mathrm{T}\right)^{*}-2.2484+\mathrm{DMLx}\right)$ \\
\hline & DTVr & -3.4 & -4.2 & -2.7 & $\left(\left(\mathrm{~T}_{\mathrm{c}}-\mathrm{T}\right)^{*}-3.4464+\mathrm{DTVr}\right)$ & -3.3 & -4.0 & -2.6 & $\left(\left(\mathrm{~T}_{\mathrm{c}}-\mathrm{T}\right)^{*}-3.3057+\mathrm{DTVr}\right)$ \\
\hline & DTVx & -0.9 & -1.2 & -0.6 & $\left(\left(\mathrm{~T}_{\mathrm{c}}-\mathrm{T}\right)^{*}-0.8849+\mathrm{DTVx}\right)$ & -2.1 & -2.3 & -1.8 & $\left(\left(\mathrm{~T}_{\mathrm{c}}-\mathrm{T}\right)^{*}-2.0677+\mathrm{DTVx}\right)$ \\
\hline
\end{tabular}


Table 2.-Results from the application of temperature corrections to brook trout BIA models. Root mean squared error (RMSE), $\mathrm{R}^{2}$, and mean estimated percent dry weight are provided for both corrected and uncorrected BIA models as well as for the two regression models for adult fish that include temperature as a parameter. Percent improvement (Improv.) in RMSE resulting from temperature corrections is also provided. Actual mean percent dry weight was 22.86 and 18.74 for adult and age-0 fish, respectively.

\begin{tabular}{|c|c|c|c|c|c|c|c|c|c|}
\hline \multirow[b]{2}{*}{ Model } & \multirow[b]{2}{*}{ Temp. $\left({ }^{\circ} \mathrm{C}\right)$} & \multirow[b]{2}{*}{ Electrode } & \multicolumn{3}{|c|}{ RMSE } & \multicolumn{2}{|c|}{$\mathrm{R}^{2}$} & \multicolumn{2}{|c|}{ Dry weight $(\%)$} \\
\hline & & & Uncorrected & Corrected & Improv. & Uncorrected & Corrected & Uncorrected & Corrected \\
\hline \multirow[t]{6}{*}{ Age-0 } & 5.0 & Needles & 1.23 & 0.97 & 21.14 & 0.39 & 0.26 & 19.82 & 19.12 \\
\hline & 12.5 & Needles & 0.63 & 0.63 & 0.00 & 0.61 & 0.61 & 18.74 & 18.74 \\
\hline & 20.0 & Needles & 0.75 & 0.72 & 4.00 & 0.58 & 0.61 & 18.29 & 19.17 \\
\hline & 5.0 & Rods & 1.18 & 0.98 & 16.95 & 0.33 & 0.21 & 19.79 & 18.93 \\
\hline & 12.5 & Rods & 0.58 & 0.58 & 0.00 & 0.66 & 0.66 & 18.75 & 18.75 \\
\hline & 20.0 & Rods & 0.82 & 0.77 & 6.10 & 0.46 & 0.53 & 18.18 & 19.14 \\
\hline \multirow[t]{8}{*}{ Adult } & 5.0 & Needles & 1.93 & 0.93 & 51.81 & 0.88 & 0.90 & 24.59 & 22.83 \\
\hline & 12.5 & Needles & 0.81 & 0.81 & 0.00 & 0.92 & 0.92 & 22.86 & 22.86 \\
\hline & 20.0 & Needles & 1.93 & 0.96 & 50.26 & 0.83 & 0.91 & 21.02 & 23.20 \\
\hline & $4.9-20.9$ & Needles & NA & 0.94 & NA & NA & 0.89 & NA & 22.97 \\
\hline & 5.0 & Rods & 2.32 & 1.00 & 56.90 & 0.88 & 0.87 & 25.06 & 22.96 \\
\hline & 12.5 & Rods & 0.76 & 0.76 & 0.00 & 0.93 & 0.93 & 22.86 & 22.86 \\
\hline & 20.0 & Rods & 2.02 & 1.03 & 49.01 & 0.78 & 0.91 & 20.94 & 23.42 \\
\hline & $4.4-20.9$ & Rods & NA & 0.93 & NA & NA & 0.89 & NA & 22.93 \\
\hline
\end{tabular}


Table 3.-Regression coefficients for the $12.5^{\circ} \mathrm{C}$ BIA models developed in this study that predict percent dry weight of age-0 or adult brook trout. Models were developed for both subdermal needle and external rod electrodes. The parameter column tells which location's resistance and reactance mesurements should be used when calculating the electrical parameter in parenthesis. Calculations for all parameters are listed in Table 6.

\begin{tabular}{|c|c|c|c|c|}
\hline \multirow[b]{3}{*}{ Parameter } & \multicolumn{2}{|c|}{ Adults } & \multicolumn{2}{|c|}{ Age-0 } \\
\hline & Needles & Rods & Needles & Rods \\
\hline & DML DTVpre & DML DTVpre & DTL DTVpre & DTL DTVpre \\
\hline Intercept & 17.3855 & 26.6039 & 16.2400 & 14.6193 \\
\hline $\mathrm{FL}$ & -0.0794 & -0.1000 & & 0.0888 \\
\hline WW & 0.0558 & 0.0663 & 0.6281 & \\
\hline $\operatorname{DTL}(r)$ & & & -0.0033 & -0.0019 \\
\hline DTL(Xc) & & & & 36.0957 \\
\hline DTL(Xcp) & & & -22.9200 & \\
\hline DTL(Rp) & & & & 7.7824 \\
\hline DTL(Zp) & & & & -37.1532 \\
\hline DTL(DLPA) & & & 0.0153 & \\
\hline DML(Rs) & & -6.4609 & & \\
\hline DML(Rp) & 7.7144 & & & \\
\hline DML(Zs) & -7.7714 & 6.4777 & & \\
\hline DML(DLPA) & 0.0126 & 0.0108 & & \\
\hline DTVpre( r) & 0.0268 & & 0.0048 & \\
\hline DTVpre(x) & & 0.0654 & & 0.0165 \\
\hline DTV(Rp) & & -0.4466 & & \\
\hline DTVpre(PA) & & -0.3584 & 0.0602 & \\
\hline DTVpre(DLPA) & & 0.0057 & & \\
\hline Resid & & & 0.7886 & 0.6473 \\
\hline
\end{tabular}


Table 4.-Regression coefficients for the adult brook trout BIA models (temperature inclusive) developed in this study that predict percent dry weight. The parameter column tells which location's resistance and reactance mesurements should be used when calculating the electrical parameter in parenthesis. Calculations for all parameters are listed in Table 6.

\begin{tabular}{lcc}
\hline Parameter & Needles & Rods \\
\hline Intercept & 8.9270 & 19.8735 \\
FL & -0.0414 & -0.0738 \\
WW & 0.0362 & 0.0315 \\
DML(Xc) & 0.9444 & \\
DML(Rp) & & 3.4730 \\
DML(Zs) & & -3.4201 \\
DML(Zp) & -0.9337 & \\
DML(PA) & 0.5157 & \\
DML(DLPA) & 0.0031 & 0.0076 \\
DTVpre(r) & 0.0315 & \\
DTVpre(x) & & 0.0785 \\
DTV(Rs) & & -0.3151 \\
DTVpre(PA) & & -0.4616 \\
DTVpre(DLPA) & & 0.0090 \\
Pre core temp. & & -0.4004 \\
Post core temp. & 0.1578 & 0.6864 \\
\hline
\end{tabular}


Table 5.- $\mathrm{R}^{2}$, RMSE, number of parameters, and AICc estimates for the adult fish BIA models developed in this study.

\begin{tabular}{llcccc}
\hline Model & Needles/Rods & $\mathrm{R}^{2}$ & RMSE & No. Parameter & AICc \\
\hline $12.5{ }^{\circ} \mathrm{C}$ & Needles & 0.92 & 1.08 & 7 & 35.53 \\
$12.5{ }^{\circ} \mathrm{C}$ & Rods & 0.92 & 1.05 & 10 & 33.94 \\
Temp. inclusive & Needles & 0.89 & 1.25 & 9 & 80.59 \\
Temp. inclusive & Rods & 0.91 & 1.13 & 12 & 59.24 \\
\hline
\end{tabular}


Table 6.-Provided is a list of parameters that are included in the BIA models used in this study. For the residual from length-weight equation we have provided the length weight equation, and the residual is calculated by subtracting the predicted from the observed wet weight (WW).

\begin{tabular}{lcll}
\hline Parameter & Symbol & Units & Calculation \\
\hline Resistance & $\mathrm{r}$ & ohms & measured by Quantum II \\
Reactance & $\mathrm{x}$ & ohms & measured by Quantum II \\
Resistance in series & $\mathrm{Rs}$ & ohms & $\mathrm{DL}^{2} / \mathrm{r}$ \\
Reactance in series & $\mathrm{Xc}$ & ohms & $\mathrm{DL}^{2} / \mathrm{x}$ \\
Resistance in parallel & $\mathrm{Rp}$ & ohms & $\mathrm{DL}^{2} /\left(\mathrm{r}+\left(\mathrm{x}^{2} / \mathrm{r}\right)\right)$ \\
Reactance in parallel & $\mathrm{Xcp}$ & ohms & $\mathrm{DL}^{2} /\left(\mathrm{x}+\left(\mathrm{r}^{2} / \mathrm{x}\right)\right)$ \\
Impedance in series & Zs & ohms & $\mathrm{DL}^{2} /\left(\mathrm{r}^{2}+\mathrm{x}^{2}\right)^{0.5}$ \\
Impedance in parallel & $\mathrm{Zp}$ & ohms & $\mathrm{DL}^{2} /\left(\mathrm{r} \cdot \mathrm{x} /\left(\mathrm{r}^{2}+\mathrm{x}^{2}\right)^{0.5}\right)$ \\
Phase angle & $\mathrm{PA}$ & degrees & atan $(\mathrm{x} / \mathrm{r}) \cdot 180 / \pi$ \\
Standardized phase angle & $\mathrm{DLPA}$ & degrees & $\mathrm{DL} \cdot(\mathrm{atan}(\mathrm{x} / \mathrm{r}) \cdot 180 / \pi)$ \\
Residual from length-weight equation & Resid & N/A & $\mathrm{WW}=0.0000072 \cdot \mathrm{TL}^{3.0056}$
\end{tabular}

$\mathrm{DL}=$ detector length 


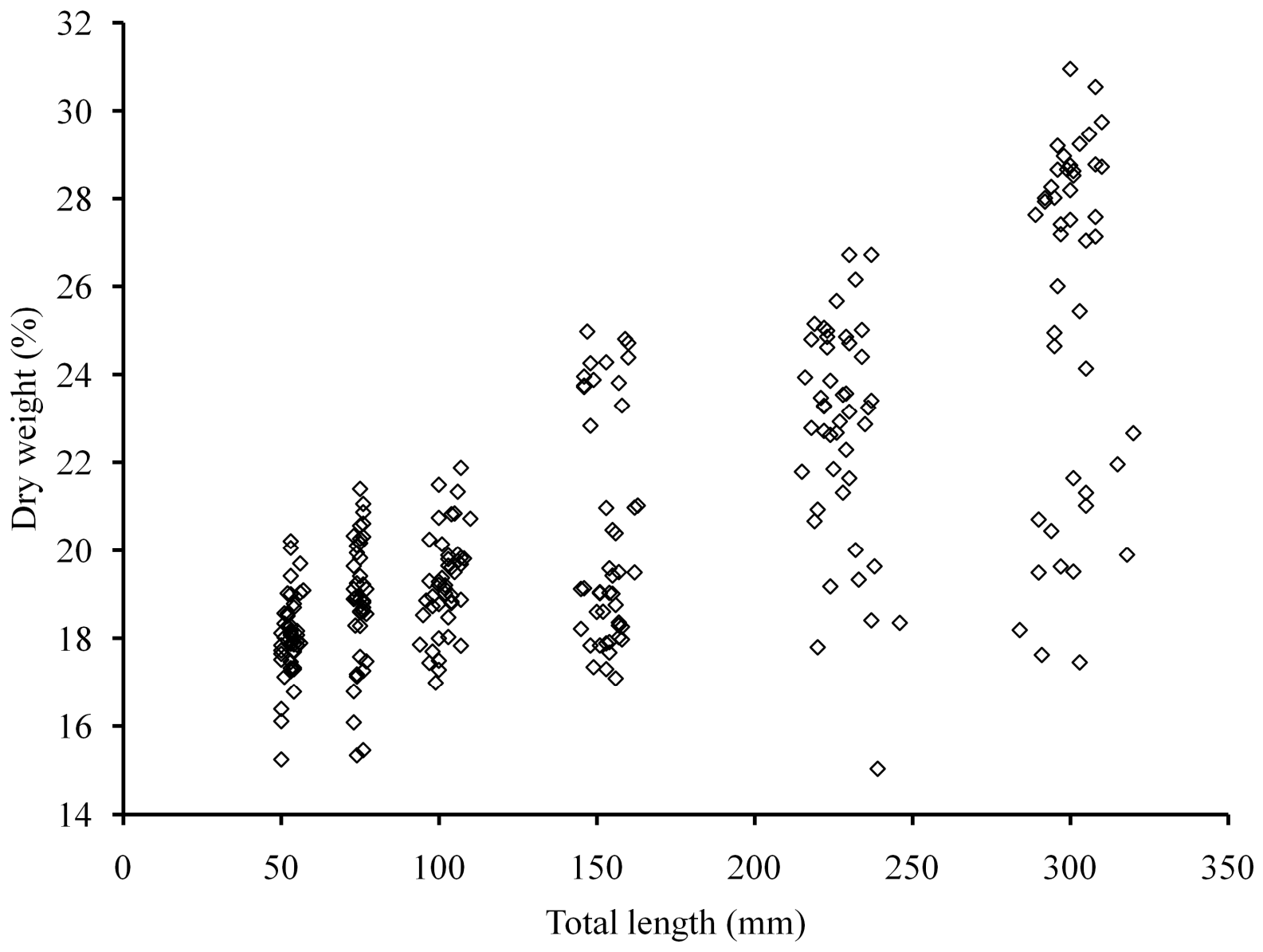

Figure 1.-Range of total lengths and percent dry weights of the fish sampled $(n=270)$ to develop the temperature corrections in this study. 

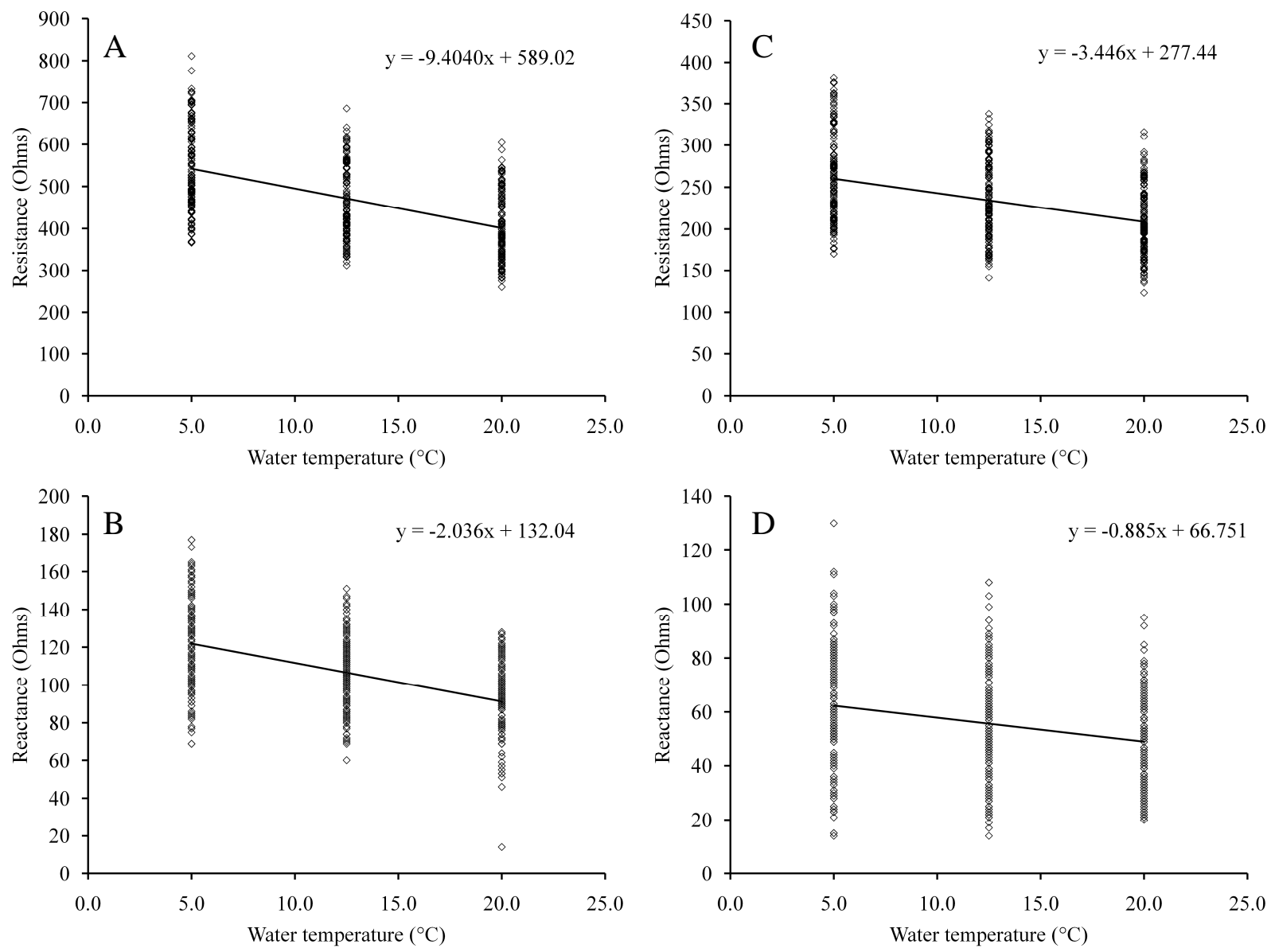

Figure 2.-Trends in measured resistance and reactance across a range of temperature for adult brook trout using subdermal needle electrodes at the DML location (Graph A and B) and the DTV location (Graph C and D). 

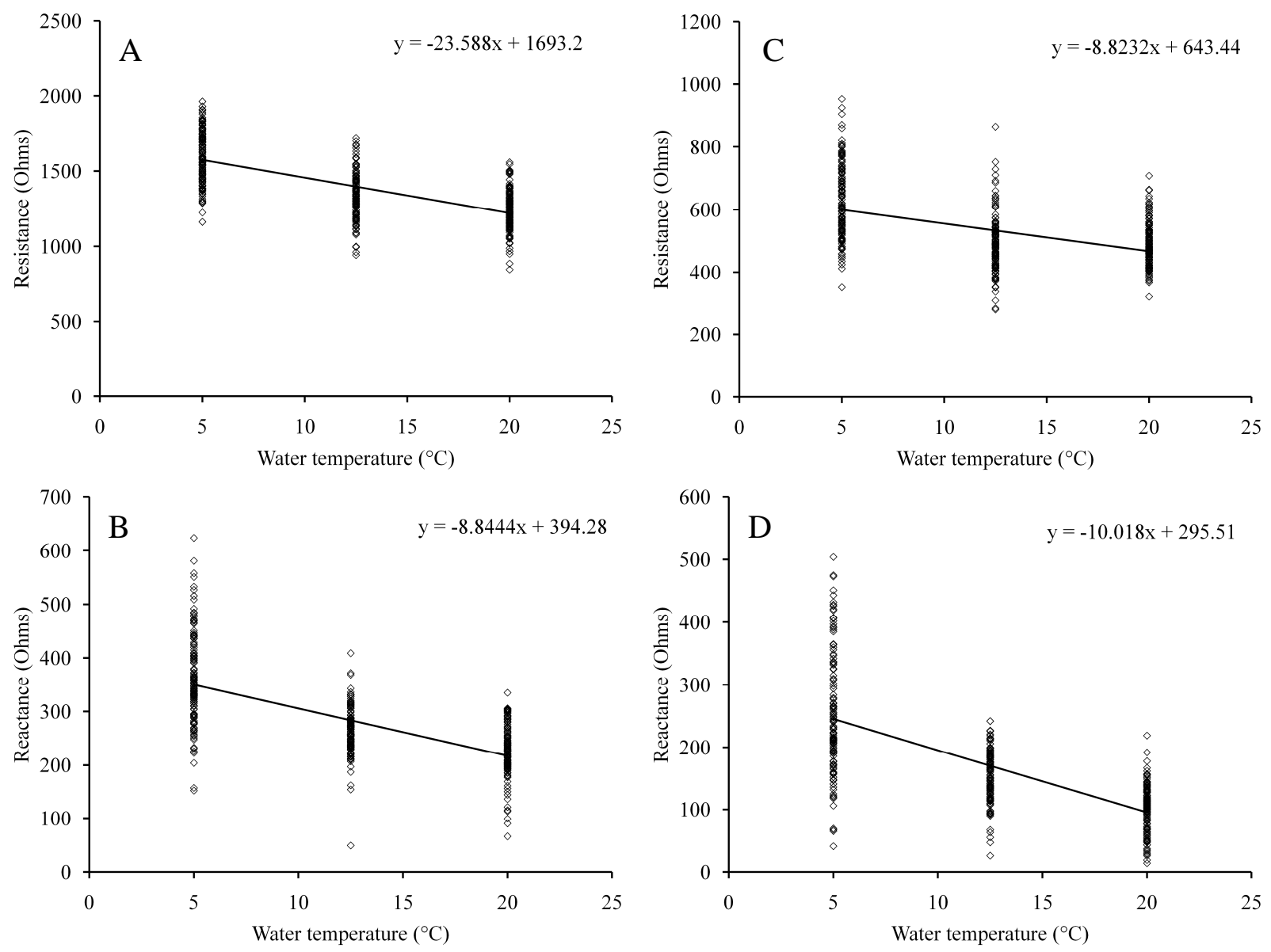

Figure 3.-Trends in measured resistance and reactance across a range of temperature for age0 brook trout using subdermal needle electrodes at the DTL location (Graph A and B) and the DTV location (Graph C and D). 

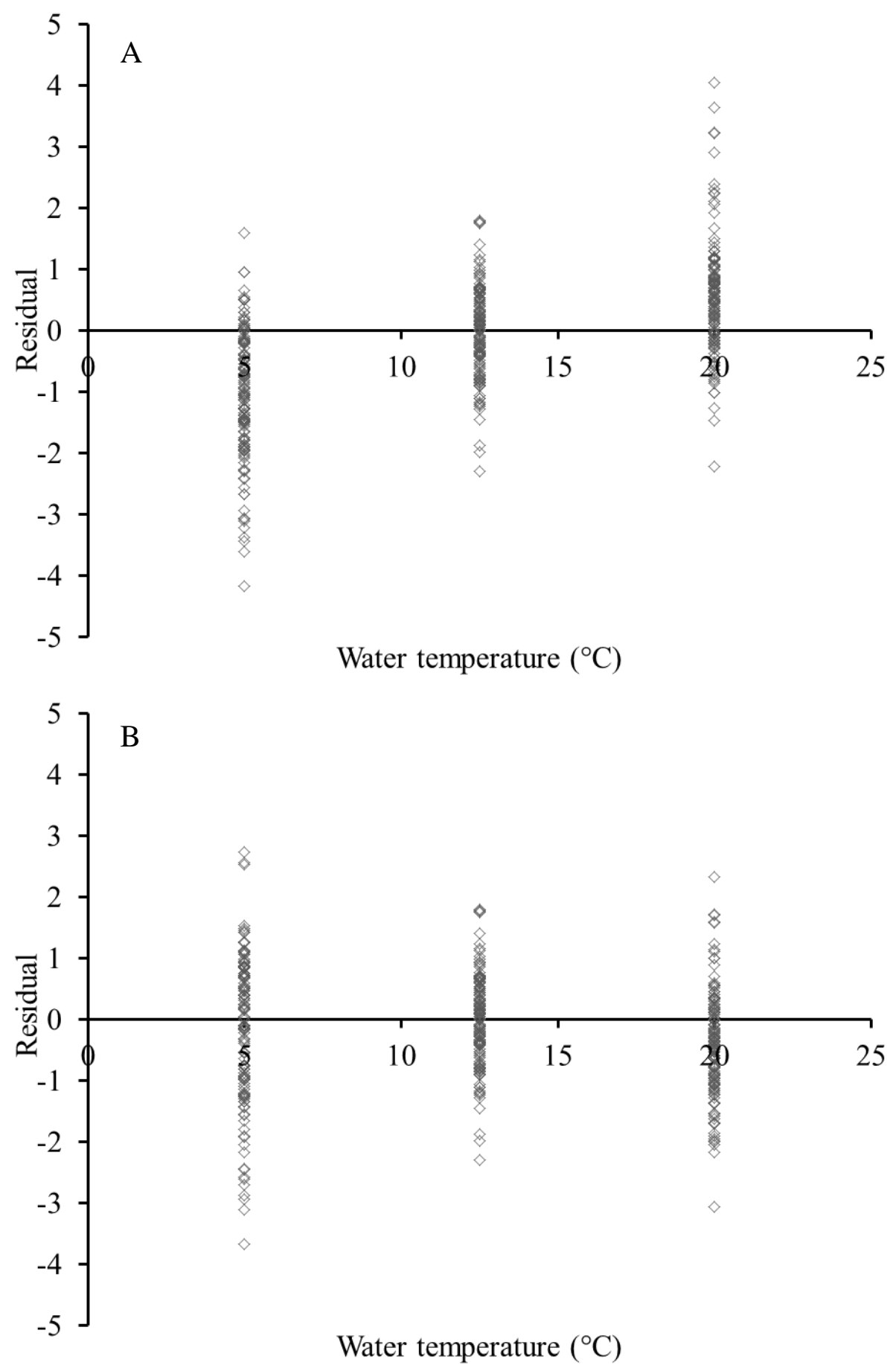

Figure 4.-The change in residuals resulting from the application of temperature corrections to the age-0 external rod electrode BIA model. Graph A is the uncorrected residuals that become less centered on zero as temperature deviates from $12.5^{\circ} \mathrm{C}$, and Graph B shows the residuals from the temperature corrected BIA model which are centered around zero at all temperatures. 


\title{
Chapter 5: Application of BIA to Fish Ecology: Validation and Application of Brook Trout BIA Models to Detect Seasonal Changes in Percent Dry Weight and Energy Density
}

\begin{abstract}
Although recent studies have had good success with bioelectrical impedance analysis (BIA) in laboratory settings, field validation is needed and would increase confidence in current methods. One objective of this study was to validate laboratory derived BIA models by using them to predict percent dry weight of brook trout from BIA data collected in the field and establish trends in condition (represented by percent dry weight). A second objective was to determine if BIA can be used to measure seasonal changes in energy density. To accomplish these objectives BIA was done on Appalachian brook trout Salvelinus fontinalis sampled once per month May 2010-April 2011. Adult condition decreased during reproductive periods and also followed a pattern that resembled trends in terrestrial invertebrate consumption rates published in previous literature. When subdermal needle electrodes were used for BIA measurements on adult fish, monthly mean condition was predicted with good results $(\mathrm{RMSE}=$ $\left.1.20, \mathrm{R}^{2}=0.71\right)$. When external rod electrodes were used similar results occurred $(\mathrm{RMSE}=1.27$, $\left.\mathrm{R}^{2}=0.70\right)$. Prediction of condition for individual fish was unreliable suggesting that more work is needed to control sources of error unexplained in this study such as fish surface temperature. The BIA model for age-0 fish was unable to provide reliable predictions for either individual fish or monthly mean estimates $\left(\mathrm{RMSE}=1.15, \mathrm{R}^{2}=0.40\right)$ due in large part to the small range in measured condition. BIA models will have to improve before higher $\mathrm{R}^{2}$ values can be achieved for age-0 fish in the field. Field based BIA models developed in this study from the validation fish data performed better than $12{ }^{\circ} \mathrm{C}$ BIA models. An energy density percent dry weight relationship was established that should allow for more accurate predictions from bioenergetics equations. BIA models were able to predict mean percent dry weight with enough accuracy to allow mean energy density predictions $\left(\mathrm{R}^{2} \geq 0.94\right)$ for use in bioenergetics equations.
\end{abstract}

\section{Introduction}

Researchers and fisheries biologist often seek reliable estimates of fish condition. Bioelectrical impedance analysis (BIA) is a tool that past researchers have used to provide nonlethal estimates of fish condition (Bosworth and Wolters 2001; Cox and Hartman 2005; Duncan et al. 2007; Pothoven et al. 2008; Willis and Hobday 2008; Cox and Heintz 2009; 
Fitzhugh et al. 2010; Cox et al. 2011; Hafs and Hartman 2011; Hartman et al. 2011). Detailed information about fish condition can provide insight to fisheries researchers and managers about the overall health of an ecosystem (Karr 1981). Fish condition has been shown to be correlated to environmental variables such as flow (Weisberg and Burton 1993), sedimentation (Sullivan and Watzin 2010), pH (Suns and Hitchin 1990), dissolved oxygen level (Benejam et al. 2008), and concentration of heavy metals (Suns and Hitchin 1990; Clements and Rees 1997). Because changes in these important variables often occur due to anthropogenic environmental degradation, reliable estimates of fish condition can be used to monitor and ultimately protect aquatic ecosystems, and in many circumstances the human populations using them.

Fish condition also varies naturally over time as changes in food abundance (Jackson et al. 2002; Yamamura et al. 2002), temperature (McClendon and Rabeni 1987), flow (OlivaPaterna et al. 2003), and reproductive cycles (Kortet et al. 2003) occur. Therefore, by closely monitoring fish condition we can better understand the ecological function of aquatic ecosystems. With this detailed knowledge we can make better management decisions that will help improve damaged, and prevent degradation to, healthy aquatic ecosystems.

Many of the BIA models currently available were developed in a laboratory or aquaculture setting where temperature was held constant (Bosworth and Wolters 2001; Duncan et al. 2007; Hafs and Hartman 2011; Hafs 2011, Chapter 3; Hartman et al. 2011). Cox and Hartman (2005) sampled brook trout Salvelinus fontinalis from the field, but their sample size was small $(\mathrm{n}=22)$ and fish were taken from a narrow range of temperatures. Willis and Hobday (2008) used BIA to demonstrate that there were differences in the condition of southern bluefin tuna Thunnus maccoyii between years, however, they did not account for the differences in water temperature that have been shown to affect BIA measures (Gudivaka et al. 1996; Marchello et al. 1999; Buono et al. 2004; Cox et al. 2011; Hartman et al. 2011; Hafs 2011, Chapter 4). Fitzhugh et al. (2010) used BIA to successfully evaluate condition of several marine species, but they did not report the range of temperatures that BIA measures were taken at. Previous research indicates that more work is needed validating BIA models across a wide range of temperatures.

The field applications of BIA range from providing reliable estimates of fish condition to estimating seasonal changes in energy density without having to sacrifice fish. However, a BIA field study that validates previously developed BIA models by collecting data that is completely independent from model development, and is also from a large temporal and temperature range 
is needed. BIA models and temperature corrections that were established in the laboratory are currently available for brook trout (Hafs 2011, Chapter 4) and provide an excellent starting point for a BIA field validation study. Furthermore, Utz and Hartman (2009) sampled brook trout at nine different sites that spanned a wide range of stream sizes and brook trout densities. They were able to provide evidence for density dependence for both age-0 size and adult brook trout growth in these Appalachian streams. By sampling the same sites that Utz and Hartman (2009) did over a large temporal scale (one year) we should be able to sample brook trout from a large range of body conditions and water temperatures creating favorable conditions for a BIA field validation study. Based on the results of previous research (Utz and Hartman 2009; Hafs and Hartman 2011; Hafs 2011, Chapter 3; Hafs 2011, Chapter 4) the objectives of this study are to (1) field validate the previous BIA models for brook trout and establish seasonal trends in percent dry weight, and (2) determine if BIA can be used to measure seasonal changes in energy density.

\section{Methods}

\section{Fish sampling}

This study's sampling design was modeled after Utz and Hartman (2009). Brook trout were collected at nine different sample sites (200 m) on six different Appalachian Mountain headwater streams (Strahler order 1 or 2), all within the Middle Fork River watershed, WV (Figure 1). Kittle Creek had three sites on it and Rocky Run had two, all other streams had only one site on each. When a stream contained multiple sites, the sites were separated by $\geq 2 \mathrm{~km}$. Basin area at sample sites ranged from 0.83 to $15.38 \mathrm{~km}^{2}$ while mean riffle depth and pool depth of sample sites ranged 7.46-15.21 and 15.53-32.52 cm, respectively (Utz and Hartman 2009). Previous research (Utz and Hartman 2009) indicated that these nine sites had a wide range of brook trout densities $\left(0.028-0.237 \mathrm{~N} / \mathrm{m}^{2}\right)$ therefore the fish from these sites should also be in a wide range of condition providing a good situation for BIA model validation. Each $200 \mathrm{~m}$ long site was sampled on the first weekend of every month from May 2010 to April 2011 except in February. Snow covered roads prevented us from reaching Mitchell Lick, Kittle Up, Brush, and Kittle Mid during that month. Two passes with backpack electrofishing equipment was done at each site to capture trout. Upon capture trout were anesthetized with MS-222 and BIA analysis was done.

\section{BIA data collection}


Resistance and reactance was measured on all adult brook trout ( $>100 \mathrm{~mm}$ total length; Hakala 2000; Sweka 2003) with both external rods and subdermal needle electrodes using a Quantum II bioelectrical body composition analyzer (RJL Systems, Clinton Township, MI). We used only external rod electrodes for age- 0 trout because age- 0 brook trout are more sensitive and we wanted to limit sampling time. Electrode specifications were the same as those in Hafs and Hartman (2011) for adult fish and Hafs (2011, Chapter 3) for age-0 brook trout. For adult fish subdermal needle electrodes used were 29 gauge mounted $10 \mathrm{~mm}$ apart and set to penetrate to a depth of $3 \mathrm{~mm}$. External rod electrodes consisted of stainless steel rods $3.2 \mathrm{~mm}$ in diameter with the center of the rods mounted $10 \mathrm{~mm}$ apart. For age- 0 fish the external rod electrodes were made from two stainless steel rods (1.6 mm diameter) set $5 \mathrm{~mm}$ apart in epoxy. BIA measurements were taken at two locations for both adult and age- 0 trout based on the recommendations of Hafs and Hartman (2011) and Hafs (2011, Chapter 3). For adult brook trout the first measurement was taken by placing the electrodes along the dorsal midline of the fish with one electrode located immediately posterior to the head while the other electrode was positioned immediately anterior to the adipose fin (DML). For age-0 trout the first measurement was taken by placing one electrode parallel to the lateral line half way between the lateral line and the dorsal midline directly above where the lateral line intersects the opercular flap. The other electrode was placed half way between the lateral line and the dorsal midline directly below the adipose fin (DTL). The second set of measurements for both adult and age-0 trout was taken by placing one electrode on along the dorsal midline just anterior to the dorsal fin while the other electrode was placed along the ventral midline below the other electrode (DTV). Electrode placements are shown in Figure 2. Following the directions of Hafs and Hartman (2011) we also measured the distance between the detector rod/needles of the electrodes. For adult fish their core temperatures were measured using a standard meat thermometer inserted down the esophagus into the stomach. Because core temperatures could not be taken on the small age-0 fish water temperature was measured instead. These temperature measurements were later used to correct the BIA measures to $12.5^{\circ} \mathrm{C}$ following the suggestion of Hafs (2011, Chapter 4). Upon completion of BIA wet weight (WW), total length (TL), and fork length (FL) of each fish was measured.

Every tenth adult fish and every tenth age-0 fish collected from each site in each month were sacrificed in an overdose of MS-222. These fish were brought back to the lab, oven dried at 
$80{ }^{\circ} \mathrm{C}$ to a constant weight, and percent dry weight was calculated and used as an estimate of body condition. At the end of the study, thirty of the sacrificed adult trout that represented a wide range of percent dry weights were sent to Dominion Environmental, the environmental quality subsidiary of Dominion Resources, Inc., Richmond, Virginia, to have bomb calorimetry done providing estimates of energy density. Because the calorimetry methods used by Dominion Environmental require $1 \mathrm{~g}$ samples and the dry weights of age- 0 fish often less than that, only adult fish were selected for energy density measurements.

\section{Data analysis}

BIA measurements were corrected to $12.5^{\circ} \mathrm{C}$ using the temperature corrections (Table 1) from (Hafs 2011, Chapter 4). Corrected resistance and reactance were then entered in to the BIA models (Table 2) from Hafs (2011, Chapter 4) to provide estimates of percent dry weight. Calculations for all parameters used in the BIA models are located in Table 3. BIA models developed by Hafs (2011, Chapter 4) were then validated by comparing predicted percent dry weight values to actual measured values from the harvested validation fish. R-square and root mean square error (RMSE) estimates were calculated and used to determine the reliability of BIA in field conditions.

Changes in fish condition, represented by percent dry weight, were tracked through time using both estimated and actual measured values of percent dry weight. Root mean square error and $\mathrm{R}^{2}$ values were used to compare estimated and actual percent dry weight values. Tests for significant differences in measured mean percent dry weight by month were done using ANOVA with a TukeyHSD test for pairwise comparisons. Nonnormal data was normalized by applying the Box-Cox transformation, a procedure that selects the best power transformation to normality (Sokal and Rohlf, 1995).

The relationship between energy density (J/g wet weight) and percent dry weight was used to develop regression equations following the procedures in Hartman and Brandt (1995). Measured energy density was then compared to the predicted energy density that was calculated when the BIA estimated percent dry weight was entered into the equation. $\mathrm{R}^{2}$ and RMSE estimates were then used to compare predicted and measured energy density estimates. All statistical analyses were performed in program R ( $\mathrm{R}$ Development Core Team 2009).

\section{Results}


Over the course of the study BIA measurements were taken and percent dry weight was estimated for 938 adult brook trout and 1383 age- 0 fish. A total of 115 age- 0 and 98 adult fish were harvested for validation of percent dry weight estimates over the course of the study.

There were significant differences in body condition (based on actual percent dry weight of validation fish) by month for both adult $\left(\mathrm{F}_{11,86}=6.61, P<0.01\right)$ and age-0 $\left(\mathrm{F}_{10,104}=5.46, P<\right.$ 0.01) brook trout (Figure 3). For adult brook trout, Tukey test results from month by month comparisons indicated that body condition was significantly higher throughout the summer months but declined sharply after the first weekend of September and was significantly lower during late fall and winter (Figure 3 ). Trends in age- 0 body condition were not as clear. Body condition was significantly lower in July than most months, then from August through November condition improved and was significantly greater than July body condition. However, in December body condition again decreased enough to be significantly lower than both August and in the spring when body condition had recovered (Figure 4).

When comparing percent dry weight estimates from only the validation fish, the subdermal needle electrode model produced mean percent dry estimates that fell within the $95 \%$ confidence intervals of actual mean percent dry weight values 7 out of the 12 months (Figure 3). The root mean squared error for these 98 fish was 1.67 and the $\mathrm{R}^{2}=0.35$. However, when comparing the predicted monthly mean percent dry weight values from these same 98 fish to the actual monthly means the RMSE and $\mathrm{R}^{2}$ estimates were 1.20 and 0.71 , respectively (Figure 5).

Results from the measurements taken by external rod electrodes were similar to those produced by subdermal needle electrodes. For adult brook trout the predicted mean percent dry weight estimate was within $95 \%$ confidence intervals of actual percent dry weight measured 8 out of the 12 months (Figure 3). For the 98 validation fish the RMSE and $\mathrm{R}^{2}$ estimates were 1.76 and 0.38 , respectively. When comparing monthly mean predicted to actual monthly mean percent dry weight calculated using only the 98 validation fish, RMSE (1.27) and $\mathrm{R}^{2}(0.70)$ estimates improved and were similar to the estimates produced by subdermal needle electrodes (Figure 5). Although the models for subdermal needles and external rods are corrected for temperature analysis of residuals demonstrates that model error increased as body temperatures approached or exceed $20^{\circ} \mathrm{C}$ and drop below $5^{\circ} \mathrm{C}$ for adult brook trout (Figure 6). Model error also increased substantially for age- 0 fish when water temperature exceeded $15^{\circ} \mathrm{C}$. 
For age-0 brook trout the external rod electrode models produced predicted mean percent dry weight estimates the were within $95 \%$ confidence intervals of actual percent dry weight measured 5 out of the 11 months that age- 0 brook trout were captured (Figure 4 ). When comparing predicted percent dry weight from the 115 validation fish to measured percent dry weight RMSE and $\mathrm{R}^{2}$ estimates were 1.28 and 0.27 , respectively. When comparing monthly mean percent dry weight and to monthly mean values from validation fish RMSE was 1.15 and $\mathrm{R}^{2}=0.40$ (Figure 5).

Figure 5 also demonstrates that laboratory derived $12.5^{\circ} \mathrm{C}$ BIA models tend to overestimate percent dry weight when applied to data collected on brook trout in the field. Because of this we decided to use our validation fish to generate new field based BIA models and see how they compared to the results from the $12.5^{\circ} \mathrm{C}$ BIA models. Overall, the field based BIA models performed much better than the $12.5^{\circ} \mathrm{C}$ BIA models. $\mathrm{R}^{2}$ estimates were higher, RMSE estimates were lower, and models contained fewer parameters. Figure 7 shows $\mathrm{R}^{2}$ and RMSE estimates at both the individual and monthly mean level for all three field based models developed (adult needles, adult rods, and age- 0 rods). Coefficients and parameters for the three new field based models are listed in Table 4.

Because the $\mathrm{R}^{2}$ values for the field based BIA models were $\geq 0.67$ when comparing monthly mean data, we can assume that monthly mean estimates calculated using these same models and all 938 adult and 1383 age- 0 fish sampled would produce similar $\mathrm{R}^{2}$ estimates if all fish had been sacrificed. That being said, adult brook trout body condition, estimated by the subdermal needle model using all fish sampled, peaked in early September at $22.82 \%$ dry weight, declined steadily to a low of $19.45 \%$ in January, and then at the end of the study went back up to $20.45 \%$ in April (Figure 8 ). Mean monthly body condition estimates provided by the external rod field based model produced similar results when all 938 fish were used (Figure 8). Excluding May 2010 when few large age-0 fish were captured, monthly mean percent dry weight estimates, calculated using all 1383 age-0 fish and the field based BIA model, were stable throughout the year at a value of approximately $18.5 \%$ (Figure 8). Only 43 age-0 fish had an estimated percent dry weight value below $17 \%$ and none were lower than $16.22 \%$.

The relationship between percent dry weight and energy density $\left(R^{2}=0.93\right)$ resulted in the following equation:

Energy density $(\mathrm{J} / \mathrm{g}$ wet weight $)=-1803.5+286.43 *($ percent dry weight $)$ 
When the BIA predicted percent dry weight values from the $12.5^{\circ} \mathrm{C}$ subdermal needle and external rod electrode model were entered into this equation and compared to actual measured energy densities the $\mathrm{R}^{2}$ values were 0.39 and 0.56 , respectively. RMSE estimates were 604.8 and 596.3 for subdermal needle and external rod electrode models, respectively. There were six months in which two or more samples were taken for energy density estimates. When monthly mean predicted energy density was compared to actual mean energy density the $\mathrm{R}^{2}=0.91$ for the subdermal needle model and $\mathrm{R}^{2}=0.98$ for the external rod model. For monthly mean estimates RMSE was 315.5 and 426.3 when using subdermal needle and external rod electrode models, respectively. When the field based model BIA predictions of percent dry weight values where used in place of the $12.5^{\circ} \mathrm{C}$ model predictions the results improved substantially. $\mathrm{R}^{2}$ values were 0.63 and 0.60 for subdermal needle and external rod electrode field based models, respectively. RMSE estimates were 393.9 and 438.6 for subdermal needle and external rod electrode field based models, respectively. When monthly mean predicted energy density was compared to actual mean energy density the $\mathrm{R}^{2}=0.94$ for the subdermal needle field based model and $\mathrm{R}^{2}=$ 0.97 for the external rod field based model. For monthly mean estimates RMSE was 216.7 and 220.1 when using subdermal needle and external rod electrode field based models, respectively. Because energy density is a function of percent dry weight monthly trends in energy density closely follow patterns described earlier for percent dry weight.

\section{Discussion}

\section{BIA field application}

Validation of BIA models is a necessary step before the models can be used in the field. This study tested the reliability of the brook trout BIA models over a wide range of field conditions that included air temperatures ranging -4.2 to $34.2^{\circ} \mathrm{C}$, wind, snow, and rain. The indepth field validation of this study has allowed us to determine the strengths and weaknesses of BIA as well as determine the limits of the models being tested. For example, $12{ }^{\circ} \mathrm{C}$ BIA models for subdermal needle electrodes were able to predict monthly mean body condition of adult brook trout, represented via percent dry weight, with good results. RMSE and $\mathrm{R}^{2}$ estimates were 1.20 and 0.71 , respectively, for the 12 months of the study. This means that if the goal is to predict the average condition of adult brook trout in an aquatic ecosystem, using BIA with subdermal needle electrodes and following the methods and models provided by Hafs and 
Hartman (2011) and Hafs (2011, Chapter 4) mean body condition of adult brook trout can be predicted successfully in a wide range of field conditions.

However, field conditions clearly had an influence on the ability of BIA to predict percent dry weight for individual fish. Rain and snow forced us to take measurements under tarps on multiple occasions. Wind affected the accuracy of electronic scales and even sunlight was a major factor during the summer causing elevated air temperatures. The combination of these factors resulted in unexplained measurement error that, in general, caused our estimates of percent dry weight for individual fish to be less reliable than those produced previously in laboratory studies. For example, estimates of both RMSE and $\mathrm{R}^{2}$ using subdermal needles for individual adult fish in this study were 1.67 and the 0.35 , respectively. These values were worse than average RMSE (0.90) and $\mathrm{R}^{2}$ (0.91) from Hafs (2011, Chapter 4) under controlled laboratory conditions over a wide range of temperatures. However, very rarely in fisheries are we worried about the individual fish and we are often more interested in trends of the population as a whole. When using BIA to calculate monthly mean percent dry weight, BIA did a much better job and produced very reliable estimates, especially for adult fish with either subdermal needle or external rod electrodes. The most likely explanation for this result is that the models are unbiased so measurement error on the individual fish can at times be high, but when averaged over many fish the method produces estimates that are very close to actual body condition of the population. In our opinion the $12{ }^{\circ} \mathrm{C}$ BIA models tested in this paper did not produce reliable estimates of body condition for individual fish and should not be used for that purpose, but if an estimate of the overall condition of the population is the goal, BIA will perform well.

When comparing the performance of subdermal needles to the external rods for adult brook trout both methods produced similar results. The fact that external rod electrodes produced monthly mean estimates of body condition that were similar to subdermal needle electrodes is encouraging, and indicates that the method could be used if a less invasive method is required. Analysis of residuals clearly indicated that both external rod and subdermal needle electrode models performed the worst as body temperatures approached or exceeded $20^{\circ} \mathrm{C}$. In our opinion, the reason there was a large amount of unexplained error as temperatures approached or exceeded $20^{\circ} \mathrm{C}$ was that during the summer when the fish's body temperature was near $20^{\circ} \mathrm{C}$ the air temperatures were often much warmer and the sun was out. This probably caused the fish's skin temperature to be much warmer than the internal body temperature of the fish. Skin 
temperature of humans has been shown to significantly influence BIA measures in past research (Gudivaka et al. 1996) and it is likely that elevated skin temperatures during the summer introduced a large amount of unexplained variation during this study. It is possible that if skin temperature was measured model performance could be improved. In our opinion, BIA measurements taken during warm summer months should be in a shaded area out of direct sunlight to avoid the fish's skin temperature to be increased in comparison to the body temperature. In this study, model residuals also indicated that $12^{\circ} \mathrm{C} \mathrm{BIA} \mathrm{model} \mathrm{performance}$ decreased as body temperatures dropped below $5^{\circ} \mathrm{C}$. The models were developed at temperatures ranging 4.4-20.9 ${ }^{\circ} \mathrm{C}$ (Hafs 2011, Chapter 4) so this model error is likely the result of extrapolating outside the range of the data set.

A major problem with age- 0 fish is that the range of percent dry weights measured in the field is very low (16.57-19.41\%) and even a RMSE as low as 1.15 results in a $\mathrm{R}^{2}$ of only 0.40 . To achieve a higher $\mathrm{R}^{2}$ one of two things must occur: either the range of percent dry weights sampled must be increased, which may not be possible for wild populations of age-0 fish, or more work needs to be done to improve age- 0 models and decrease RMSE estimates. The age- 0 model used in this study was developed by Hafs (2011, Chapter 4) in a laboratory setting were measurements were taken on each fish with two electrode types and at three different temperatures in an effort to develop temperature corrections. It is possible that the BIA model for age-0 fish could be improved by taking BIA measurements at only the two best locations (DTL and DTV) with one electrode type on age-0 brook trout that span a wide range of body conditions. This could minimize any error associated with repeated BIA measures or temperature-related influences caused by contact with the experimenter.

New field based BIA models were developed using the data collected on the validation fish because the $12{ }^{\circ} \mathrm{C}$ BIA models consistently over estimated percent dry weight. It is possible that the inability of the $12{ }^{\circ} \mathrm{C}$ BIA models to accurately predict percent dry weight for individual wild fish can be attributed to the fact that these BIA models were developed by Hafs (2011, Chapter 4) in the laboratory using fish that originated from a hatchery. Past research has demonstrated that there are differences in the morphology of wild and hatchery salmonid populations (Taylor 1986). There is also evidence to suggest that the physiological stress responses are vastly different between wild and hatchery salmonids (Woodward and Strange 1987). Because the morphology and physiology of a fish have a large influence on BIA measures 
it is likely that BIA models developed using wild fish will be able to predict percent dry weight of individual wild fish better than the $12{ }^{\circ} \mathrm{C}$ models tested in this study. The field based BIA models that were developed in this study did perform much better than the $12{ }^{\circ} \mathrm{C}$ laboratory models. Resulting RMSE estimates (0.99, subdermal needles; 1.09 external rods) for individual fish predictions were similar to the results from the studies done in the laboratory under controlled conditions (Hafs 2011, Chapter 4) which is encouraging. However, the field based models developed in this study need to be tested by independent researchers on other systems before we can become confident in the predictions of percent dry weight from these models.

\section{Brook trout body condition}

Based on the streams we sampled during the course of this study, it is clear that adult brook trout populations present in headwater streams of the Appalachian Mountains undergo major changes in body condition over the course of a normal year. Changes in percent dry weight seem to follow a pattern similar to a sine wave with condition peaking in June. Brook trout body condition, represented by percent dry weight, then declines sharply during the month of October. Brook trout spawning in WV typically begins in early October and often continues through early December (Hakala and Hartman 2004; Petty et al. 2005). During this time period a substantial portion of the lipid reserves are used for reproduction and can often lead to high mortality rates during winter (Hutchings 1994). Because percent dry weight is correlated to percent fat (Hartman and Margraf 2008), the significant decline in body condition we witnessed in this study can be explained by the losses in lipids that occur during reproduction (Hutchings 1994). From November through early February body condition of adult brook trout continues to decline. During these months terrestrial invertebrates are no longer available to brook trout, eliminating a major source of energy required for positive growth and increased body condition (Allen 1981; Utz and Hartman 2007; Sweka and Hartman 2008). Utz and Hartman (2007) determined that brook trout consumption of terrestrial invertebrates was the major factor in determining whether or not brook trout fed above maintenance ration in the Middle Fork River watershed. The temporal trends in terrestrial invertebrate consumption by brook trout measured by Utz and Hartman (2007) closely resemble the trends in body condition we report in this study. Therefore, it is likely that terrestrial invertebrate consumption and brook trout reproductive cycles are the two major factors controlling the trends in adult brook trout condition. 
The trend in average percent dry weight for age- 0 fish were not as pronounced as the trend in condition for adult fish. Two interesting patterns in age-0 condition were the drop in July condition and the lack of the substantial drop in winter condition that was prevalent with adult brook trout. The drop in July condition is most likely explained by the fact average water temperature in July was the highest measured during the study at $18.0^{\circ} \mathrm{C}$ and water levels were also lower than any of the other sample periods (mean $=12 \mathrm{cf} / \mathrm{s}$; USGS 2011, Station ID 03052000). It is possible that during this time period of low flow, aquatic invertebrate numbers would have been diminished (Schlosser and Ebel 1989) and with limited surface area, intuitively fewer terrestrial invertebrates would have fallen into the streams. The combination of reduced food availability and the increased metabolism resulting from elevated water temperature is a likely explanation for the decreased condition of age-0 fish in July. The pattern was not evident for adult fish which was probably the result of the larger adult fish out competing age-0 fish for limited remaining preferred habitat locations (Young 2004).

The other interesting trend in age- 0 brook trout condition was the lack of the substantial drop in condition from October to February that was measured in adults. There are likely two contributing factors that would help explain this. First age-0 fish did not have the energy losses that come with reproduction. Secondly, the sum of percent fat, protein, and ash components, when based on wet weights, will equal the percent dry weight of the fish. Protein and ash components of age- 0 brook trout typically add up to about $13.5 \%$ of the fish based on their wet weights (Phillips et al. 1960). The results of this study indicate that few age-0 fish were captured that had percent dry weight estimates below $17 \%$. This means that the average fish has about 3.5 $\%$ fat based on the wet weight of the fish which agrees well with the published values in Phillips et al. (1960). When the percent fat drops below $1 \%$, increased mortality has been shown to occur (Biro et al. 2004). Therefore, fish with percent dry weight estimates much lower than $17 \%$ will be rarely captured because of their increased chance of mortality resulting from low lipid reserves.

\section{Brook trout energy density}

This is the first paper to publish an energy density equation that is specifically designed for brook trout. The equation provided in this paper demonstrates that the relationship between energy density and percent dry weight for brook trout captured in the Middle Fork watershed is different than the relationships for other salmonids published in Hartman and Brandt (1995). As 
the percent dry weight of brook trout increases energy density increases at a slower rate (slope $=$ 283.4) than with general salmonid relationship published previously (slope $=386.7$; Hartman and Brandt 1995). As result, at a low percent dry weight value (17\%) energy density estimates produced by the general salmonid model from Hartman and Brandt (1995) and those from our brook trout model differed by only $4.0 \%$, while at a high percent dry weight value (31\%) energy density values differed by $15.3 \%$. Energy density estimates can be one of the most sensitive parameters included in bioenergetics models (Beauchamp et al. 1989) and although the energy density relationship from our research should be independently verified for brook trout from different locations, bioenergetics predictions for brook trout should be improved if the equation provided in this paper is used in place of the more general salmonid model which is currently used.

Using predictions of percent dry weight from BIA field based models resulted in mean energy density estimates that were very close $\left(R^{2} \geq 0.94\right)$ to measured monthly mean estimates provided by bomb calorimeter. This is exciting because it means that future researchers should be able to use BIA models to produce reliable estimates of mean energy density for a target population of brook trout. Furthermore, any future improvements in BIA models that predict percent dry weight will likely strengthen the ability of BIA to predict energy density for use in bioenergetics models.

\section{Conclusions}

Adult brook trout have large changes in body condition throughout the year that closely resemble reproductive patterns and trends in terrestrial invertebrate consumption rates. Age-0 fish do not have a large change in measured condition between summer and winter. This is most likely because they do not incur energy depletion due to reproduction. Furthermore, energy is not reserved during the summer as an adult would do but is instead used for growth to avoid predation. Also, fish in poor condition experience higher mortality rates and are rarely sampled essentially putting a limit on how low measured percent dry weight can get during winter.

The general trend for $12.5^{\circ} \mathrm{C} \mathrm{BIA} \mathrm{model} \mathrm{prediction} \mathrm{in} \mathrm{this} \mathrm{study} \mathrm{was} \mathrm{that} \mathrm{average} \mathrm{body}$ condition for the population could be predicted with very reliable results but predictions were not as good for the individual fish. Subdermal needle electrodes predictions were similar to those of external rod electrodes for adult brook trout. BIA predictions for age-0 fish resulted in a low RMSE; however, the range of percent dry weights that were measured in the field was very 
narrow so $\mathrm{R}^{2}$ values were also low. The new field based BIA models produced better results suggesting that BIA models that are to be used on wild populations must be developed using wild, not hatchery, fish. More work is needed to improve BIA models and researchers could start by attempting to minimize error associated with the rapid changes in temperature that occur on the surface of the fish and by independently validating the new field based BIA models presented in this study.

Energy density relationships for brook trout resulting from this study are clearly different from other salmonid models presented in previous literature and will help improve the accuracy of bioenergetics models for future research. However, because energy density relationships can differ by location independent verification is needed. BIA predictions of percent dry weight allows for the cheap, nonlethal estimation of mean energy density for brook trout populations.

\section{Acknowledgements}

We would like to thank John Sweka, Patricia Mazik, Joseph Margraf, Todd Petty, and John Howell for technical guidance. Matthew Belcher, Chris Grady, William Haus, Lisa Hudson, Mike Porto, Jared Varner, Geoff Weichert, and Lee Yost for help with data collection and entry. Lastly, we thank WVDNR and the USFS for funding this project. All methods in this study were conducted in compliance with Animal Care and Use Committee protocol number 08-0602.

\section{References}

Allan, J. D. 1981. Determinants of diet of brook trout (Salvelinus fontinalis) in a mountain stream. Canadian Journal of Fisheries and Aquatic Sciences 38:184-192.

Benejam, L., J. Benito, J. Ordonez, J. Armengol, and E. Garcia-Berthou. 2008. Short-term effects of a partial drawdown on fish condition in a eutrophic reservoir. Water, Air, and Soil Pollution 190:3-11.

Beauchamp, D. A., D. J. Stewart, and G. L. Thomas. 1989. Corroboration of a bioenergetics model for sockeye salmon. Transactions of the American Fisheries Society 118:597-607.

Biro, P. A., A. E. Morton, J. R. Post, and E. A. Parkinson. 2004. Over-winter lipid depletion and mortality of age-0 rainbow trout (Oncorhynchus mykiss). Canadian Journal of Fisheries and Aquatic Sciences 61:1513-1519.

Bosworth, B. G., and W. R. Wolters. 2001. Evaluation of bioelectric impedance to predict carcass yield, carcass composition, and fillet composition in farm-raised catfish. Journal of the World Aquaculture Society 32:72-78. 
Buono, M. J., S. Burke, S. Endemann, H. Graham, C. Gressard, L. Griswold, and B. Michalewicz. 2004. The effect of ambient air temperature on whole-body bioelectrical impedance. Physiological Measurement 25:119-123.

Clements, W. H., and D. E. Rees. 1997. Effects of heavy metals on prey abundance, feeding habits, and metal uptake of brown trout in the Arkansas River, Colorado. Transactions of the American Fisheries Society 126:774-785.

Cox, M. K., and R. Heintz. 2009. Electrical phase angle as a new method to measure fish condition. Fisheries Bulletin 107:477-487.

Cox, M. K., and K. J. Hartman. 2005. Non-lethal estimation of proximate composition in fish. Canadian Journal on Fisheries and Aquatic Sciences 62:269-275.

Cox, M. K., R. Heintz, and K. Hartman. 2011. Measurements of resistance and reactance in fish with the use of bioelectrical impedance analysis: sources of error. Fisheries Bulletin 109:3447.

Duncan, M., S. R. Craig, A. N. Lunger, D. D. Kuhn, G. Salze, and E. McLean. 2007. Bioimpedance assessment of body composition in cobia Rachycentron canadum (L. 1766). Aquaculture 271:432-438.

Fitzhugh, G. R., M. J. Wuenschel, and R. S. McBride. 2010. Evaluation of bioelectrical impedance analysis (BIA) to measure condition and energy allocated to reproduction in marine fishes. Journal of Physics: Conference Series 224:1-4.

Gudivaka, R., D. Schoeller, and R. F. Kushner. 1996. Effect of skin temperature on multifrequency bioelectrical impedance analysis. Journal of Applied Physiology 81:838-845.

Hafs, A. W., and K. J. Hartman. 2011. Influence of electrode type and location upon bioelectrical impedance analysis measurements of brook trout. Transactions of the American Fisheries Society 140:1290-1297.

Hafs, A. W. 2011. Chapter 3: Developing bioelectrical impedance analysis methods for small fish. Doctoral dissertation. West Virginia University, Morgantown.

Hafs, A. W. 2011. Chapter 4: Temperature corrections for bioelectrical impedance analysis models developed for age- 0 and adult brook trout. Doctoral dissertation. West Virginia University, Morgantown. 
Hakala, J. P. 2000. Factors influencing brook trout (Salvelinus fontinalis) abundance in forested headwater streams with emphasis on fine sediment. Master's thesis. West Virginia University, Morgantown.

Hakala, J. P., and K. J. Hartman. 2004. Drought effect on stream morphology and brook trout (Salvelinus fontinalis) populations in forested headwater streams. Hydrobiologia 515:203213.

Hartman, K. J., and S. B. Brandt. 1995. Estimating energy density of fish. Transactions of the American Fisheries Society 124:347-355.

Hartman, K. J., and F. J. Margraf. 2008. Common relationships among proximate composition components in fishes. Journal of Fish Biology 73:2352-2360.

Hartman, K. J., B. A. Phelan, and J. E. Rosendale. 2011. Temperature effects on bioelectrical impedance analysis (BIA) used to estimate dry weight as a condition proxy in coastal bluefish. Marine and Coastal Fisheries: Dynamics, Management, and Ecosystem Science 3:307-316.

Hutchings, J. A. 1994. Age- and size-specific costs of reproduction within populations of brook trout, Salvelinus fontinalis. Oikos 70:12-20.

Jackson, A. C., S. D. Rundle, and M. J. Attrill. 2002. Fitness consequences of prey depletion for the common goby Pomatoschistus microps. Marine Ecology Progress Series 242:229-235.

Karr, J. R. 1981. Assessment of biotic integrity using fish communities. Fisheries 6:21-27.

Kortet, R., J. Taskinen, T. Sinisalo, I. Jokinen. 2003. Breeding-related seasonal changes in immunocompetence, health state and condition of the cyprinid fish, Rutilus rutilus, L. Biological Journal of the Linnean Society 78:117-127.

Marchello, M. J., W. D. Slanger, and J. K. Carlson. 1999. Bioelectrical impedance: fat content of beef and pork from different size grinds. Journal of Animal Science 77:2464-2468.

McClendon, D. D., and C. F. Rabeni. 1987. Physical and biological variables useful for predicting population characteristics of smallmouth bass and rock bass in an Ozark stream. North American Journal of Fisheries Management 7:46-56.

Oliva-Paterna, F. J., P. A. Minano, and M. Torralva. 2003. Habitat quality affects the condition of Barbus sclateri in Mediterranean semi-arid streams. Environmental Biology of Fishes 67:13-22. 
Petty, J. T., P. J. Lamothe, and P. M. Mazik. 2005. Spatial and seasonal dynamics of brook trout populations inhabiting a central Appalachian watershed. Transactions of the American Fisheries Society 134:572-587.

Phillips Jr., A. M., D. L. Livingston, and R. F. Dumas. 1960. Effect of starvation and feeding on the chemical composition of brook trout. The Progressive Fish-Culturist 22:147-154.

Pothoven, S. A., S. A. Ludsin, T. O. Hook, D. L. Fanslow, D. M. Mason, P. D. Collingsworth, and J. J. Van Tassell. 2008. Reliability of bioelectrical impedance analysis for estimating whole-fish energy density and percent lipids. Transactions of the American Fisheries Society 137:1519-1529.

R Development Core Team 2009. R: A language and environment for statistical computing. $R$ Foundation for Statistical Computing, Vienna, Austria. ISBN 3-900051-07-0, URL http://www.R-project.org.

Schlosser, I. J. and K. K. Ebel. 1989. Effects of flow regime and cyprinid predation on a headwater stream. Ecological Monographs 59:41-57.

Sokal, R. R., Rohlf, F. J. 1995. Biometry, 3rd edition. Freeman, San Francisco.

Sullivan, S. M. P., and M. C. Watzin. 2010. Towards a functional understanding of the effects of sediment aggradation on stream fish condition. River Research and Applications 26:12981314.

Suns, K., and G. Hitchin. 1990. Interrelationships between mercury levels in yearling yellow perch, fish condition and water quality. Water, Air, and Soil Pollution 650:255-265.

Sweka, J. A. 2003. Aquatic-terrestrial linkages in Appalachian streams: influence of riparian inputs on stream habitat, brook trout populations, and trophic dynamics. Doctoral dissertation. West Virginia University, Morgantown.

Sweka, J. A., and K. J. Hartman. 2008. Contribution of terrestrial invertebrates to yearly brook trout prey consumption and growth. Transactions of the American Fisheries Society 137:224235.

Taylor, E. B. 1986. Differences in morphology between wild and hatchery populations of juvenile Coho salmon. The Progressive Fish-Culturist 48:171-176.

USGS (U.S. Geological Survey). 2011. USGS surface water daily data for the nation. Available: http://waterdata.usgs.gov/nwis/dv. (July 2011.) 
Utz, R. M., and K. J. Hartman. 2007. Identification of critical prey items to Appalachian brook trout (Salvelinus fontinalis) with emphasis on terrestrial organisms. Hydrobiologia 575:259270.

Utz, R. M., and K. J. Hartman. 2009. Density-dependent individual growth and size dynamics of central Appalachian brook trout (Salvelinus fontinalis). Canadian Journal of Fisheries and Aquatic Sciences 66:1072-1080.

Weisberg, S. B., and W. H. Burton. 1993. Enhancement of fish feeding and growth after an increase in minimum flow below the Conowingo Dam. North American Journal of Fisheries Management 13:103-109.

Willis, J., and A. J. Hobday. 2008. Application of bioelectrical impedance analysis as a method for estimating composition and metabolic condition of southern bluefin tuna (Thunnus maccoyii) during conventional tagging. Fisheries Research 93:64-71.

Woodward, C. C., and R. J. Strange. 1987. Physiological stress responses in wild and hatcheryreared rainbow trout. Transactions of the American Fisheries Society 116:574-579.

Yamamura, O., S. Honda, O. Shida, and T. Hamatsu. 2002. Diets of walleye Pollock Theragra chalogramma in the Doto area, northern Japan: ontogenetic and seasonal variations. Marine Ecology Progress Series 238:187-198.

Young, K. A. 2004. Asymmetric competition, habitat selection, and niche overlap in juvenile salmonids. Ecology 85:134-149. 
Table 1.-Temperature correction equations from Hafs (2011; Chapter 4) for both resistance (r) and reactance (x) at both dorsal total length (DTL) and dorsal to ventral (DTV) locations for age-0 brook trout and for the dorsal midline (DML) and DTV locations for adult fish. Equations are provided that correct BIA measures to $12.5^{\circ} \mathrm{C}$, the water temperature that BIA models were originally developed at in the laboratory.

\begin{tabular}{lllc}
\hline Model & Measurement & Electrode & \multicolumn{1}{c}{ Equation } \\
\hline Age-0 & DTLr & Rods & $\left((12.5-\mathrm{T})^{*}-24.8632+\mathrm{DTLr}\right)$ \\
& DTLx & & $\left((12.5-\mathrm{T})^{*}-8.7328+\mathrm{DTLx}\right)$ \\
& DTVr & & $\left((12.5-\mathrm{T})^{*}-12.3012+\mathrm{DTVr}\right)$ \\
& DTVx & & $\left((12.5-\mathrm{T})^{*}-10.3659+\mathrm{DTVx}\right)$ \\
Adult & DMLr & Needles & $\left((12.5-\mathrm{T})^{*}-9.4040+\mathrm{DMLr}\right)$ \\
& DMLx & & $\left((12.5-\mathrm{T})^{*}-2.0361+\mathrm{DMLx}\right)$ \\
& DTVr & & $\left((12.5-\mathrm{T})^{*}-3.4464+\mathrm{DTVr}\right)$ \\
& DTVx & & $\left((12.5-\mathrm{T})^{*}-0.8849+\mathrm{DTVx}\right)$ \\
Adult & DMLr & Rods & $\left((12.5-\mathrm{T})^{*}-9.4296+\mathrm{DMLr}\right)$ \\
& DMLx & & $\left((12.5-\mathrm{T})^{*}-2.2484+\mathrm{DMLx}\right)$ \\
& DTVr & & $\left((12.5-\mathrm{T})^{*}-3.3057+\mathrm{DTVr}\right)$ \\
& DTVx & & $\left((12.5-\mathrm{T})^{*}-2.0677+\mathrm{DTVx}\right)$ \\
\hline
\end{tabular}


Table 2.-Regression coefficients for BIA models used to predict percent dry weight of age-0 or adult brook trout (from Hafs 2011, Chapter 4). Subdermal needle and external rod electrodes were used for adult fish but only rods for age- 0 . The parameter column tells which location's resistance and reactance mesurements should be used to calculate the electrical parameter in parenthesis. Calculations for parameters are listed in Table 3.

\begin{tabular}{|c|c|c|c|}
\hline \multirow[b]{3}{*}{ Parameter } & \multicolumn{2}{|c|}{ Adults } & \multirow{2}{*}{$\begin{array}{c}\text { Age-0 } \\
\text { Rods }\end{array}$} \\
\hline & Needles & Rods & \\
\hline & $\begin{array}{c}\text { DML } \\
\text { DTVpre }\end{array}$ & $\begin{array}{c}\text { DML } \\
\text { DTVpre }\end{array}$ & $\begin{array}{c}\text { DTL } \\
\text { DTVpre }\end{array}$ \\
\hline Intercept & 17.3855 & 26.6039 & 14.6193 \\
\hline FL & -0.0794 & -0.1000 & 0.0888 \\
\hline WW & 0.0558 & 0.0663 & \\
\hline DTL(r) & & & -0.0019 \\
\hline DTL(Xc) & & & 36.0957 \\
\hline DTL(Xcp) & & & \\
\hline DTL(Rp) & & & 7.7824 \\
\hline DTL(Zp) & & & -37.1532 \\
\hline DTL(DLPA) & & & \\
\hline DML(Rs) & & -6.4609 & \\
\hline DML(Rp) & 7.7144 & & \\
\hline DML(Zs) & -7.7714 & 6.4777 & \\
\hline DML(DLPA) & 0.0126 & 0.0108 & \\
\hline DTVpre( r) & 0.0268 & & \\
\hline DTVpre(x) & & 0.0654 & 0.0165 \\
\hline DTV(Rp) & & -0.4466 & \\
\hline DTVpre(PA) & & -0.3584 & \\
\hline DTVpre(DLPA) & & 0.0057 & \\
\hline Resid & & & 0.6473 \\
\hline
\end{tabular}


Table 3.-Provided is a list of parameters that are included in the BIA models used in this study. For the residual from length-weight equation we have provided the length weight equation, and the residual is calculated by subtracting the predicted from the observed wet weight (WW).

\begin{tabular}{|c|c|c|c|}
\hline Parameter & Symbol & Units & Calculation \\
\hline Resistance & $\mathrm{r}$ & ohms & measured by Quantum II \\
\hline Reactance & $\mathrm{x}$ & ohms & measured by Quantum II \\
\hline Resistance in series & Rs & ohms & $\mathrm{DL}^{2} / \mathrm{r}$ \\
\hline Reactance in series & $\mathrm{Xc}$ & ohms & $\mathrm{DL}^{2} / \mathrm{x}$ \\
\hline Resistance in parallel & $\mathrm{Rp}$ & ohms & $\mathrm{DL}^{2} /\left(\mathrm{r}+\left(\mathrm{x}^{2} / \mathrm{r}\right)\right)$ \\
\hline Reactance in parallel & $\mathrm{Xcp}$ & ohms & $\mathrm{DL}^{2} /\left(\mathrm{x}+\left(\mathrm{r}^{2} / \mathrm{x}\right)\right)$ \\
\hline Capacitance & Cpf & picoFarads & $\mathrm{DL}^{2} /\left((1 /(2 \cdot \pi \cdot 50000 \cdot \mathrm{r})) \cdot\left(1 \cdot 10^{12}\right)\right)$ \\
\hline Impedance in series & $\mathrm{Zs}$ & ohms & $\mathrm{DL}^{2} /\left(\mathrm{r}^{2}+\mathrm{x}^{2}\right)^{0.5}$ \\
\hline Impedance in parallel & $\mathrm{Zp}$ & ohms & $\mathrm{DL}^{2} /\left(\mathrm{r} \cdot \mathrm{x} /\left(\mathrm{r}^{2}+\mathrm{x}^{2}\right)^{0.5}\right)$ \\
\hline Phase angle & PA & degrees & $\operatorname{atan}(\mathrm{x} / \mathrm{r})^{*} 180 / \pi$ \\
\hline Standardized phase angle & DLPA & degrees & $\mathrm{DL} \cdot\left(\operatorname{atan}(\mathrm{x} / \mathrm{r})^{*} 180 / \pi\right)$ \\
\hline Residual from length-weight equation & Resid & N/A & $\mathrm{WW}=0.0000072 \cdot \mathrm{TL}^{3.0056}$ \\
\hline
\end{tabular}


Table 4.-Regression coefficients for field based BIA models used to predict percent dry weight of age- 0 or adult brook trout. Subdermal needle and external rod electrodes were used for adult fish but only rods for age- 0 . The parameter column tells which location's resistance and reactance mesurements should be used to calculate the electrical parameter in parenthesis. Calculations for parameters are listed in Table 3.

\begin{tabular}{|c|c|c|c|}
\hline \multirow[b]{3}{*}{ Parameter } & \multicolumn{2}{|c|}{ Adults } & Age-0 \\
\hline & Needles & Rods & Rods \\
\hline & $\begin{array}{c}\text { DML } \\
\text { DTVpre }\end{array}$ & $\begin{array}{c}\text { DML } \\
\text { DTVpre }\end{array}$ & $\begin{array}{c}\text { DTL } \\
\text { DTVpre }\end{array}$ \\
\hline Intercept & 21.3950 & 25.3865 & 20.9806 \\
\hline DTL(x) & & & -0.0096 \\
\hline DTL(DLPA) & & & 0.0067 \\
\hline $\mathrm{DML}(\mathrm{Xc})$ & 0.0623 & & \\
\hline DML(Rp) & & -7.0530 & \\
\hline DML(Cpf) & -28.1286 & & \\
\hline DML(Zs) & & 6.5535 & \\
\hline DML(DLPA) & 0.0095 & 0.0034 & \\
\hline DTVpre(Zp) & -0.2513 & & \\
\hline DTVpre(PA) & -0.1914 & -0.2147 & -0.1032 \\
\hline
\end{tabular}




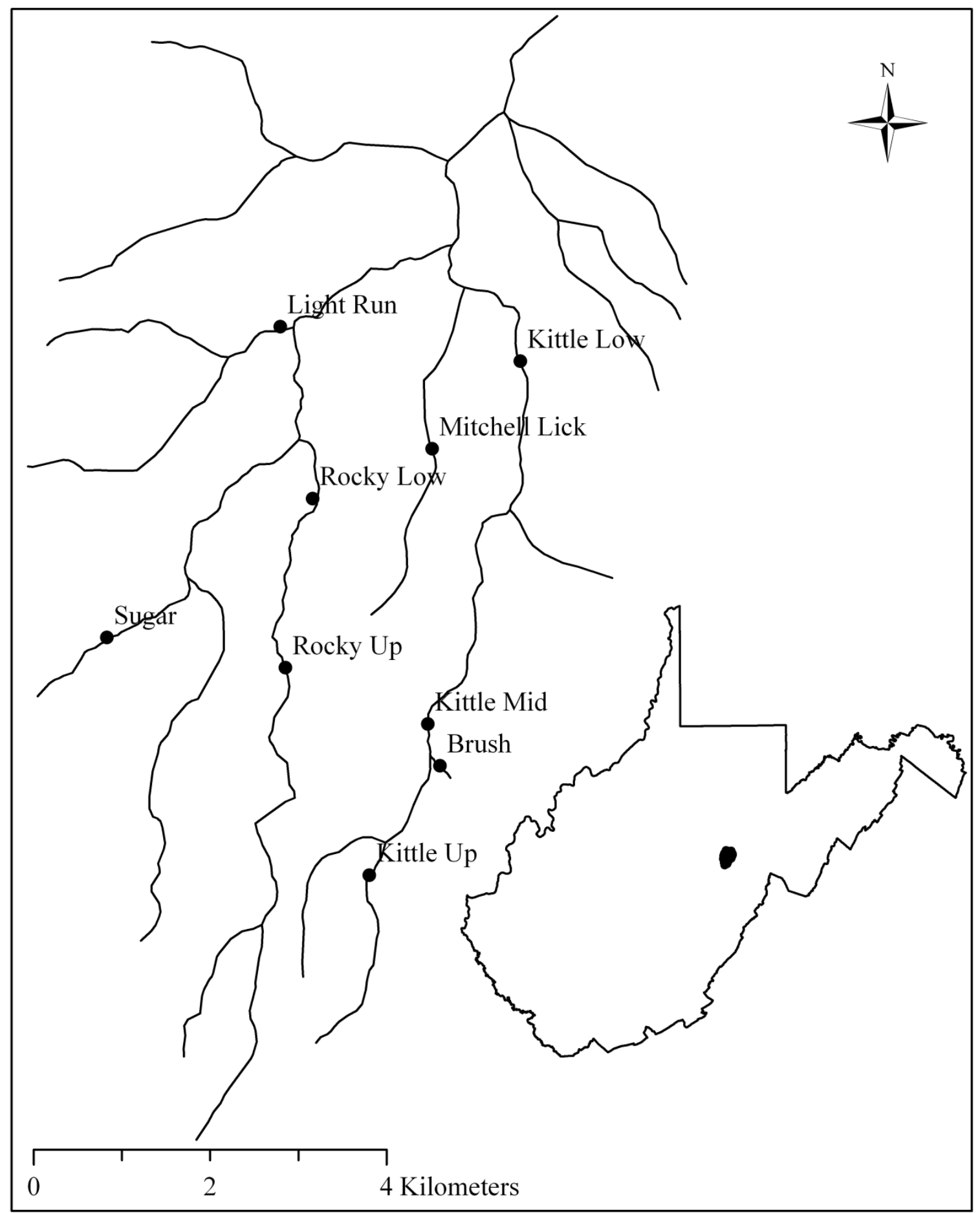

Figure 1.-Study site locations within the Middle Fork River watershed, WV. Sites were sampled on the first weekend of every month from May 2010 to April 2011. 


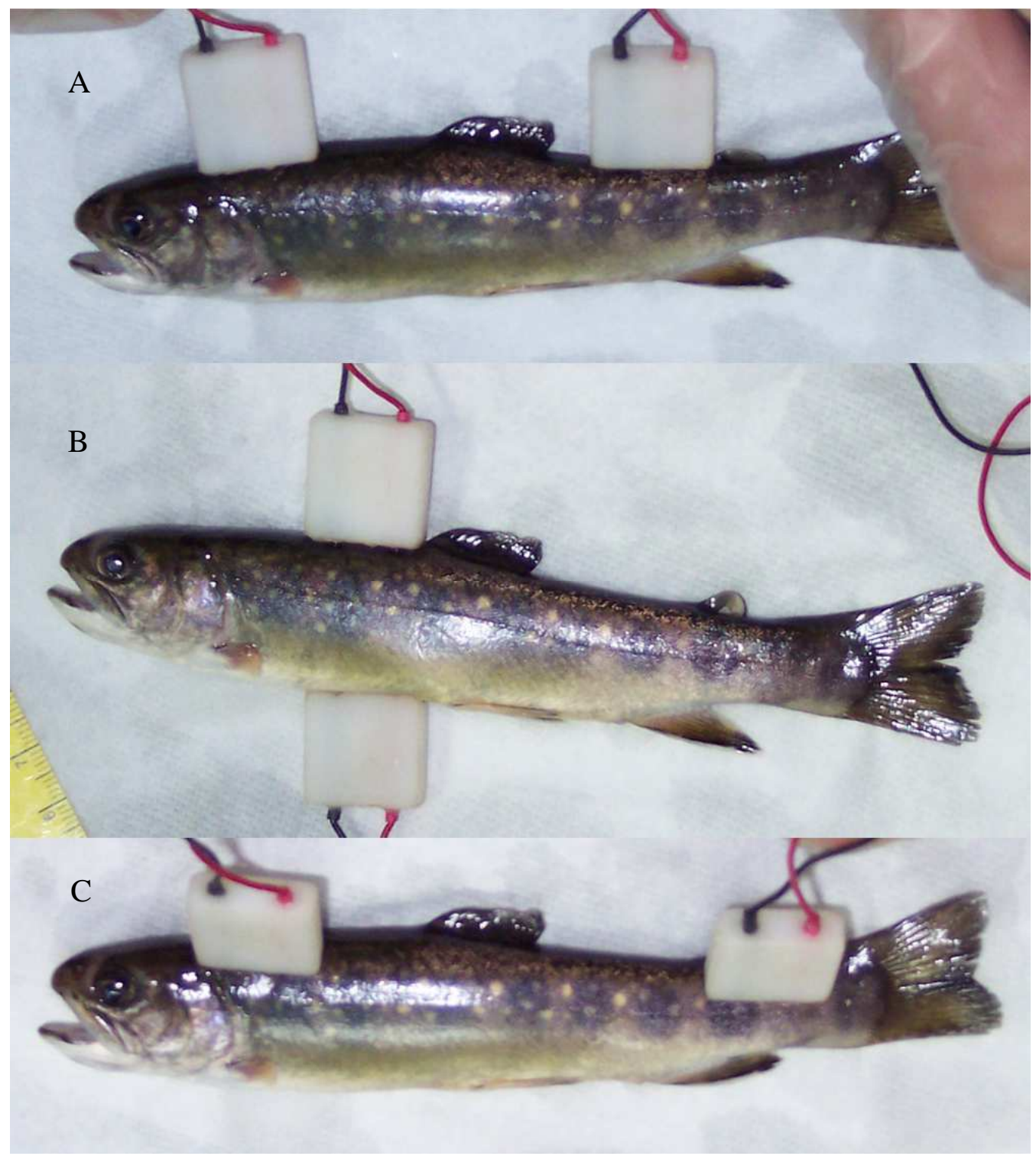

Figure 2.-Electrode locations: (A) dorsal midline (DML), (B) dorsal to ventral pre dorsal fin (DTV), and (C) dorsal total length (DTL). The DML and DTV electrode locations were used to take BIA measurements on adult brook while the DTL and DTV locations were used for age-0 fish. 


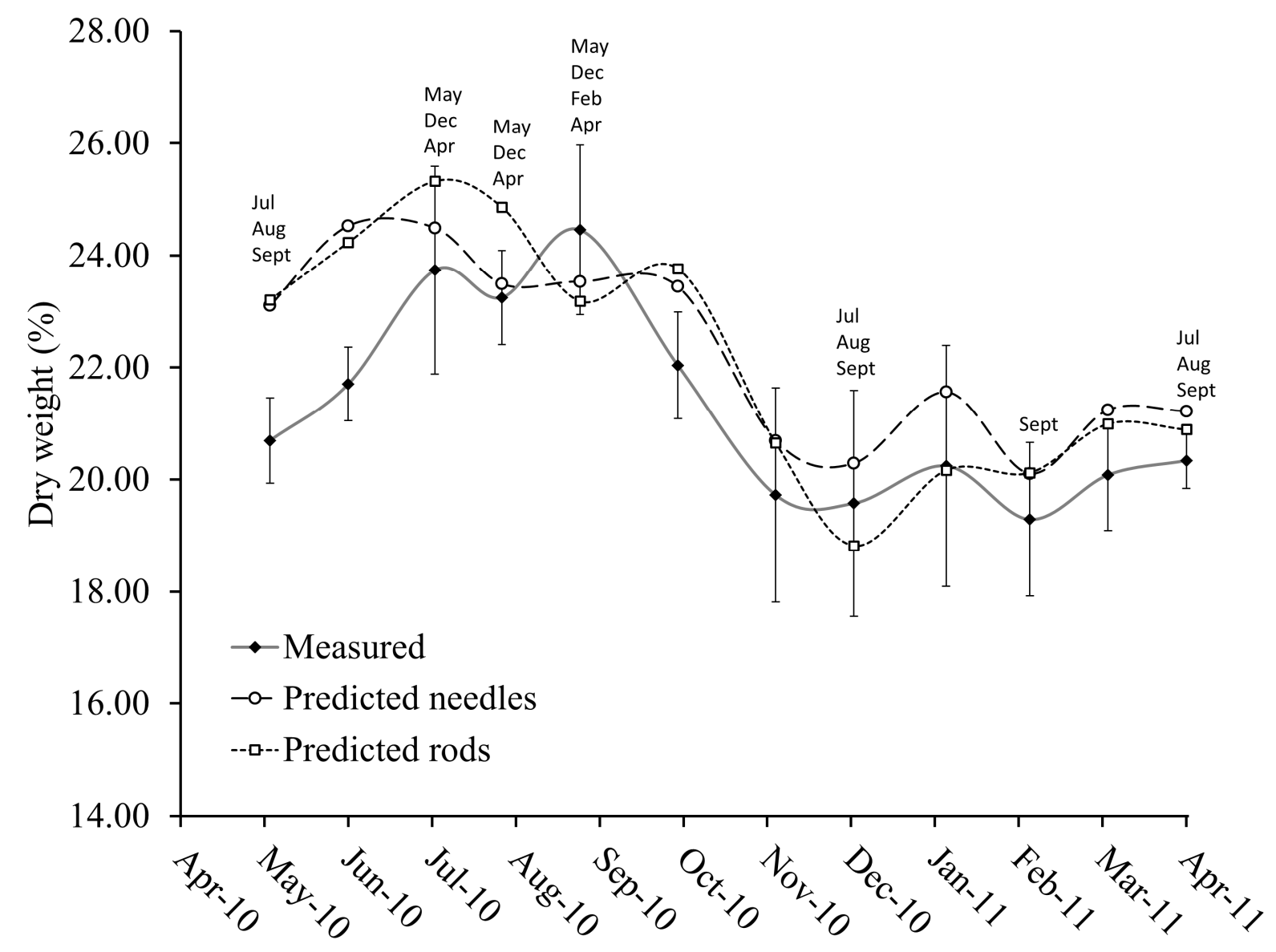

Figure 3.-Predicted mean percent dry weight estimates for adult validation $(n=98)$ brook trout for both subdermal needle (hollow circles) and external rod (hollow squares) models in comparison to actual measured mean values (black diamonds). Black bars represent $95 \%$ confidence intervals. Months listed on top of data points indicated measured monthly means (black diamonds) that are significantly different from the month indicated on the x-axis. 


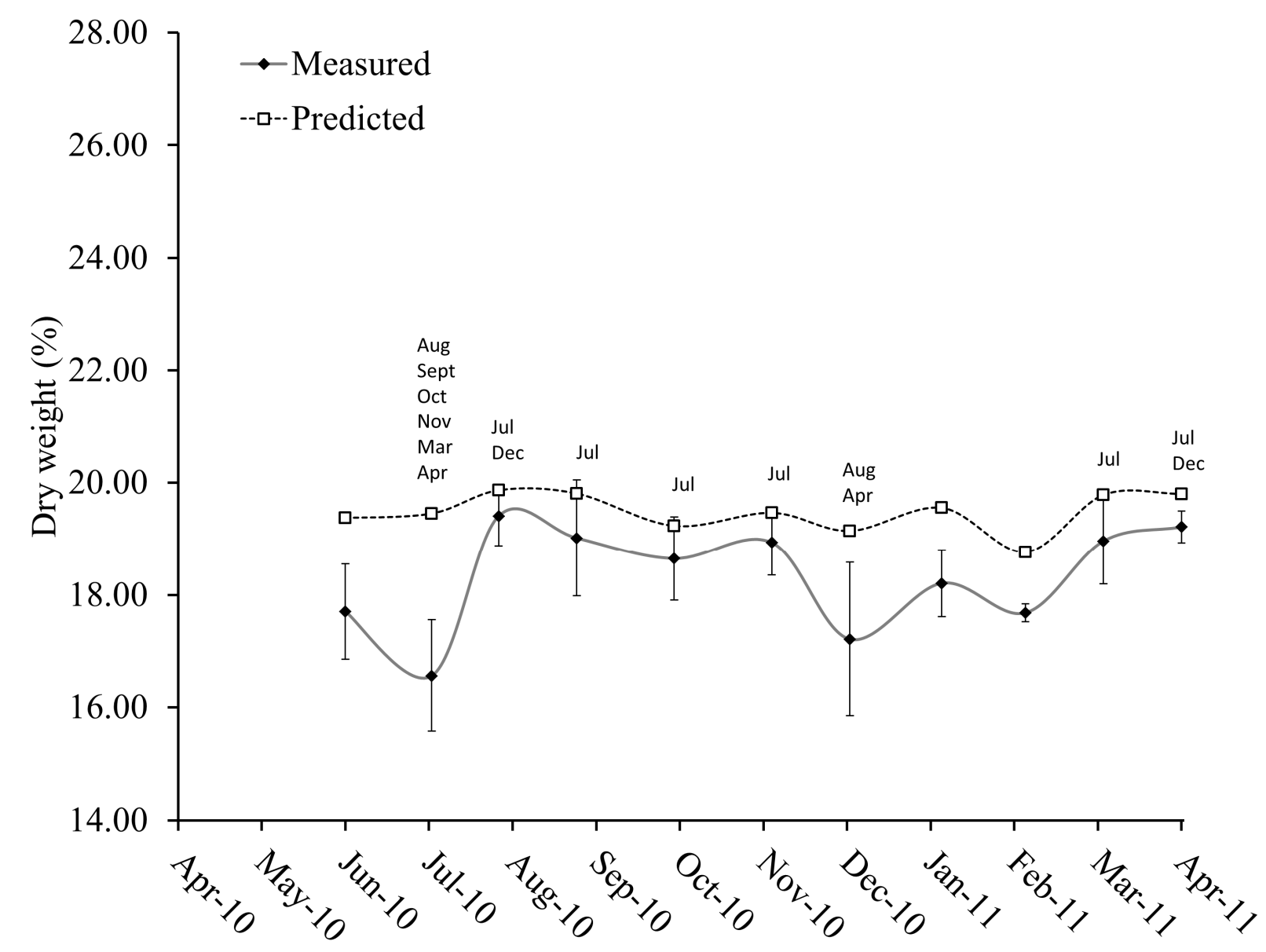

Figure 4.-Predicted (hollow squares) monthly mean percent dry weight of age-0 validation trout $(\mathrm{n}=115)$ in comparison to actual measured mean values (black diamonds). Black bars represent $95 \%$ confidence intervals. Months listed on top of data points indicated measured monthly means (black diamonds) that are significantly different from the month indicated on the $\mathrm{X}$-axis. 

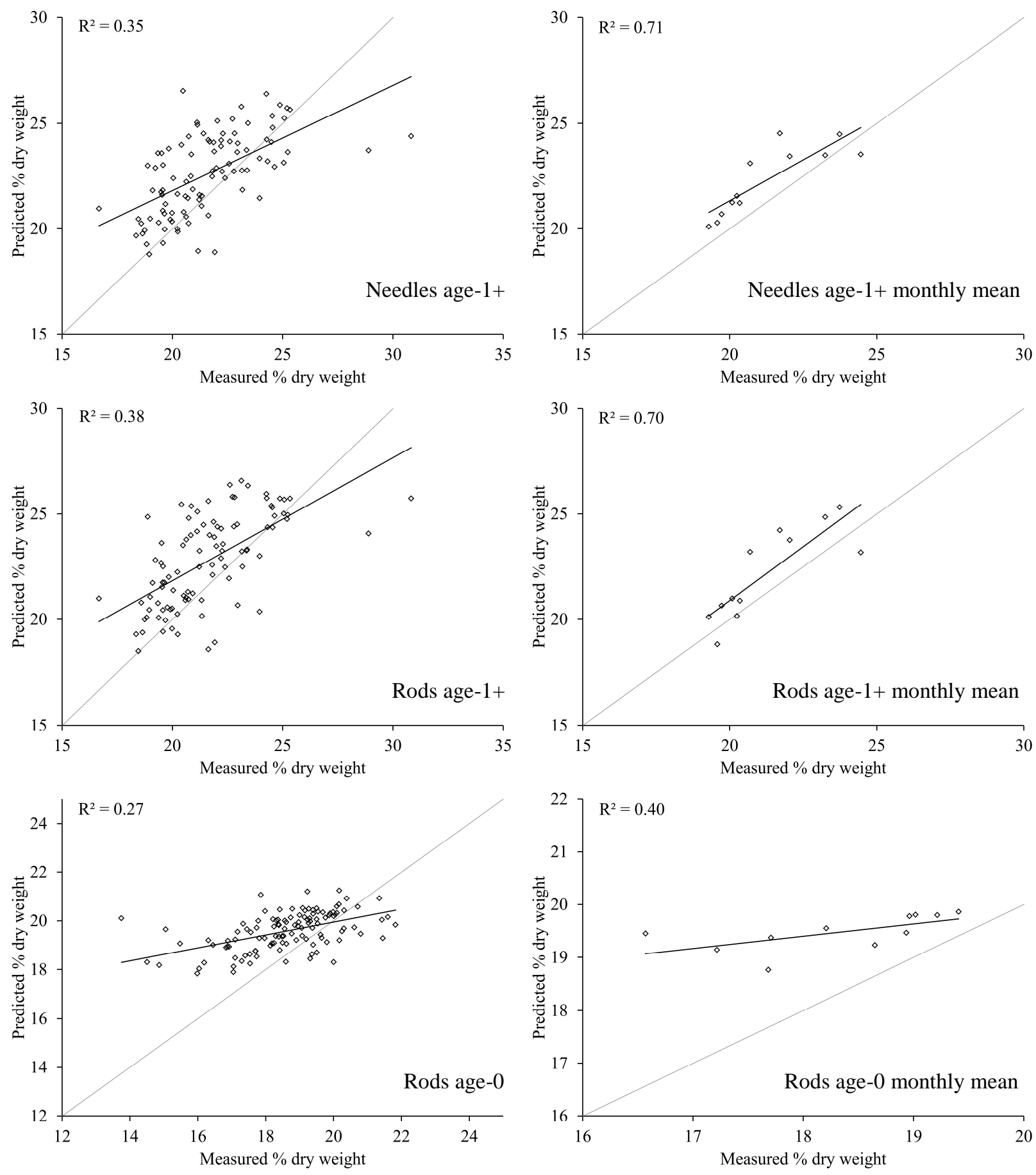

Figure 5.-Predicted verses measured percent dry weight for the BIA models that had BIA measures corrected to $12.5^{\circ} \mathrm{C}$. The light grey line in each graph represents what the trend line (dark black line) should look like if there was a 1:1 relationship between measured and predicted percent dry weight values. 

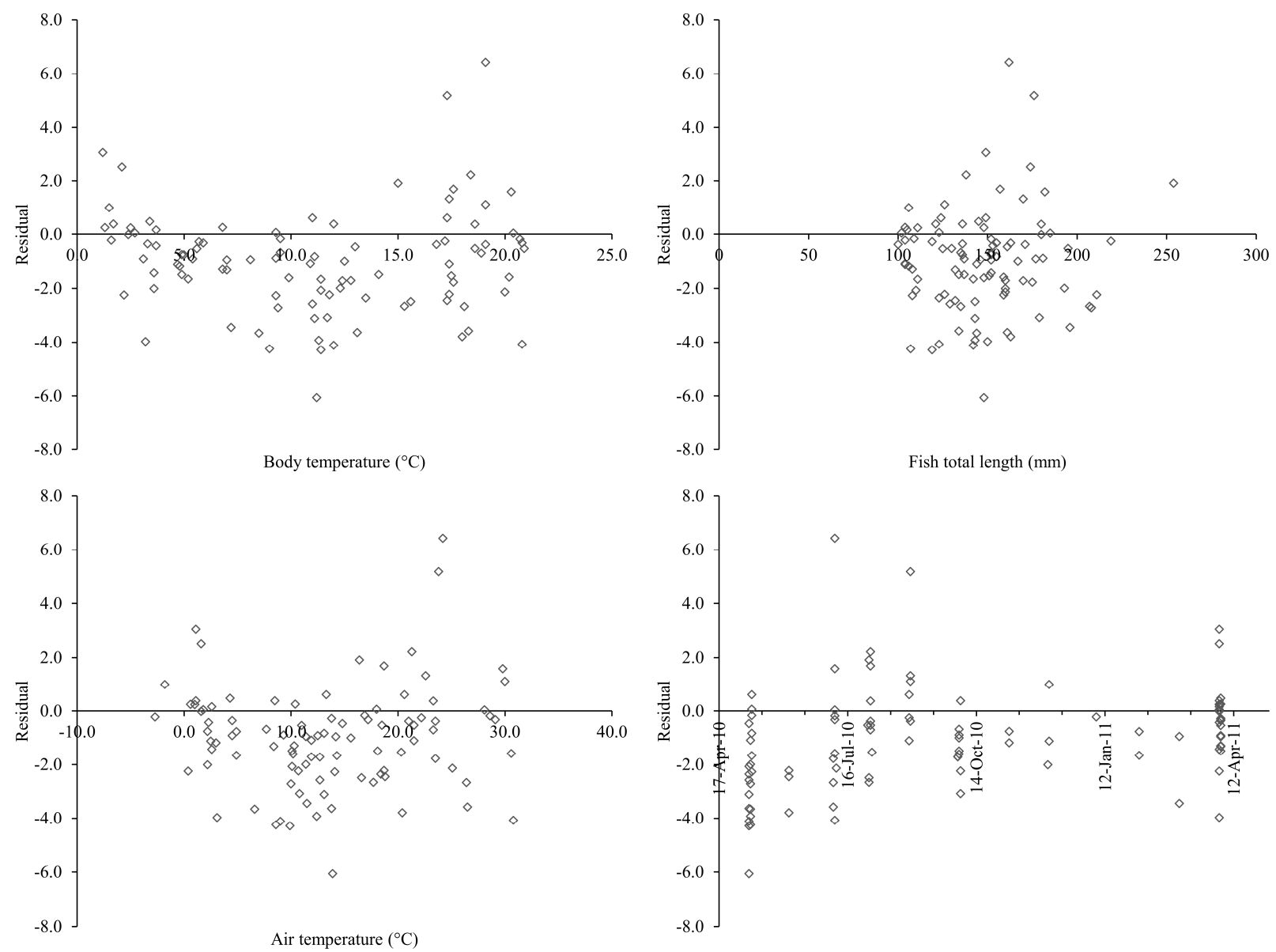

Figure 6.-Residuals from the subdermal needle BIA models, that predict percent dry weight of adult brook trout, plotted against fish body temperature, total length, air temperature, and the date the sampled was taken on. 

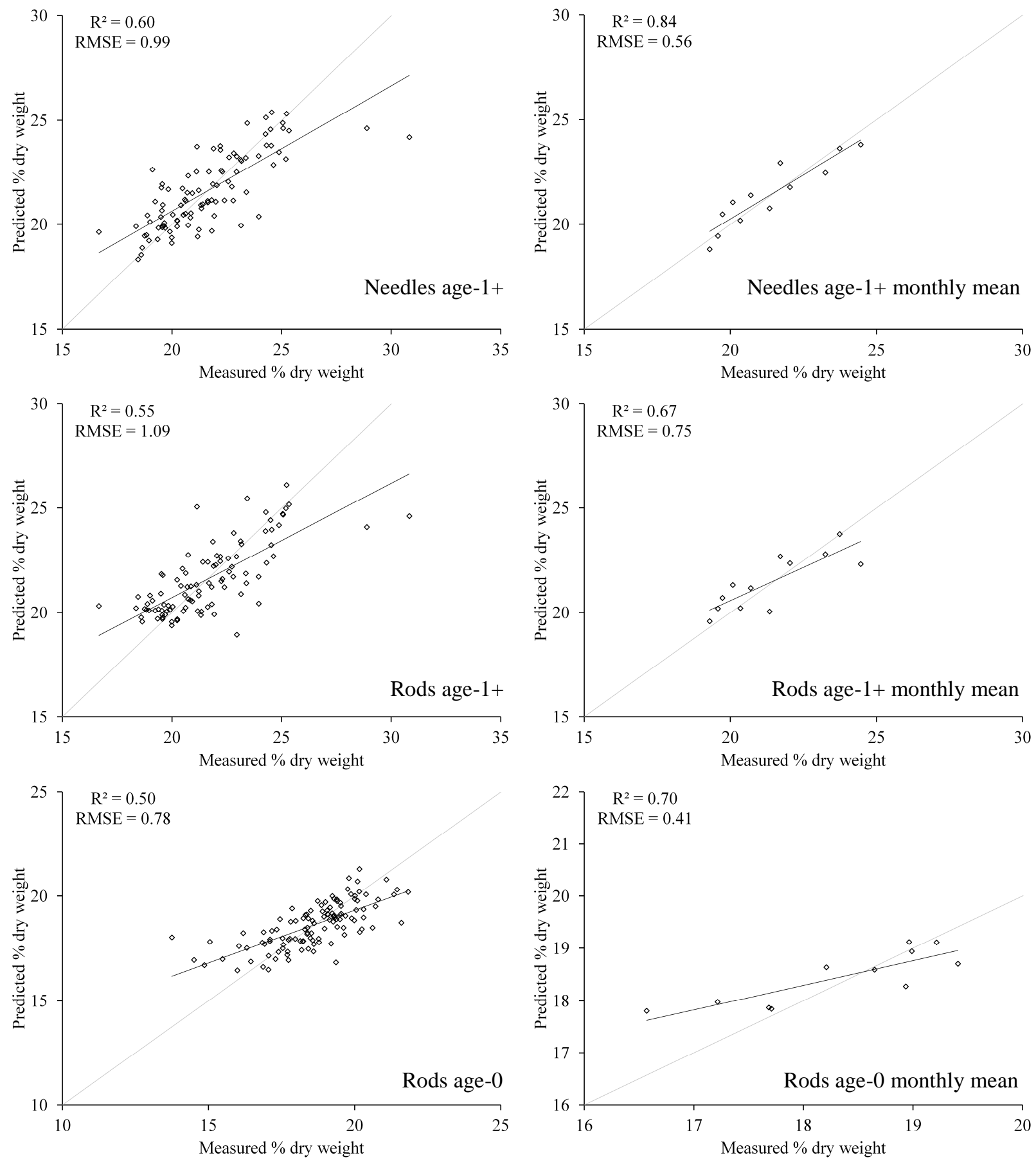

Figure 7.-Predicted verses measured percent dry weight for the field based BIA models developed in during this study. The light grey line in each graph represents what the trend line (dark black line) should look like if there was a 1:1 relationship between measured and predicted percent dry weight values. 


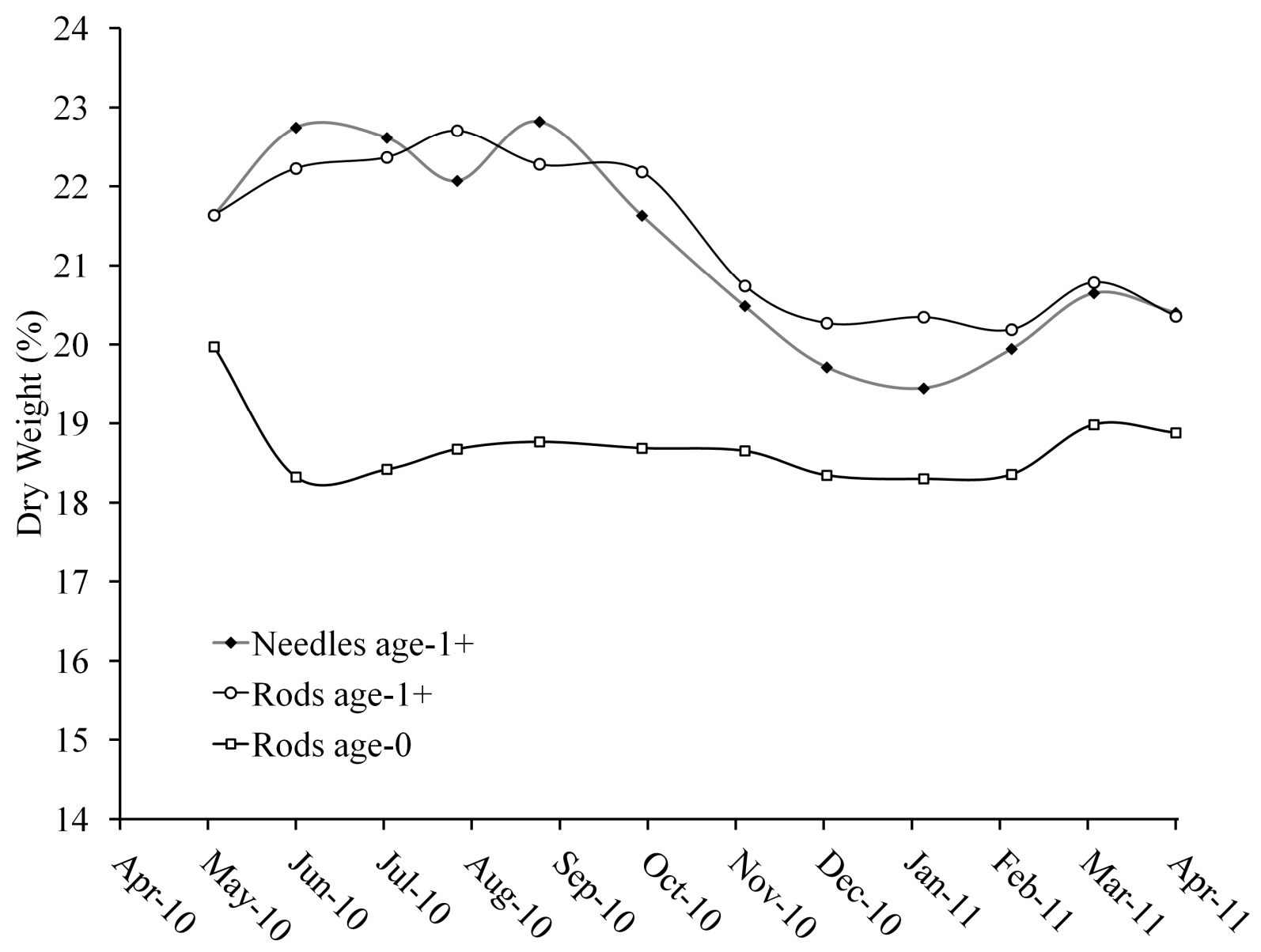

Figure 8.-Trends in body condition, represented by percent dry weight, for adult and age-0 (hollow squares) brook trout. For adult brook trout condition estimates are provided from both external rod (hollow circles) and subdermal needle (black diamonds) field based models. Data points represent mean percent dry weight calculated using all fish sampled (including validation fish) on each sample period. Over the course of the study period 938 adult and 1383 age- 0 brook trout were sampled. 


\section{Appendix A: Sample Size Effects on the Ability to Predict the Mean Percent Dry Weight of a Population}

The results of the field study from Chapter 5 demonstrated that BIA was able to produce reliable estimates of monthly mean percent dry weight (PDW) values but what is unclear is how many fish need to be sampled to provide a reliable estimate of PDW for the population. Our objective in this appendix is to provide some insight, using the field data collected in the study from Chapter 5, about the effect of sample size on the root mean square error estimates (RMSE) when evaluating mean PDW. To accomplish this objective random samples of size 2 through 90 were drawn from Chapter 5 validation fish. For each random sample the mean BIA estimated PDW and mean actual PDW were calculated. This entire process was repeated 100 times for each model type and for adults and age-0 fish individually. From the results of this analysis it appears that RMSE drops and becomes more stable as sample size increases until approximately twenty fish have been sampled (Figure 1). After that point RMSE is stable and levels out. Based on this result it is our recommendation that when attempting to estimate the PDW of a population using BIA at least twenty samples should be taken.
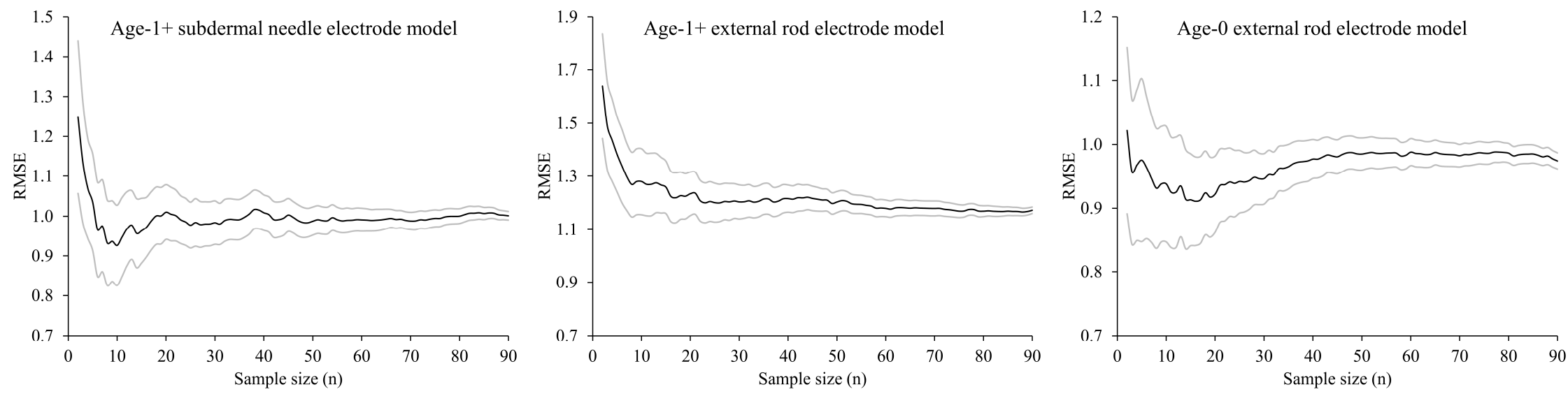

Figure 1.-Plots demonstrating the influence of sample size on RMSE when attempting to predict the mean PDW of a fish population. Gray lines represent $95 \%$ confidence intervals. 


\section{Vitae}

\section{ANDREW W. HAFS}

1806 San Pascual St. Unit A

Phone: (920) 265-3388

Santa Barbara, CA 93101

Email: ahafs@bren.ucsb.edu

\section{EDUCATION}

Ph.D., Fisheries and Wildlife Resources, West Virginia University, 2011

Dissertation Title: Bioelectrical Impedance Analysis Methods for Prediction of Brook Trout Salvelinus fontinalis Percent Dry Weight

Advisor: Kyle J. Hartman

M.S., Fisheries and Wildlife Science, Arkansas Tech University, 2007

Thesis Title: Smallmouth Bass Survival, Movement, and Habitat Use in Response to Seasonally Discontinuous Surface Flow.

Advisor: Charles J. Gagen

B.S., Double major in Water Resources and Biology, University of Wisconsin at Stevens Point, 2005 Advisor: Michael J. Hansen

\section{Postdoctoral Research}

University of California at Santa Barbara

August 2011-Present. My objectives for this project are to develop, validate, and field test, a drift feeding bieoenergicts model for juvenile Chinook salmon that is combined with a hydrodynamic model established for a restored section of the Merced River, CA. This will allow us to assess and quantify the influence of habitat alteration and flow regime on juvenile salmon growth.

\section{HONORS, AWARDS, PROFESSIONAL AFFILIATION AND SERVICE}

\section{Dissertation Fellowship award winner $\mathbf{( \$ 6 , 0 0 0 )}$}

2010 Committee member for North American Journal of Fisheries Management 2009 best paper award

2010 West Virginia American Fisheries Society Student Travel Award

2009 Skinner Memorial Award

2009 Committee member for North American Journal of Fisheries Management 2008 best paper award

2008 Committee member for Eastern Brook Trout Joint Venture assessment of project proposal funding process

2008 President elect-Student Chapter of AFS at West Virginia University

2007 Jim Ed McGee Graduate Honors Award (outstanding graduate student of the year)

2007 Arkansas Game and Fish Commission Conservation Scholarship $(\$ 3,000)$

2005 Musky Bill Hoeft Memorial Scholarship

I have moderated technical sessions at AFS national and regional meetings and I have reviewed numerous articles that have been submitted to scientific journals including Fisheries Management and Ecology (4), Transactions of the American Fisheries Society (3), Southeastern Association of Fish and Wildlife Agencies (2), Fisheries Bulletin (1), North American Journal of Fisheries Management (1), the Journal of Fish and Wildlife Management (1), and the Journal of the Arkansas Academy of Science (1). 


\section{REFEREED PUBLICATIONS}

Hafs, A. W., and K. J. Hartman. 2011. Influence of electrode type and location upon bioelectrical impedance analysis measurements of brook trout. Transactions of the American Fisheries Society 140:1290-1297.

Hafs, A. W., J. M. Niles, and K. J. Hartman. 2011. Efficiency of gastric lavage on age-0 brook trout and the influence on growth and survival. North American Journal of Fisheries Management 31:530-534.

Hafs, A. W., C. D. Horn, P. M. Mazik, and K. J. Hartman. 2010. Influences of acid mine drainage and thermal enrichment on stream fish reproduction and larval survival. Northeastern Naturalist 17:575:592.

Hafs, A. W., C. J. Gagen, and J. K. Whalen. 2010. Smallmouth bass summer habitat use, movement, and survival in response to low flow in the Illinois Bayou, Arkansas. North American Journal of Fisheries Management 30:604-612.

Hafs, A. W., P.M. Mazik, P.B. Kenney, and J.T. Silverstein. In Review. Impact of carbon dioxide level, water velocity, strain, and feeding regimen on growth and fillet attributes of cultured rainbow trout (Oncorhynchus mykiss). Aquaculture.

Hafs, A. W., and K. J. Hartman. In Review. Bioelectrical impedance analysis on homogenized fish samples. Journal of Animal Science.

\section{PRESENTATIONS AT PROFESSIONAL MEETINGS}

Hafs, A. W., and K. J. Hartman. Validation and application of bioelectrical impedance analysis to detect seasonal changes in brook trout fat content in Appalachian mountain streams. West Virginia Chapter of the American Fisheries Society; Cacapon State Park, WV. February-2011.

Hafs, A. W., and K. J. Hartman. Developing bioelectrical impedance analysis methods for small fish. American Fisheries Society National Meeting; Pittsburgh, PA. September-2010.

Niles, J. M., A. W. Hafs, and K. J. Hartman. Diet of young-of-year brook trout in Appalachian headwater streams. American Fisheries Society National Meeting; Pittsburgh, PA. September-2010 (invited).

Hafs, A. W., K. J. Hartman, and J. W. Howell. Influence of electrode type and location upon BIA - body composition relationships in fish. American Fisheries Society National Meeting; Nashville, TN. August-2009 (invited).

Hartman, K. J., A. W. Hafs, F. J. Margraf, J. A. Sweka, and M. K. Cox. Using bioelectrical impedance analysis to estimate fat levels and growth in fish. Southern Division of the American Fisheries Society; New Orleans, LA. January-2009.

Hafs, A. W., and C. J. Gagen. Smallmouth bass mortality, movement, and habitat use in response to seasonally discontinuous surface flow. Southern Division of the American Fisheries Society; Memphis, TN. February-2007.

Hafs, A. W., and C. J. Gagen. Smallmouth bass mortality, movement, and habitat use in response to seasonally discontinuous surface flow. Arkansas Chapter of the American Fisheries Society; Mt. View, AR. February-2007. 


\section{PROFESSIONAL MEETINGS ATTENDED}

West Virginia Chapter of the American Fisheries Society; Cacapon State Park, WV. February-2011. American Fisheries Society National Meeting; Pittsburgh, PA. September-2010.

West Virginia Chapter of the American Fisheries Society; Davis, WV. March-2010.

American Fisheries Society National Meeting; Nashville, TN. August-2009.

West Virginia Chapter of the American Fisheries Society; Huntington, WV. March-2009.

American Fisheries Society National Meeting; Ottawa, Canada. August-2008.

Southern Division of the American Fisheries Society; Wheeling, WV. February-2008.

Southern Division of the American Fisheries Society; San Antonio, TX. February-2006.

Arkansas Chapter of the American Fisheries Society; Bismarck, AR. February-2006.

American Fisheries Society National Meeting; Madison, WI. August-2004.

Membership:

American Fisheries Society (National)

Southern Division of the American Fisheries Society

West Virginia Chapter of the American Fisheries Society

Wisconsin Chapter of the American Fisheries Society

\section{TEACHING EXPERIENCE}

Ichthyology (Biology 341)

West Virginia University

January 2008-August 2011. I was the laboratory instructor for all sections of ichthyology

(taxonomy, identification, and biology of fishes) at West Virginia University. I gave lectures to

start every class teaching students how to identify more than 180 different fishes present in West Virginia.

Introduction to Biology (Biology 115)

West Virginia University January 2008-August 2011. I taught introductory biology during the fall semesters. The laboratory was designed to teach students the scientific method and correct design of experiments. I helped each student in my class design and implement their own unique research experiment. Following data collection I taught the students how to write a research paper based on their data as if they were preparing a manuscript for publication.

Advanced Wildlife and Fisheries Management (Wildlife management 450) - Guest lectures West Virginia University January 2008-August 2011. I was asked by professors at West Virginia University to give multiple guest lectures on population dynamics, age and growth of fishes, and other topics related to fisheries management.

Introduction to Biology (Biology 1014)

Arkansas Tech University

January 2006-May 2007. I was a laboratory instructor of introductory biology for three semesters. Topics included mitosis, meiosis, evolution, genetics, and protein synthesis. I began each class by giving a lecture on the topic at hand and then helped guide the students through a short experiment or activity that provided the students with an opportunity to get hands on experience related to the lecture topic. 


\section{TEACHING INTERESTS}

While working for my M.S. and Ph.D. degrees I was provided with the opportunity to teach multiple laboratory sections from a variety of different courses including Ichthyology and Biology. Although research funding was often available for me and teaching was not required I volunteered for two reasons; first and foremost, I enjoy interacting with the students and helping them to better understand biology and ecology, two fields that many student have a difficult time with. Interacting and connecting with the students at the individual level helps them to become more comfortable and makes it more likely they will stay interested and learn the material being presented to them. The second reason I wanted to teach throughout my graduate education was that it provided me with the opportunity to gain valuable experience that has helped me to become more comfortable and better prepared to lead classes of my own. In the future I would like to have the opportunity to teach the core fisheries and aquatic science classes to undergrad and/or graduate students. I am well prepared and would be very interested in teaching classes such as Ichthyology, Limnology, Fisheries Management, Fisheries Research, Biology, and Biostatistics. By teaching the core fisheries and aquatic sciences classes it would be my goal to establish a reputation that the program I am working with produces quality graduates that are ready to make valuable contributions to the field of fisheries.

During my time at West Virginia University I was given the opportunity to mentor over a dozen different undergraduate students during their internships. Working with these students at the individual level allowed me to provide them with a very strong background in fisheries management and ecology. I found it very rewarding to see them get hired to quality full-time jobs because of the internship positions they had done with me. I enjoy teaching, especially at the individual level, and although lectures are a necessary part of many courses I will strive to make any course I teach as interactive as possible. This can be difficult to accomplish with a lecture only style of teaching. To avoid this problem I like to frequently incorporate activities that will require the students to work through problems that are designed to help them learn with a more hands on approach. While they are working on these activities I like to walk around the classroom and ask the individual students questions about what I have been teaching and if they have any questions of their own. This allows me to understand what topics are well covered and where more work is needed. For several of the classes I took during my educational career the final exam was a job interview based oral exam at the individual level with the instructor and one other person who worked in a field related to the class. I enjoyed this as a student because it provided real life experience and I would like to incorporate that type of thinking into the classes I teach.

I have spent time working with and learning about the fisheries biology, ecology, and management of the northern (WI), eastern (WV), southern (AR), and western (CA) United States. This has provided me with a very diverse background and knowledge base that I look forward to sharing with my future students. It is my opinion that teaching students about the experiences I have had from a broad range of geographic regions will help better prepare them for their future career paths and I will strive to incorporate this diversity into all of my classes. 


\section{REFERENCES}

Kyle J. Hartman, Ph.D., Professor

Wildlife \& Fisheries Resources Program, West Virginia University

322 Percival Hall

Morgantown, WV 26506-6125

Telephone: (304) 293-4797

Fax: (304) 293-2441

Email: hartman@wvu.edu

F. Joseph Margraf, Ph.D., Supervisor Cooperative Research Units U. S. Geological Survey

Box 25046 MS 406 DFC

Denver, CO 80225-0046

Phone: (303) 236-1454

Cell: (303) 656-0906

Fax: (303) 236-1451

E-mail: jmargraf@usgs.gov

Patricia M. Mazik, Ph.D., Unit Leader and Adjunct Assoc. Professor WVU/WVCFWRU

322 Percival Hall

Morgantown, WV 26506-6125

Telephone: (304) 293-4943

Email: pmazik@wvu.edu

Charles J. Gagen, Ph.D., Professor of Fisheries Science

Fisheries and Wildlife Science Program, Arkansas Tech University 1701 N. Boulder Avenue

Russellville, AR 72801

Telephone: (479) 964-0814

Fax: (479) 964-0837

Email: cgagen@atu.edu 